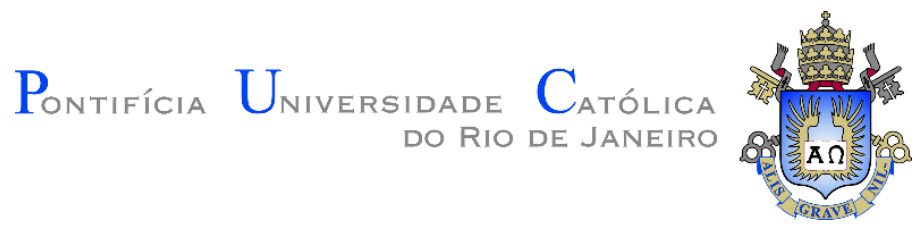

Christovam de Moraes Weidlich

\title{
Aplicação do método da resistência direta ao dimensionamento de vigas casteladas
}

Dissertação de Mestrado

Dissertação apresentada como requisito parcial para obtenção do grau de Mestre pelo Programa de PósGraduação em Engenharia Civil do Departamento de Engenharia Civil e Ambiental da PUC-Rio.

Orientadora: Prof ${ }^{\mathrm{a}}$ Elisa Dominguez Sotelino

Coorientador: Prof. Daniel Carlos Taissum Cardoso

Rio de Janeiro setembro de 2020 


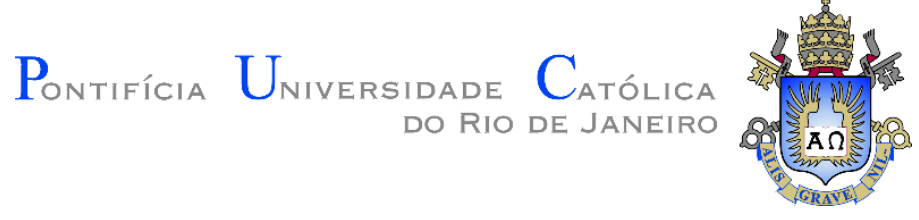

Christovam de Moraes Weidlich

\section{Aplicação do método da resistência direta ao dimensionamento de vigas casteladas}

Dissertação apresentada como requisito parcial para obtenção do grau de Mestre pelo Programa de PósGraduação em Engenharia Civil da PUC-Rio. Aprovada pela Comissão Examinadora abaixo.

Profa. Elisa Dominguez Sotelino

Orientador

Departamento de Engenharia Civil e Ambiental - PUC-Rio

Prof. Daniel Carlos Taissum Cardoso

Coorientador

Departamento de Engenharia Civil e Ambiental - PUC-Rio

Prof. Paulo Batista Gonçalves

Departamento de Engenharia Civil e Ambiental - PUC-Rio

Prof. Maximiliano Malite Departamento de Engenharia de Estruturas - EESC-USP 
Todos os direitos reservados. É proibida a reprodução total ou parcial do trabalho sem autorização da universidade, da autora e do orientador.

\section{Christovam de Moraes Weidlich}

Graduado em Engenharia Civil pela UPF (Universidade de Passo Fundo) em 2017. Sua área de interesse compreende instabilidade de estruturas, modelagem numérica e estruturas metálicas.

Ficha Catalográfica

\section{Weidlich, Christovam de Moraes}

Aplicação do método da resistência direta ao dimensionamento de vigas casteladas / Christovam de Moraes Weidlich; orientadora: Elisa Dominguez Sotelino; coorientador: Daniel Carlos Taissum Cardoso. - 2020.

87 f. : il. color. ; $30 \mathrm{~cm}$

Dissertação (mestrado) - Pontifícia Universidade Católica do Rio de Janeiro, Departamento de Engenharia Civil e Ambiental, 2020.

Inclui bibliografia

1. Engenharia Civil e Ambiental - Teses. 2. Método da Resistência Direta. 3. Vigas casteladas. 4. Interação entre modos de flambagem. 5. Modelagem computacional. 6 . Flambagem global. 7. Flambagem local. I. Sotelino, Elisa Dominguez. II. Cardoso, Daniel Carlos Taissum. III. Pontifícia 


\section{Agradecimentos}

Antes de tudo, gostaria de agradecer aos meus orientadores Elisa D. Sotelino e Daniel C.T. Cardoso por todos os conselhos, orientações e direcionamentos no decorrer deste trabalho, os quais foram imprescindíveis tanto para meu crescimento, como para a conclusão dessa pesquisa.

Agradeço a todos os colegas e professores da pós-graduação em engenharia civil da PUC-Rio e à banca examinadora, professores Paulo Batista Gonçalves e Maximiliano Malite, obrigado por aceitarem esse convite.

Ao $\mathrm{CNPq}$ por financiar e possibilitar a realização deste trabalho investindo na produção científica nacional.

Aos meus grandes amigos e pessoas incríveis que conheci durante o curso de mestrado, em especial, Christian, E’ric, Felipe, Ícaro, João, Lucian, Manuel, Marcello, Osmar, Ronald, Vitor A. e Vitor M. Obrigado pelo companheirismo e viverem juntos comigo esse momento.

À Taiana, por todo o apoio e estar do meu lado em todas as situações. Obrigado por compartilhar tantos momentos incríveis e pela paciência desde o início dessa jornada.

Agradeço à minha família, Amanda e Maria Teresa por todo o suporte e incentivo, sempre estando presentes e formando a base para meu desenvolvimento. Em especial aos meus pais, Silvano e Desirée os quais não mediram esforços para incitar o senso crítico em seus filhos, sempre estimulando a busca do conhecimento, estudo, leitura e desenvolvimento como ser humano.

E agradeço a Deus, o grande arquiteto do universo.

O presente trabalho foi realizado com apoio da Coordenação de Aperfeiçoamento de Pessoal de Nível Superior - Brasil (CAPES) - Código de Financiamento 001. 


\section{Resumo}

Weidlich, Christovam de Moraes; Sotelino, Elisa Dominguez; Cardoso, Daniel Carlos Taissum. Aplicação do método da resistência direta ao dimensionamento de vigas casteladas. Rio de Janeiro, 2020. 87p. Dissertação de mestrado - Departamento de Engenharia Civil e Ambiental, Pontifícia Universidade Católica do Rio de Janeiro.

Essa pesquisa possui como objetivo investigar os mecanismos de vigas casteladas quanto à sua estabilidade e interação entre modos de flambagem lateral com torção (FLT) e local do "tê" comprimido (FT). São verificadas as capacidades resistentes de vigas casteladas e, subsequentemente, uma abordagem baseada no Método da Resistência Direta é proposta. As normatizações e guias de dimensionamento atuais tratam dos modos de falha de maneira pouco clara ao considerar a possível interação entre eles, evidenciando a necessidade de estudos e de um método que considere tais efeitos. É realizado um amplo estudo constituído por um universo de 197 vigas casteladas do tipo Litzka biapoiadas sujeitas à flexão pura por meio de modelagem e simulação por análises de elementos finitos lineares e não lineares de material com imperfeições geométricas. Os modelos são validados e o momento último resistente é computado, bem como os momentos críticos dos modos de flambagem global e local. Por fim, são aplicados os conceitos do Método da Resistência Direta e, através de regressão, são propostas equações para previsão do momento nominal resistente levando em conta a interação entre modos de flambagem global e local. Os resultados são comparados com a atual normatização demonstrando melhores valores de previsão para todos os casos, principalmente os que são governados pelo modo local de falha e/ou pela interação dos modos de flambagem. É evidenciada certa discordância dos resultados propostos pelas normas e guias atuais em alguns casos quanto ao dimensionamento à flexão de vigas casteladas, podendo sub ou superestimar sua resistência.

\section{Palavras-chave}

Método da Resistência Direta; Vigas casteladas; Interação entre modos de flambagem; Modelagem computacional; Flambagem global; Flambagem local. 


\section{Abstract}

Weidlich, Christovam de Moraes; Sotelino, Elisa Dominguez (Advisor); Cardoso, Daniel Carlos Taissum (Coadvisor). Application of the direct strength method to the design of castellated beams. Rio de Janeiro, 2020. 87p. Dissertação de Mestrado - Departamento de Engenharia Civil e Ambiental, Pontifícia Universidade Católica do Rio de Janeiro.

The objective of this research is to investigate the stability mechanisms of castellated beams and the interaction between lateral-torsional and compression tee local buckling modes. A verification of the strength capacity of castellated beams is carried out. Subsequently, an approach based on the Direct Strength Method is proposed for the design of these beams. The treatment of failure modes by current standards and design guides is unclear when considering possible interactions between buckling modes, thus there is a need for more studies and for the development of a design method that takes into account these effects. Firstly, a comprehensive study of 197 simply supported Litzka castellated beams under pure bending moment is carried out. The study involves finite element analyses considering both linear behavior and nonlinear behavior that, which included both material nonlinearity and geometric imperfection. The models are then validated. After computing the moments associated with critical local and global failure modes, and the ultimate moments, along with their respective modes, an approach based on the Direct Strength Method is performed. Equations that consider the interaction for nominal moments prediction are obtained through regression. The developed equation is then compared with current standards procedures. The results show that the proposed equation predicts better values for strength prediction in all cases, especially those in which local and/or interaction failure modes govern the behavior of the beam. The results also show that some of the procedures suggested in standards and guides for the design of castellated beams under flexure, either underestimate or overestimate the failure moment.

\section{Keywords}

Direct Strength Method; Castellated beams; Interaction between buckling modes; Computational modeling; Global buckling; Local buckling. 


\section{Sumário}

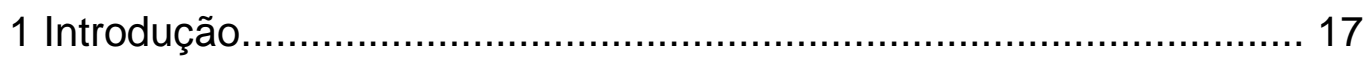

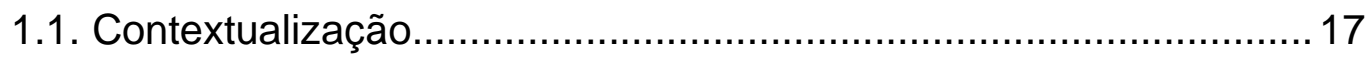

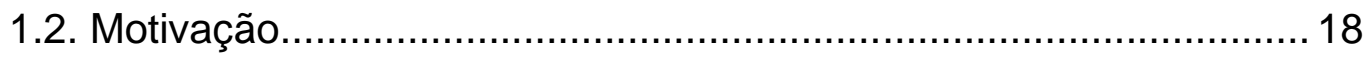

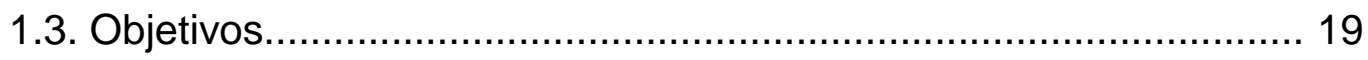

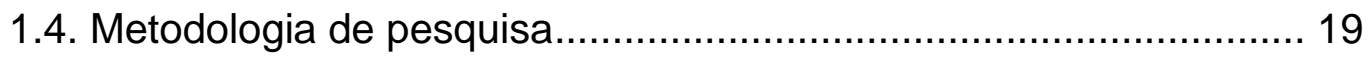

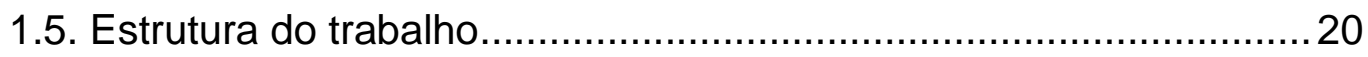

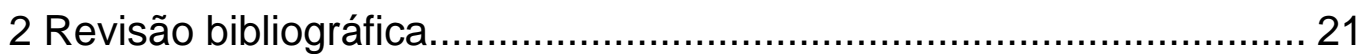

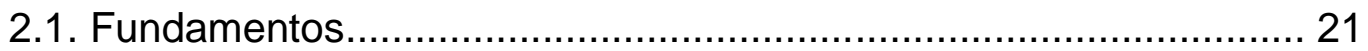

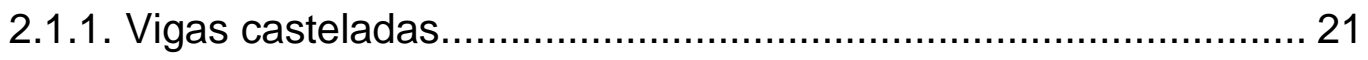

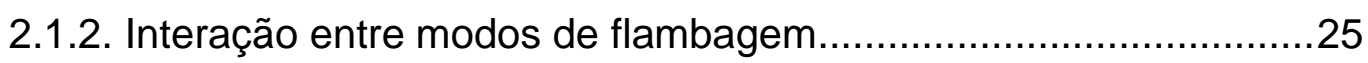

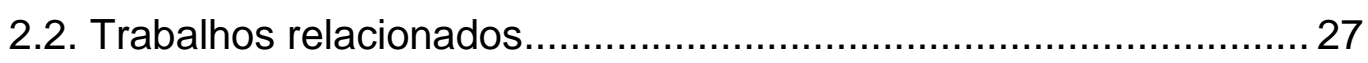

2.3. Métodos de Dimensionamento................................................... 31

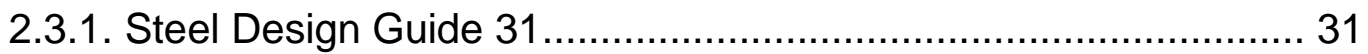

2.3.2. Método da Resistência Direta................................................... 32

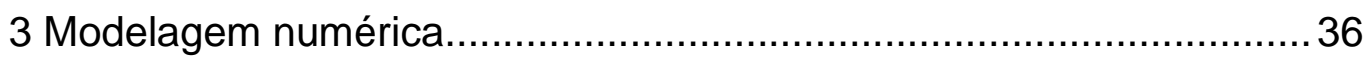

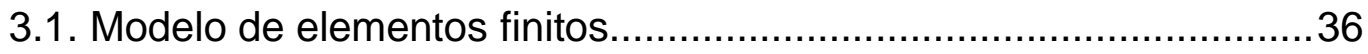

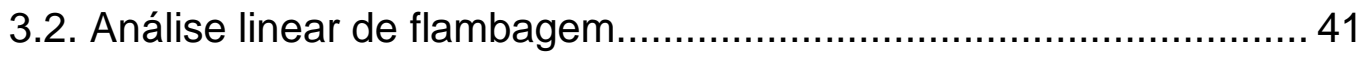

3.3. Análise não linear de flambagem................................................ 42

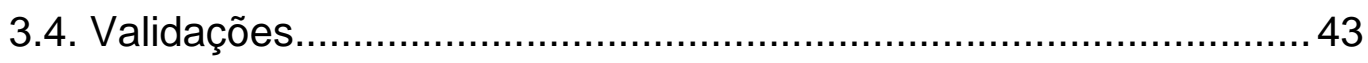

3.4.1. Validação das técnicas de modelagem - análise linear de

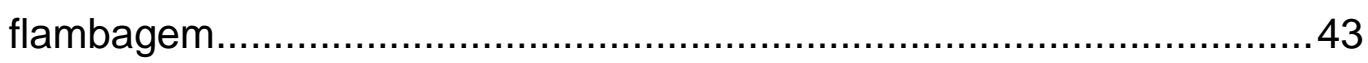

3.4.2. Validação das técnicas de modelagem - análise não linear de

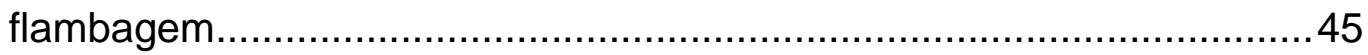

3.4.3. Validação das condições de contorno..........................................46

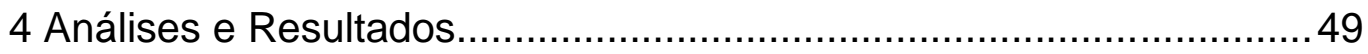

4.1. Resultados das análises lineares de flambagem............................ 49

4.2. Resultados das análises não lineares de flambagem......................53 
4.3. Proposta baseada no Método da Resistência Direta........................ 61

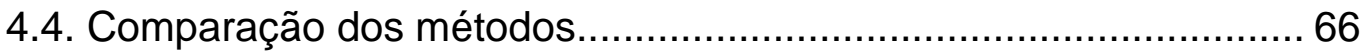

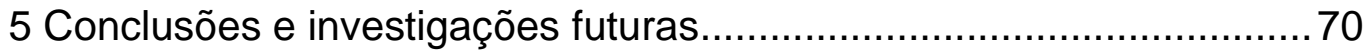

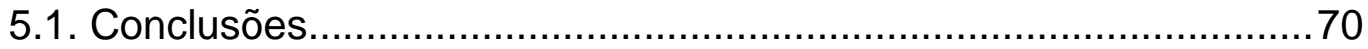

5.2. Sugestões para investigações futuras......................................... 71

6 Referências bibliográficas............................................................ 72

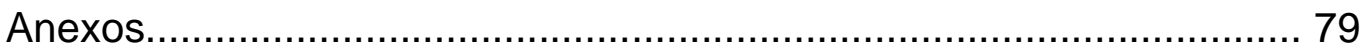

Anexo A - Tabela das especificações do estudo....................................79

Anexo B - Tabela dos resultados do estudo...........................................83 


\section{Lista de figuras}

Figura 1.1 - Construção do novo Emerson College Los Angeles Center, John A. Martin \& Associates, Inc. (2013) [1]. 18

Figura 2.1 - Fabricação viga castelada, Design Guide 31 (adaptado) [2].

Figura 2.2 - Geometria de viga Litzka-Schnittführung. .22

Figura 2.3 - Mecanismo de Vierendeel em vigas celulares [12]. 24

Figura 2.4 - Curva de interação entre modos de flambagem de coluna (adaptado) [30].

Figura 2.5 - Interação entre modos flambagem: a) Modo local; b) Modo global; e c) Modos acoplados [29].

Figura 2.6 - Propagação da plastificação com o aumento da deflexão lateral (adaptado) [30].

Figura 2.7 - Modelagem e malha de elementos finitos [8] 28

Figura 2.8 -Comparação dos resultados entre modos de flambagem: a) Modelagem numérica, Ellobody [36]; b) Teste experimental, Zirakian e Showkati [35].

Figura 2.9 - Configuração dos testes experimentais de Sonck \& Belis [39].

Figura 2.10 - Modo típico de flambagem local do "tê" - análises de autovalor [42]

Figura 2.11 - Esquema conceitual da aplicação da abordagem MRD.....34

Figura 3.1 - Malha típica adotada e tipos de elementos...........................38

Figura 3.2 - Condições de contorno e carregamento. .............................39

Figura 3.3 - Análise de convergência................................................40

Figura 3.4 - Região de elementos com propriedades elásticas nas

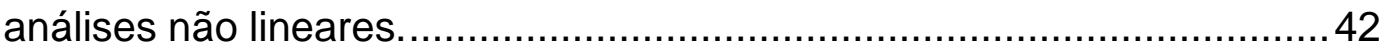

Figura 3.5 - Condições de contorno e MPC, Souza 2019 [43] ............... 44

Figura 3.6 - Validação viga CS1_L3................................................ 45

Figura 3.7 - Condições de contorno e carregamento para validação. .....48 Figura 3.8 - Resultado da análise linear de flambagem para validação das condições de contorno. 
Figura 4.1 - Modos característicos de flambagem: (a) Viga \#1 indeformada; (b) Modo flambagem global - FLT; (c) Modo flambagem local - FT

Figura 4.2 - Modos característicos de flambagem: (a) Viga \#111 indeformada; (b) Modo flambagem local do "tê" ; (c) Modo flambagem

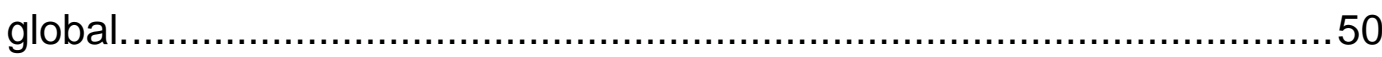

Figura 4.3 - Momento crítico global x esbeltez relativa global. ................51

Figura 4.4 - Momento crítico local x esbeltez relativa local. ....................52

Figura 4.5 - Relação entre esbeltezes global - local.............................52

Figura 4.6 - Resposta não linear \#13...............................................54

Figura 4.7 - Modo de falha modelo \#13.............................................. 54

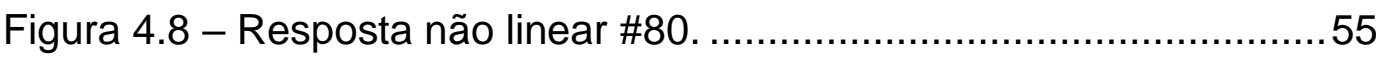

Figura 4.9 - Modo de falha modelo \#80..............................................55

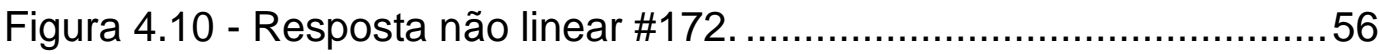

Figura 4.11 - Modo de falha modelo \#172. ........................................56

Figura 4.12 - Resposta não linear modelo \#124 ……..........................57

Figura 4.13 - Modo de falha modelo \#124 .........................................58

Figura 4.14 - Resposta não linear modelo \#123....................................59

Figura 4.15 - Modo de falha modelo \#123...........................................59

Figura 4.16 - Resultados normalizados das vigas \#13, \#80, \#123, \#124 e $\# 172$.

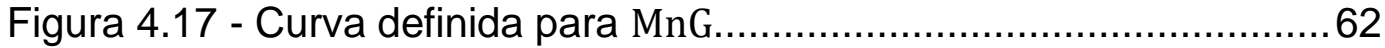

Figura 4.18 - Limites de previsão da principal equação de MnG. ............63

Figura 4.19 - Resíduos da principal equação de MnG............................63

Figura 4.20 - Curva de MnLG. .......................................................... 64

Figura 4.21 - Limites de previsão da equação de MnLG..........................65

Figura 4.22 - Resíduos da equação de MnLG. .......................................65

Figura 4.23 - Diferença relativa DG \& MRD e $\lambda \mathrm{LG}$..................................68

Figura 4.24 - Diferença relativa DG \& MRD, $\lambda$ LG e relação Mp/Mcrg. ...69 


\section{Lista de tabelas}

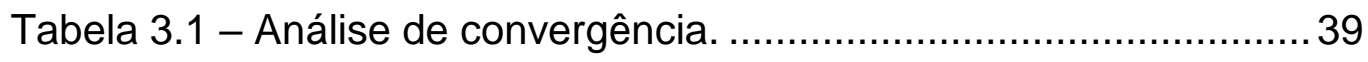

Tabela 3.2 - Resumo das propriedades dos modelos............................ 41

Tabela 3.3 - Validação técnicas de modelagem para as análises lineares...

Tabela 3.4 - Validação técnicas de modelagem para as análises não

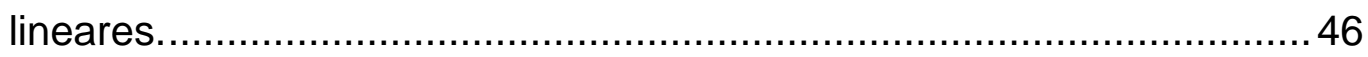

Tabela 4.1 - Resumo dos resultados das análises de elementos finitos.

Tabela 4.2 - Comparação da resistência prevista entre o Design Guide 31 e abordagem proposta do MRD em relação ao momento último obtido nas análises de elementos finitos. 67 


\section{Lista de abreviaturas}

AISC American Institute of Steel Construction

AISI American Iron and Steel Institute

ANSI American National Standards Institute

DG Design Guide 31

FLT Flambagem lateral com torção

FSM Finite Strip Method (Método das Faixas Finitas)

FT Flambagem local do 'tê'

GBT Generalized Beam Theory (Teoria da Viga Generalizada)

$L P F \quad$ Fator de proporcionalidade de momento fletor

MEF Método dos Elementos Finitos

MPC Multi Points Constraint

MRD Método da Resistência Direta

RMSE Root-Mean-Square Deviation (Raiz Quadrada do Erro Médio)

SSE

Sum of Squares Due to Error (Soma dos Quadrados dos Erros de Predição) 


\section{Lista de símbolos}

\section{Romanos:}

$b_{f} \quad$ Comprimento da mesa

$b_{w} \quad$ Altura do tê

$C_{w} \quad$ Constante de empenamento da seção

$C_{b} \quad$ Fator de modificação de diagrama de momento fletor

d $\quad$ Altura da seção

dif.rel Diferença relativa

E $\quad$ Módulo de elasticidade

$F \quad$ Carga última resistente

$f_{y} \quad$ Tensão de escoamento do material

H Altura total da seção transversal

h $\quad$ Altura do furo

$\begin{array}{ll}\text { ly } & \text { Momento de inér } \\ \text { seção transversal }\end{array}$

Imp.g Fator de amplitude de imperfeição global

Imp./ Fator de amplitude de imperfeição local

$J \quad$ Constante torsional da seção transversal

L Comprimento destravado

$L_{b} \quad$ Comprimento destravado

$M_{c r} \quad$ Momento crítico de flambagem

Mcre Momento crítico de flambagem global 
$M_{c r g} \quad$ Momento crítico de flambagem global

Mcr $\quad$ Momento crítico de flambagem local

$M_{n} \quad$ Momento nominal

$M_{n e} \quad$ Momento resistente nominal global de Euler

$M_{n G} \quad$ Momento resistente nominal global

$M_{n l} \quad$ Momento resistente nominal local

$M_{n L G} \quad$ Momento resistente nominal local-global

$M_{p} \quad$ Momento de plastificação total da seção

$M_{n, D G} \quad$ Momento último nominal segundo Design Guide

$M_{n, M R D} \quad$ Momento último nominal segundo Método da Resistência Direta

$M_{n, M E F}$ Momento último segundo Método dos Elementos Finitos

My Momento de início de plastificação

$R z \quad$ Grau de liberdade de rotação em torno de $z$

$R^{2} \quad$ Coeficiente de determinação

$t_{f} \quad$ Espessura da mesa

$t_{w} \quad$ Espessura da alma

Ux Grau de liberdade de deslocamento em $x$

Uy Grau de liberdade de deslocamento em y

Uz Grau de liberdade de deslocamento em z

\section{Gregos:}

a Ângulo do furo

$\lambda_{g} \quad$ Esbeltez relativa global

$\lambda_{l} \quad$ Esbeltez relativa local 
$\lambda_{L G} \quad$ Esbeltez relativa local-global

$v \quad$ Coeficiente de Poisson

$\pi \quad$ Constante matemática pi 
"A verdade será sempre encontrada na simplicidade, e não na multiplicidade e confusão das coisas." 
1

\section{Introdução}

\section{1.}

\section{Contextualização}

Conforme o avanço das técnicas de construção, também surgem novas exigências, principalmente no que diz respeito às demandas de elementos estruturais. Essa adequação possui como finalidade proporcionar soluções eficientes que integrem o desempenho, otimização do espaço e relacionamento com arquitetura, permitindo novos recursos criativos e a constante evolução. As vigas casteladas surgiram a partir desse processo, demonstrando diversas capacidades e aplicações, sendo reconhecidas e utilizadas amplamente como uma solução vantajosa.

Desde a metade do século XX, numerosos aperfeiçoamentos foram realizados, tanto no processo de fabricação quanto em seu desempenho e emprego, permitindo novas possibilidades estruturais. A viga castelada, ao apresentar furos em sua seção, configura ganhos econômicos e integra as técnicas modernas de construção ao permitir a passagem de dutos e tubulações e reduzindo a altura entre pavimentos. A sua estética atrativa também foi um fator que difundiu esse tipo de elemento estrutural.

Além disso, ao expor a economia devido ao aumento da capacidade de carga e maior rigidez, apresenta potencial para variadas aplicações e funções. Como é evidenciado na figura $1.1 \mathrm{em}$ que vigas casteladas são utilizadas não apenas na sustentação do heliponto sendo construído, mas também como diafragma estrutural conectando as duas torres do projeto [1].

Entretanto, em função de suas características, emergem diferentes aspectos do comportamento e mecanismos de falha que demandam estudos para sua compreensão e apropriado dimensionamento. 


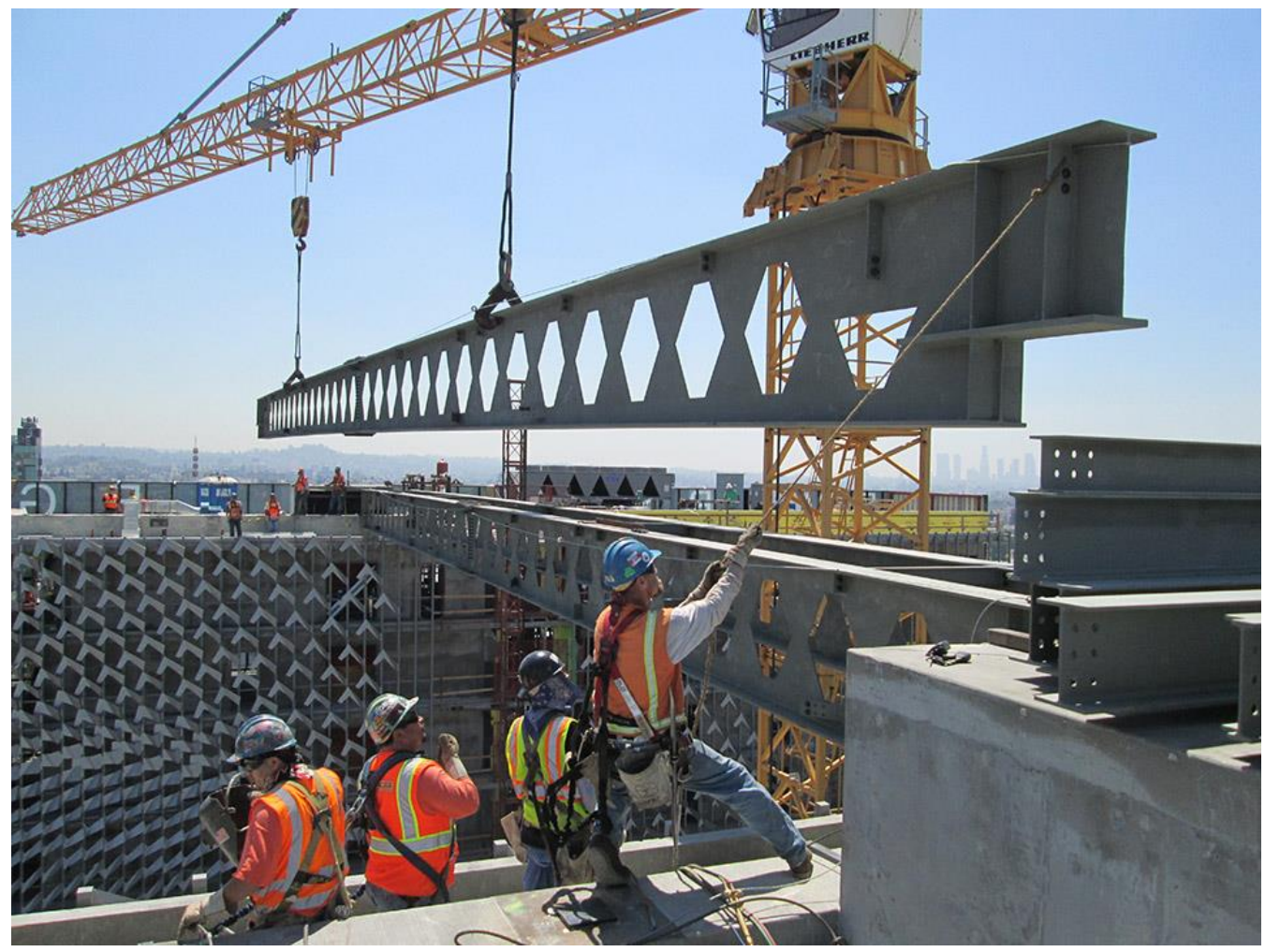

Figura 1.1 - Construção do novo Emerson College Los Angeles Center, John A. Martin \& Associates, Inc. (2013) [1].

\section{2. \\ Motivação}

Em função do aumento da esbeltez das vigas casteladas, quando comparadas com o perfil original, a estabilidade do elemento estrutural torna-se um dos fatores de grande importância e compreensão.

De forma que a presença das descontinuidades faz com que possam ocorrer modos de flambagem e de falha diferentes dos bem conhecidos em vigas de alma cheia.

Além disso, embora a interação entre os modos seja bastante abordada em trabalhos referentes aos perfis formados a frio e outros tipos de elementos estruturais, em vigas casteladas esse assunto ainda requer maiores investigações, tendo em vista os poucos estudos que tratam do tema. Consequentemente, as normatizações e guias de dimensionamento acabam tratando a interação dos estados limites com pouca clareza. 
Ainda, ao tratar do dimensionamento quanto à flexão, o Steel Design Guide 31 [2] sugere a utilização das propriedades da seção ignorando os furos ao longo da alma para a verificação quanto à flambagem lateral com torção, o que demonstra, portanto, a necessidade de um método de dimensionamento específico para vigas casteladas em tais condições.

\section{3.}

\section{Objetivos}

Os principais objetivos dessa pesquisa são investigar a interação entre os modos global (flambagem lateral com torção, FLT) e local (flambagem local do "tê" comprimido, FT) de vigas casteladas biapoiadas sob flexão pura e seus efeitos em sua capacidade de resistência através de simulações numéricas em vigas com geometrias comerciais.

Além disso, objetiva-se avaliar o atual método de dimensionamento proposto pelas normatizações e propor uma metodologia baseada no Método da Resistência Direta (MRD) para seu dimensionamento, que permita a consideração clara da interação entre os modos, desenvolvendo suas curvas de resistência e propondo suas respectivas equações.

\section{4 . Metodologia de pesquisa}

Com o intuito de realizar as análises propostas, primeiramente é estabelecido um amplo universo de vigas casteladas para o estudo a partir de geometrias de vigas comerciais, variando suas grandezas geométricas e especificações de material. É então realizada a modelagem computacional usando o Método dos Elementos Finitos (MEF) de todas as vigas selecionadas. São conduzidas análises lineares de flambagem e análises não-lineares considerando o comportamento não linear do material e imperfeições geométricas iniciais, considerando apenas a situação de flexão pura. 
A partir dos resultados das análises, por meio de regressão, é realizada a abordagem do MRD permitindo, assim, a obtenção das equações referentes à previsão do momento resistente das vigas casteladas à flexão.

\section{5.}

\section{Estrutura do trabalho}

No capítulo 2 deste trabalho, é realizada a apresentação dos conceitos, métodos de dimensionamento e revisão bibliográfica de trabalhos relacionados.

Em seguida, no capítulo 3, são descritos os procedimentos e parâmetros de modelagem, bem como suas validações.

No capítulo 4, são apresentados os resultados referentes às análises, assim como a aplicação da metodologia do Método da Resistência Direta e a comparação com as normatizações.

Por fim, no capítulo 5, são trazidas as conclusões e sugestões para pesquisas futuras. 


\section{2 \\ Revisão bibliográfica}

\section{1.}

\section{Fundamentos}

\subsection{1.}

\section{Vigas casteladas}

As vigas casteladas foram idealizadas em 1935 por Boyd, que ao se deparar com problemas para vencer determinado vão no setor naval, com poucas opções de perfis, inventou o método de fabricação de separação e soldagem, aumentando sua rigidez à flexão [2, 3]. O processo, patenteado em 1939 [4] e aperfeiçoado com o passar dos anos com a automatização das técnicas, consiste em quatro etapas: (a) corte na alma em dado padrão; (b) deslocamento das novas duas seções; (c) remoção das sobras nas extremidades; e (d) união das duas seções novamente por processo de solda formando a seção castelada, a região do montante de alma (Webpost) entre as aberturas e as seções "tê", as quais se localizam acima e abaixo dos furos [2]. A figura 2.1 ilustra as etapas de fabricação.

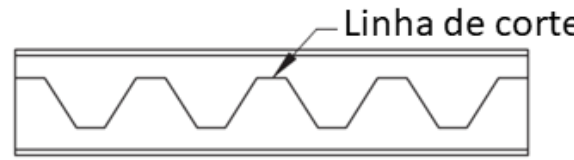

(a)

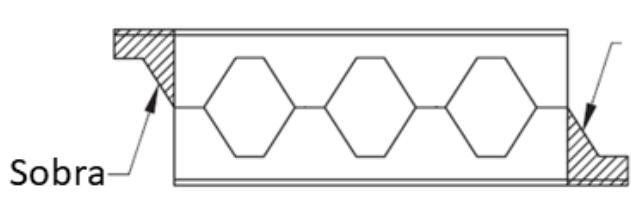

(c)

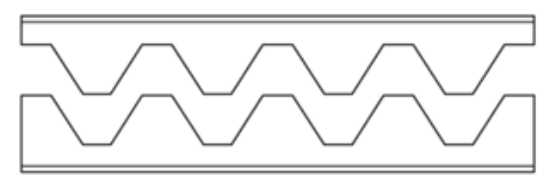

(b)

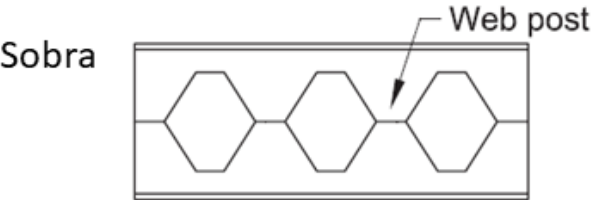

(d)

Figura 2.1 - Fabricação viga castelada, Design Guide 31 (adaptado) [2]. 
O corte em zigue-zague caracteriza a criação da viga castelada. A palavra castelada, derivada do latim castellatus, possui como significado "fortificar" e foi atribuída às vigas com aberturas em formato hexagonal. Cortes em padrão semicircular configuram vigas celulares as quais possuem aberturas circulares e geram mais sobras se comparadas às casteladas [2]. De modo similar, também podem ser inseridas placas retangulares entre as metades, criando orifícios octogonais [5]. Além desses exemplos, encontram-se vigas com diferentes formatos de aberturas, como é o caso da viga Angelina, criada a partir de corte em função senoidal [6].

As vigas casteladas Litzka-Schnittführung (também conhecida como Peiner-Schnittführung) são caracterizadas por relacionarem as dimensões geométricas de modo que: a razão entre a altura total $(H)$ e a do furo $(h)$ é igual a 1,5; a distância entre os furos é igual a altura total $(H)$; e o ângulo $\alpha$ é igual a $63,5^{\circ}$ (tangente $\alpha=2$ ) [7]. A figura 2.2 demonstra a geometria da viga do tipo Litzka e as seções "tê" localizadas acima e abaixo das aberturas.

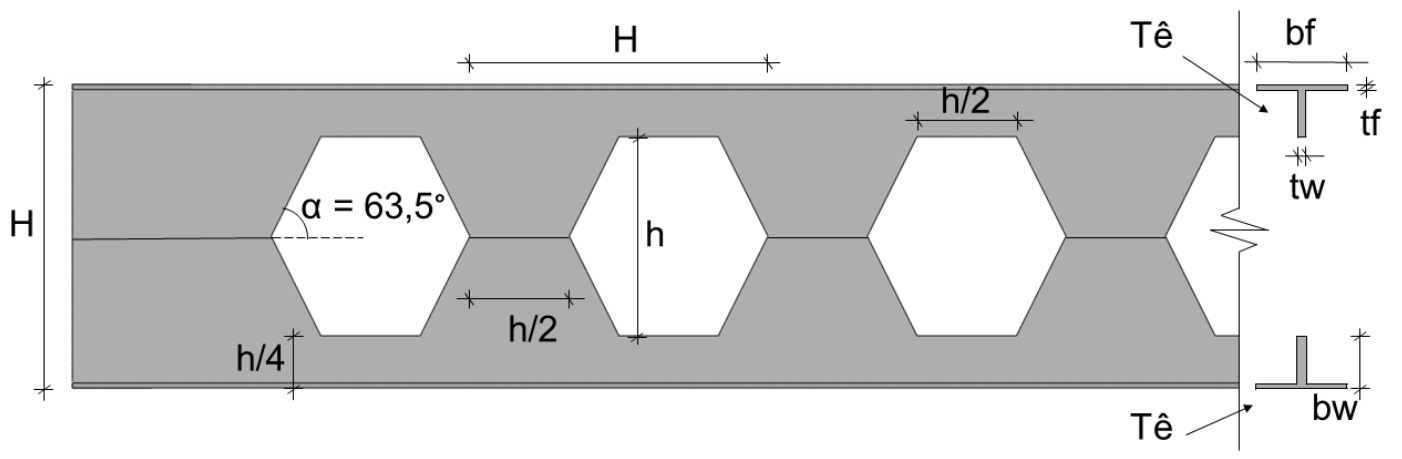

Figura 2.2 - Geometria de viga Litzka-Schnittführung.

As principais vantagens que vigas dessa natureza apresentam são: economia de material, maior razão resistência/peso, aberturas que proporcionam soluções para passagem de tubos e dutos e uma maior altura da seção aumenta sua rigidez possibilitando maiores vãos [8]. Sendo assim, principalmente designadas para resistir à flexão, além de possuírem aparência estética atrativa [8-11]. Entretanto, com a presença de furos ao longo da alma, o comportamento estrutural do elemento passa a ser 
diferente em diversos aspectos, quando comparado com a viga sem aberturas, introduzindo novos modos de falha [11-13]. Isso evidencia a necessidade de estudos para a sua melhor compreensão.

Boyer [9], estudou o comportamento de vigas casteladas e suas aplicações. Evidenciou seus processos de fabricação, critérios e procedimentos de dimensionamento, associando-as a vigas Vierendeel e sujeitas a fenômenos de instabilidade como flambagem lateral e local.

Kerdal e Nethercot [11] realizaram um amplo estudo experimental avaliando e identificando os modos de falha de vigas casteladas e suas previsões. Acerca da falha devido à flambagem lateral com torção, foi identificada uma variação tanto subestimando os métodos de previsão em relação aos resultados experimentais em até $40 \%$, em valores elevados de esbeltez, como também os superestimando. Os autores sugerem os seguintes modos de falha para vigas casteladas, em concordância com outros trabalhos [11, 14-16]:

- Formação do mecanismo de Vierendeel

- Flambagem lateral com torção do webpost

- Ruptura da solda

- Flambagem lateral com torção de todo um vão

- Formação do mecanismo de flexão (rótula)

- Flambagem do webpost

O modo de falha devido à flambagem local do "tê" comprimido (FT), ou seja, a seção acima das aberturas conforme indica a figura 2.2, não é citado pelos autores.

O mecanismo de Vierendeel, ilustrado na figura 2.3, é manifestado através da formação de quatro rótulas plásticas nas seções "tê", acima e abaixo das aberturas, em decorrência da combinação entre momento global e momento de Vierendeel, o qual é formado pela transferência das forças cortantes pelos furos. Vigas casteladas com grandes aberturas e alta relação momento/cortante demonstram estarem sujeitas a esse modo de falha [17]. Esse mecanismo foi amplamente estudado em vigas casteladas 
através de testes experimentais [14] e numéricos [12, 16 e 18] e atribuída grande relevância para determinação de sua resistência.

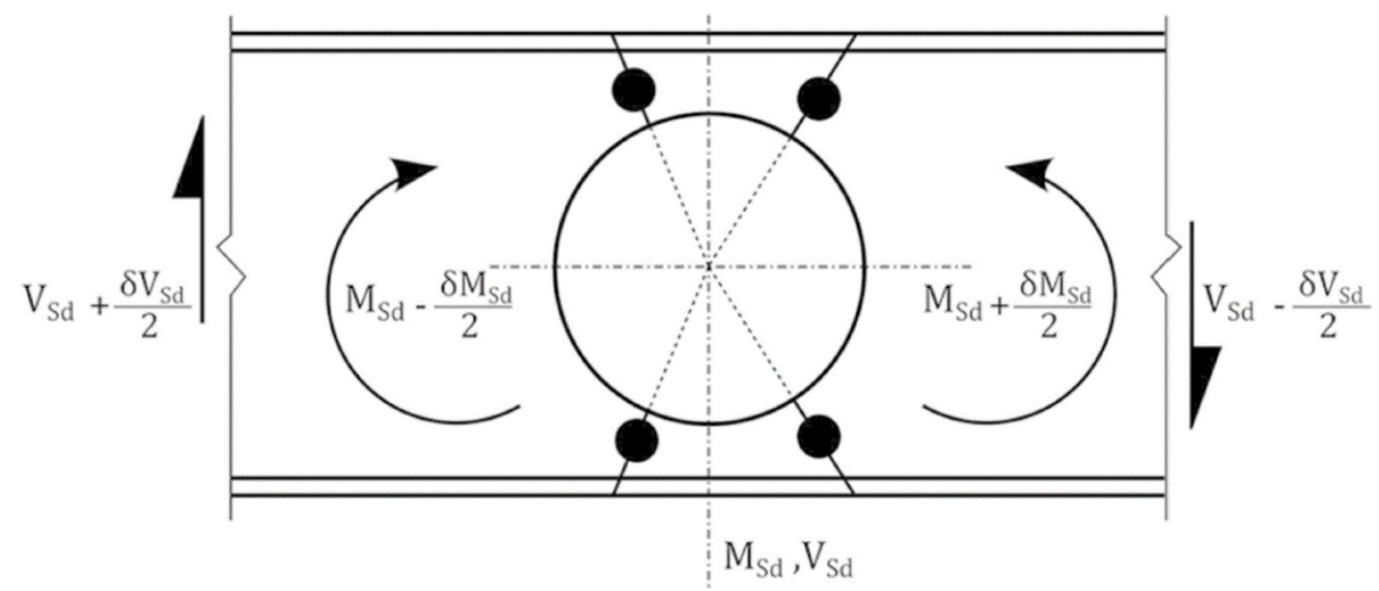

Figura 2.3 - Mecanismo de Vierendeel em vigas celulares [12].

Liu e Chung et al. $[16,18]$ realizaram um amplo estudo paramétrico considerando vigas com aberturas nas almas de diversos formatos e comparando sua capacidade de resistência sob as ações de Vierendeel. Por meio de análises de elementos finitos, sugeriram novas curvas para dimensionamento incorporando interação de momento-cortante e conduzindo a resultados mais econômicos. Também chegaram à conclusão que apesar das variadas formas de aberturas, as características estruturais desses elementos são semelhantes e levam aos mesmos modos de falha. Os autores identificam que a flambagem local do "tê" comprimido pode ocorrer em determinados casos.

O modo de falha de flambagem do webpost também foi considerado em diversos estudos quanto à sua estabilidade [5, 17]. Em destaque aos trabalhos de Zaarour e Redwood [15], Redwood e Demirdjian [19] e Demirdjian [20], os quais investigaram a estabilidade dos webposts de vigas casteladas através de análises de elementos finitos, demonstrando boa previsão e adequação com resultados experimentais, e sugerindo o uso do método proposto para estimação da resistência do webpost sob forças de cisalhamento elevadas. Erdal e Saka [21] realizaram testes experimentais e simulações usando o método dos elementos finitos em vigas celulares e destacam a interação entre os modos de falha devido à flambagem do webpost em conjunto dos momentos de Vierendeel. Os 
autores também apontam a importância dos suportes laterais visto que até mesmo em membros com comprimentos relativamente curtos foi observada a falha por flambagem lateral com torção (FLT).

Os modos de falha de flambagem lateral com torção (FLT) e flambagem local do "tê" comprimido (FT) em vigas casteladas são abordados na seção 2.2 deste trabalho.

\subsection{2.}

\section{Interação entre modos de flambagem}

A ocorrência da interação entre os modos de flambagem global e local é citada por Koiter [22] e posteriormente Chilver [23], Budiansky [24] e outros estudos [25-28], os quais foram refinando a teoria. Quando as cargas críticas de modos de flambagem naturalmente distintos coincidem ou se encontram próximas umas das outras, é identificado o acoplamento, ou seja, a interação entre os modos [23, 24, 29].

A chamada bifurcação acoplada é definida como a ocorrência de diversos modos de instabilidade quando as cargas críticas são coincidentes ou se aproximam. Nesses casos as imperfeições podem levar a significantes reduções na carga última resistente quando comparada com as cargas dos modos individuais [30]. A figura 2.4 ilustra a redução da capacidade resistente de uma coluna devido ao acoplamento dos modos de flambagem global e local, em que " $N$ " é a carga aplicada e " $N$ cr" as cargas críticas.

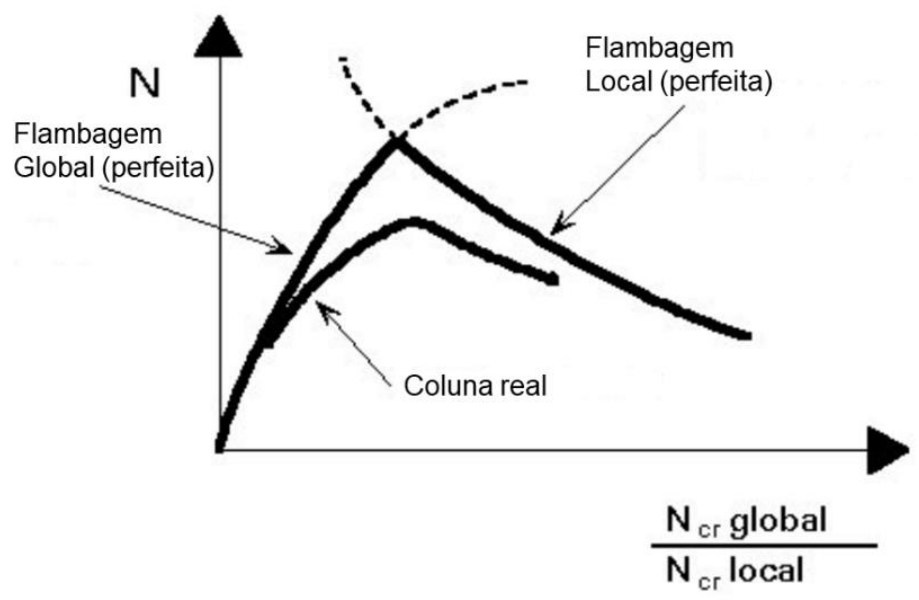

Figura 2.4 - Curva de interação entre modos de flambagem de coluna (adaptado) [30]. 
Segundo Budiansky [24], as estruturas que manifestam esse fenômeno tendem a exibir grande sensibilidade às imperfeições, possuindo cargas de pico até inferiores à metade da carga crítica. Esse é o caso, por exemplo, de esferas sob pressão externa e cilindros em compressão axial [24]. Outros estudos, como os de Goltermann \& Møllmann e Wadee \& Gardner [31, 32], constataram essa queda da capacidade resistente, inferior a $50 \%$ da carga crítica, devido à interação dos modos e, portanto, à sensibilidade às imperfeições geométricas.

Problemas de acoplamento de modo são frequentes em estruturas com paredes finas, contudo nem todas demonstram sensibilidade quanto às imperfeições. Entretanto, de modo geral, sistemas estruturais que possuem cargas críticas coincidentes, demonstram interação dos modos de flambagem e são sensíveis às imperfeições [29].

A figura 2.5 exemplifica a interação entre modos de flambagem de uma estrutura treliçada na qual ocorrem os modos local (a), global (b) e o acoplamento entre eles (c).
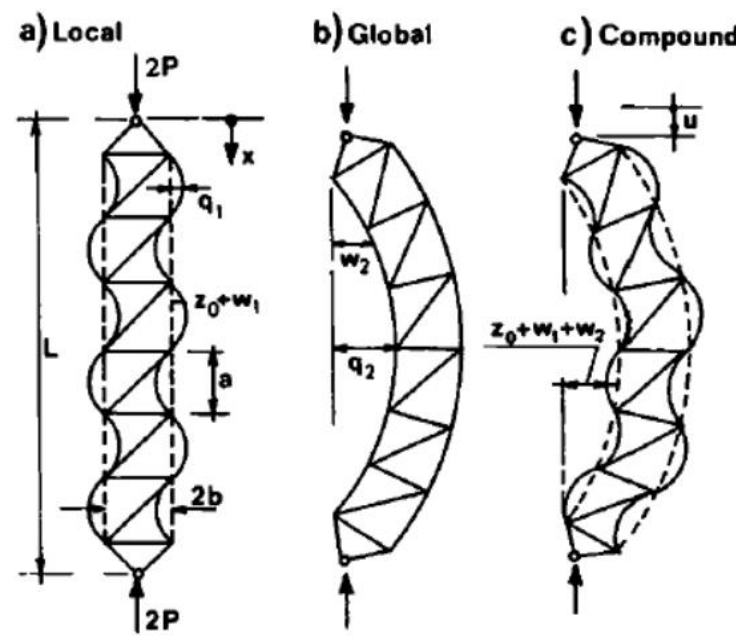

Figura 2.5 - Interação entre modos flambagem: a) Modo local; b) Modo global; e c) Modos acoplados [29].

A interação entre modos global de flambagem lateral com torção e local em vigas de perfil I foi indicada por Shokuhian et al. [33] como sendo a mais proeminente em relação à redução da capacidade de resistência de 
tais vigas, evidenciando, portanto, a importância da compreensão desse fenômeno.

Devido às imperfeições geométricas iniciais, o membro estrutural carregado axialmente apresenta deflexão lateral e a distribuição de momento é aumentada. As tensões de compressão são críticas no lado côncavo do elemento, levando à plastificação e sua propagação em qualquer aumento de carga [30], conforme ilustra a figura 2.6.

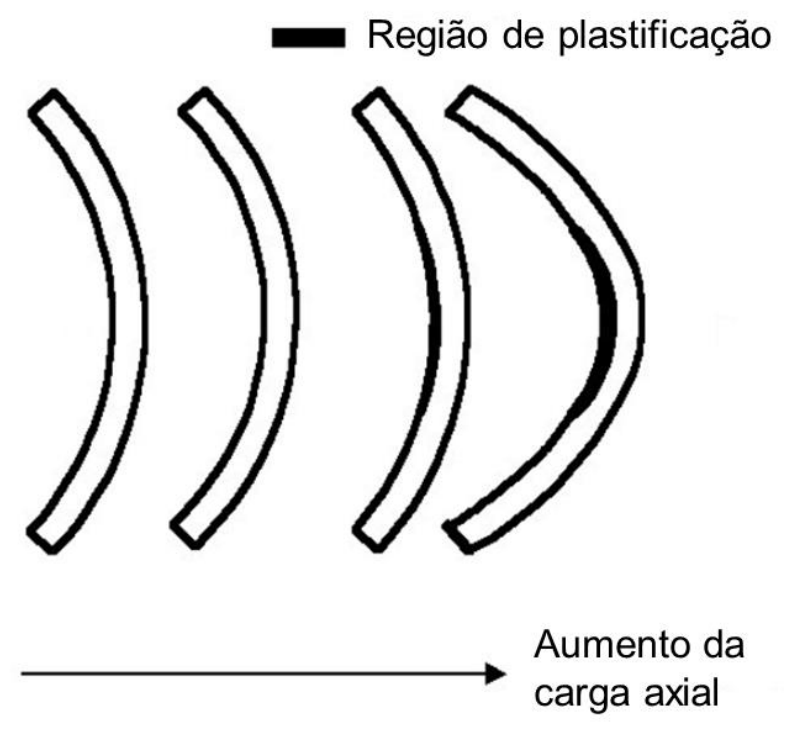

Figura 2.6 - Propagação da plastificação com o aumento da deflexão lateral (adaptado)

[30].

Apesar de diversos estudos abordando o acoplamento dos modos de flambagem, sensibilidade quanto às imperfeições e seus efeitos na estabilidade dos sistemas estruturais, em vigas casteladas essa interação não é abordada com frequência, de modo que se encontram poucos os trabalhos que discutem o tema.

\section{2.}

\section{Trabalhos relacionados}

Sherbourne e Van Oostrom [34] realizaram análises plásticas em modelos computacionais de vigas casteladas para investigar o efeito da interação entre momento, cortante e forças axiais na plastificação local em diferentes zonas obtendo êxito em testar a plastificação devido ao 
carregamento até o colapso e confirmando a analogia dos membros da viga em seções retangulares e em "tê".

Galambos et al. [10], realizaram uma análise numérica e experimental a respeito da razão ideal de expansão e verificaram que ela está relacionada diretamente com a seção original, além de ser afetada pela geometria do perfil expandido, tipo de carregamento e comprimento do vão.

Srimani e Das [8] empregaram análises pelo método dos elementos finitos (MEF) em vigas casteladas e compararam com resultados experimentais, obtendo melhores aproximações do que os outros métodos teóricos de deflexão. Também observaram que a distribuição das deformações de flexão e cisalhamento obtidas pelo MEF eram bem correlacionadas com os resultados experimentais. A modelagem e malha de elementos finitos desse estudo é apresentada na figura 2.7 em que a viga é modelada em $1 / 4$ de seu tamanho real com as respectivas condições de contorno.
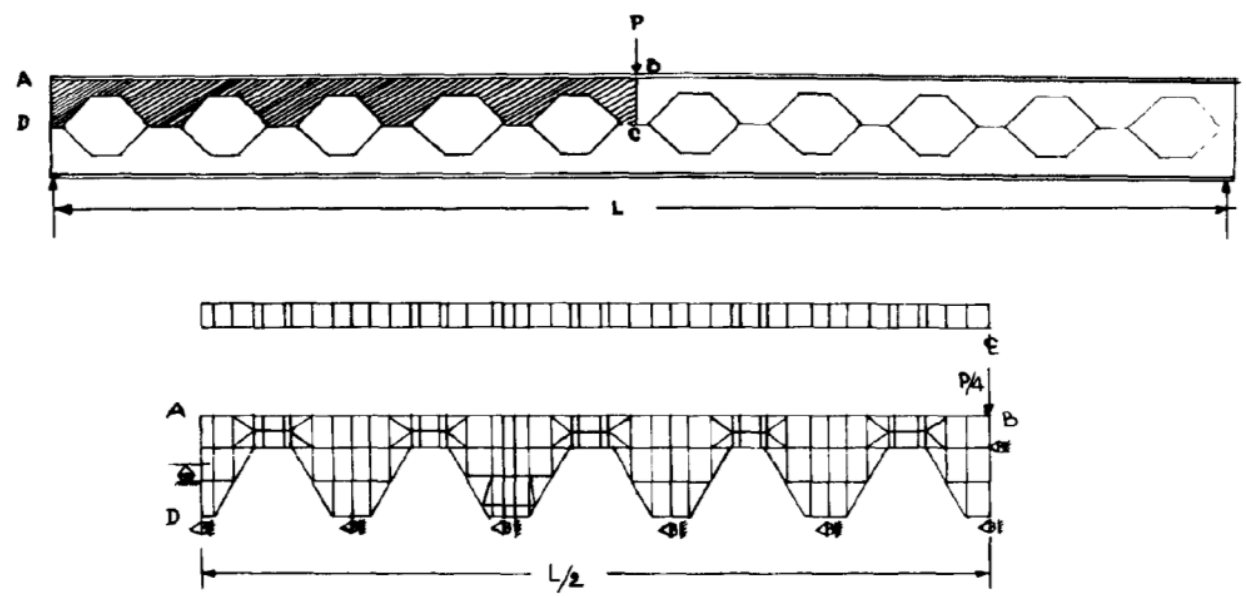

Figura 2.7 - Modelagem e malha de elementos finitos [8].

Zirakian e Showkati [35] estudaram o comportamento de vigas casteladas quanto à flambagem distorcional a qual ocorre em membros com almas esbeltas e é resultante da interação entre modos locais e laterais de flambagem, caracterizada pela distorção simultânea e deflexão lateral da seção. Foram realizados ensaios experimentais em grande escala e todas as vigas testadas exibiram flambagem lateral e obtiveram concordância satisfatória com valores teóricos. 
Ellobody [36] analisou a interação entre modos de flambagem distorcional e lateral com torção de vigas casteladas. Utilizou-se da modelagem por elementos finitos para realizar um amplo estudo paramétrico analisando a influência dessa interação. As análises não lineares de material e considerando imperfeições geométricas demonstraram que quanto maior a presença da flambagem distorcional, menor é sua capacidade resistente. Concluiu-se que as normatizações exibiam previsões conservadoras para vigas falhando por flambagem lateral com torção (FLT) e não conservadoras por distorcional. Também os resultados obtidos foram comparados com os experimentos de Zirakian e Showkati [35] obtendo uma boa concordância entre eles. A figura 2.8 exibe o primeiro modo de flambagem obtido pela simulação numérica realizada por Ellobody [36] em comparação com o obtido experimentalmente por Zirakian e Showkati [35].

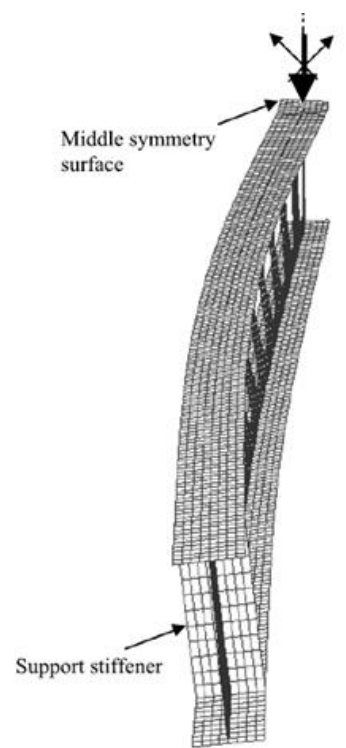

a) Numérico

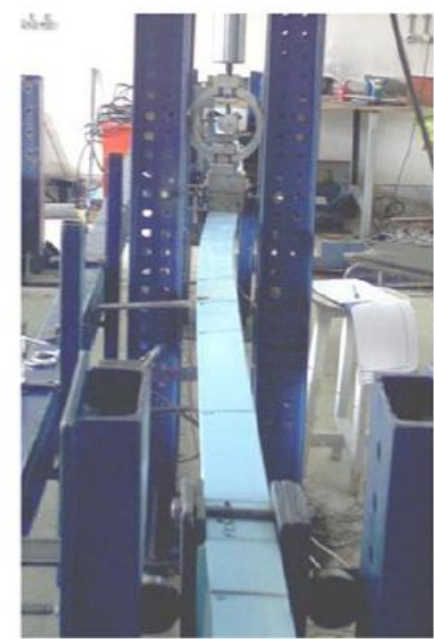

b) Experimental

Figura 2.8 -Comparação dos resultados entre modos de flambagem: a) Modelagem numérica, Ellobody [36]; b) Teste experimental, Zirakian e Showkati [35].

Boissonnade et al. [37] e Sonck et al. [38] investigaram a flambagem lateral com torção (FLT) em vigas celulares através de ensaios experimentais e análises pelo método dos elementos finitos sugerindo melhorias nas suposições dos dimensionamentos. Sonck e Belis [39] estenderam seus estudos de FLT às vigas casteladas levando em consideração tensões residuais. Executaram um estudo numérico 
paramétrico em vigas sujeitas a momento constante usando o método dos elementos finitos, e também testes experimentais, e verificaram a abordagem sugerida para estimação do momento crítico. A figura 2.9 demonstra a configuração dos apoios e carregamento dos testes experimentais dos autores em vigas casteladas sob ação de cargas pontuais.

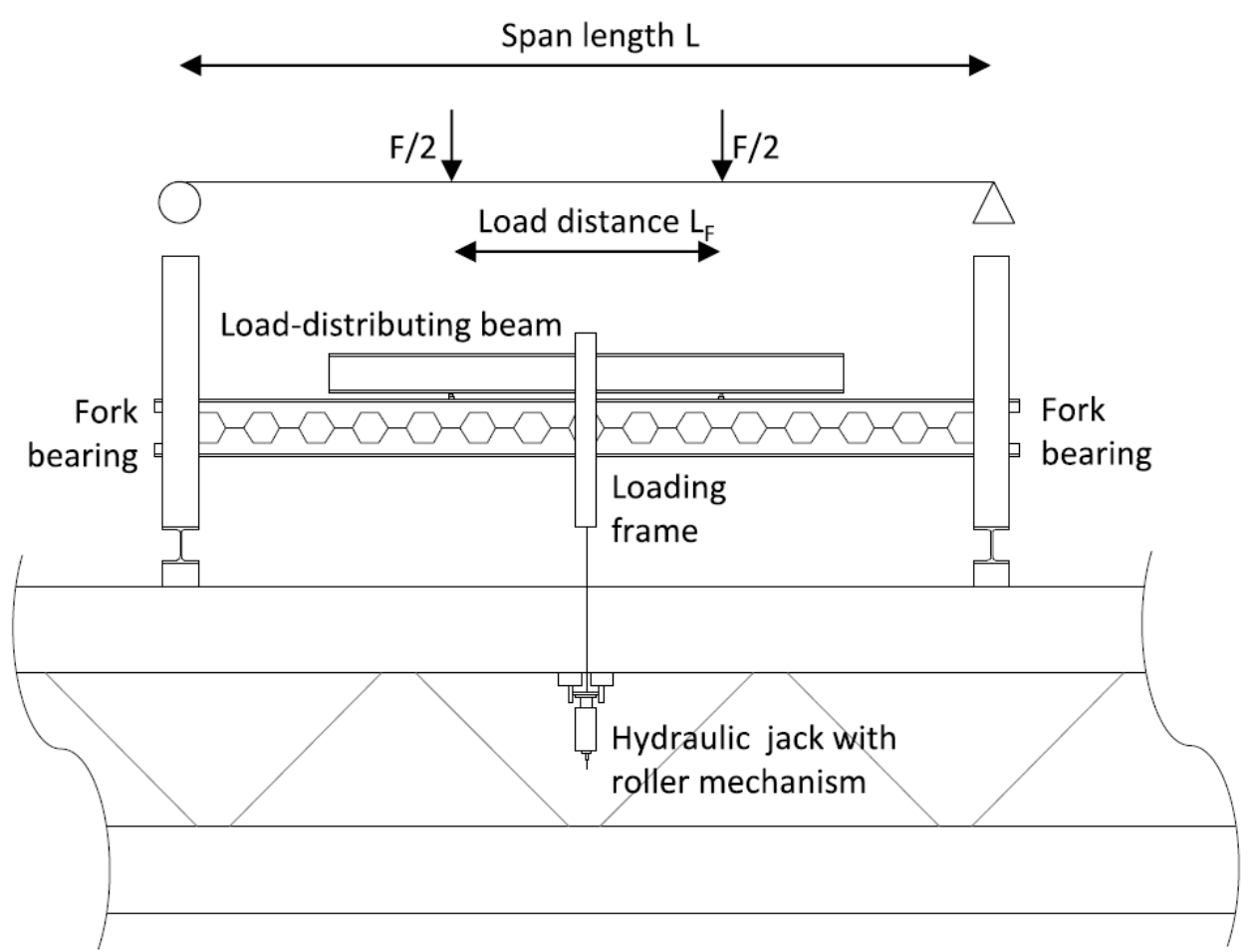

Figura 2.9 - Configuração dos testes experimentais de Sonck \& Belis [39].

Soltani et al. [40], também por meio de modelos de elementos finitos com não linearidades geométricas e de material, avaliaram a resistência de vigas casteladas com orifícios hexagonais e octogonais, evidenciando o modo de falha devido à flambagem local do "tê" (FT) e que esse modo de falha limitou a capacidade resistente das vigas. Amayreh e Saka [13] também levaram em conta o modo de falha associado à flambagem local do "tê" em seus estudos para previsão da carga resistente de vigas casteladas por meio de redes neurais, concluindo que essa ferramenta pode ser utilizada com precisão para determinação da resistência.

Oliveira et al. [41] desenvolveram expressões explícitas para a previsão da tensão crítica de flambagem elástica local do "tê" comprimido a partir de análises de autovalor através de simulações numéricas usando 
elementos finitos. A abordagem proposta conduziu a resultados satisfatórios e evidenciou que esse modo de falha se torna relevante principalmente em vigas casteladas produzidas a partir de aços com resistências elevadas. A figura 2.10 exibe o modo típico de flambagem local do "tê", obtido através de análises de autovalor das vigas casteladas.

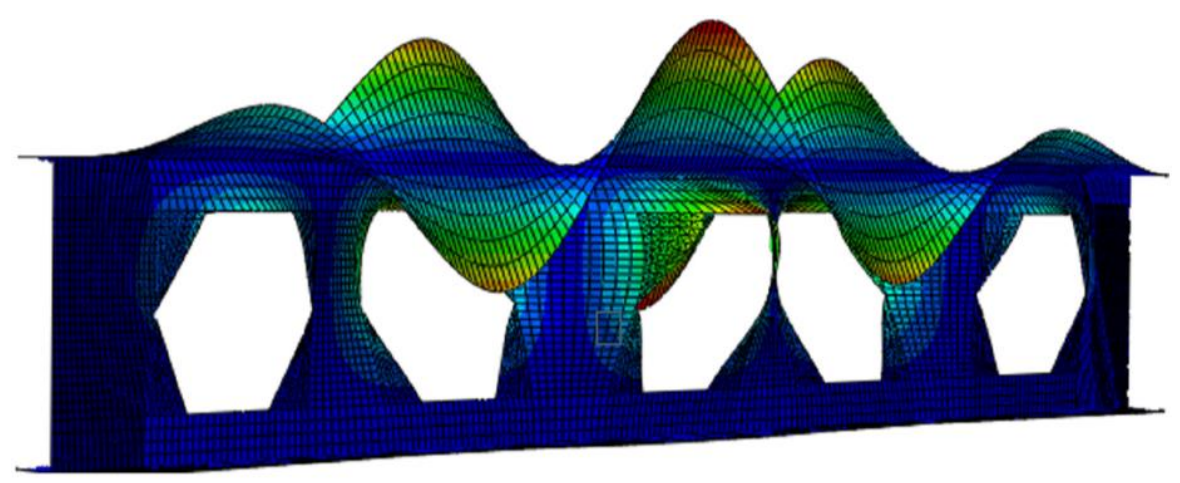

Figura 2.10 - Modo típico de flambagem local do "tê" - análises de autovalor [42].

Linhares [42] realizou um mapeamento dos modos de falha dominantes em vigas casteladas sob flexão simples em função de sua esbeltez relativa, considerando a interação entre modos isolados. O mapa sugerido correlaciona diferentes valores de esbeltez com as forças atuantes e a razão momento-cortante e designa por regiões qual modo de falha dominante deve ocorrer. Souza et al. [43] também avaliaram a interação entre os modos de FLT e local do "tê" em condições de flexão pura comparando com o método da resistência direta desenvolvido para perfis formados a frio.

\section{3.}

Métodos de Dimensionamento

\subsection{1.}

Steel Design Guide 31

O guia de dimensionamento, Steel Design Guide 31 [2], do Instituto Norte-americano de Construção em Aço (American Institute of Steel Construction - AISC) fornece os procedimentos para o projeto de vigas casteladas e celulares com base em princípios estruturais e a partir de 
resultados de pesquisas encontradas na literatura. $\mathrm{O}$ documento está de acordo com a normatização norte americana Specification for Structural Steel Buildings - AISC 2016 [44].

Além de instruir como devem ser realizadas as verificações, o manual também traz exemplos de dimensionamento. Dentre os procedimentos, introduz as verificações quanto ao momento de Vierendeel, flambagem do webpost, cisalhamento vertical e horizontal e flambagem lateral com torção, de forma individual. Para o caso deste trabalho, apenas os estados limites de FLT, FT e plastificação são abordados, pois aqui é apenas considerado o caso de flexão pura.

O Steel Design Guide 31 [2], determina que o dimensionamento quanto à flambagem lateral com torção, flambagem local do "tê" e plastificação da mesa deve ser realizado conforme a normatização ANSI/AISC 360-16 [44], no capítulo destinado ao dimensionamento de membros estruturais à flexão, "F", seções "F2" a "F5". Afirma ainda que as propriedades da seção completa (sem o furo) podem ser utilizadas para o caso de FLT.

De acordo com o procedimento proposto pela normatização em tais capítulos, é realizado o dimensionamento abrangendo os casos em que o perfil I exibe almas e mesas compactas, não compactas e esbeltas, conforme sua respectiva classificação definida na seção "B4.1" do guia. Assim, a normatização estabelece os procedimentos para 0 dimensionamento abordando estados limites de flambagem global e local separadamente e sem claramente mencionar a interação entre eles.

Portanto, o momento nominal, $M_{n}$, é tomado como o menor valor obtido para cada uma dessas verificações.

\subsection{2.}

\section{Método da Resistência Direta}

O Método da Resistência Direta (MRD), como seu nome sugere, consiste na obtenção da capacidade de resistência diretamente a partir das cargas críticas de flambagem elástica do membro estrutural. O método foi 
desenvolvido e refinado amplamente em relação a perfis formados a frio, estando presente no corpo principal da normatização norte americana para seu dimensionamento AISI S100-16: "North American Specification for the Design of Cold-Formed Steel Structural Members" [45].

O conceito já é encontrado nas curvas de resistência propostas por Hancock et al. [46] para perfis formados a frio exibindo flambagem distorcional e na abordagem de Peköz [47] abrangendo interação entre modos de flambagem, porém o método foi propriamente introduzido por Schafer e Peköz [48] como uma alternativa aos procedimentos de dimensionamento disponíveis. Dessa forma, o método proposto pelos autores empregou o uso de soluções numéricas para obtenção das cargas críticas como possibilidade ao dimensionamento de perfis formados a frio, demonstrando estarem de acordo e serem uma alternativa confiável. Portanto, o método consiste em uma ideia antiga aplicada a novos estados limites de instabilidade [49].

Entre as vantagens da utilização da abordagem de resistência direta se destacam a capacidade de fornecer alternativas incorporando processos numéricos para dimensionamento e otimização de membros estruturais a fim de evitar previsões contra a segurança dos métodos disponíveis. Além disso, a interação entre modos de flambagem é contemplada e erros sistemáticos são eliminados [50-52]. O método ainda encoraja diversas extensões e potencial para várias aplicações, focando na determinação correta do comportamento elástico de flambagem, ao invés de comprimentos efetivos [51]. Desse modo, é destacada a habilidade do MRD de integrar simulações de flambagem elástica e fornecer previsões estruturais eficientes para seções complexas [53].

Assim, o método foi desenvolvido para vigas e colunas de perfis formados a frio e teve seu reconhecimento formal em 2004, ao entrar nas especificações das normatizações norte americanas como uma alternativa ao tradicional método da largura efetiva. A norma AISI-S100-07 [54] de 2007 exibe em seu "Apêndice 1" o procedimento. Em 2010, o MRD também foi adotado pela norma brasileira: ABNT NBR 14762:2010 "Dimensionamento de estruturas de aço constituídas por perfis formados a frio" [55]. 
Desse modo, a análise de estabilidade elástica é o seu conceito fundamental. Ou seja, o Método da Resistência Direta prevê que se o engenheiro determina as cargas críticas globais e locais, além da carga de plastificação, a resistência do elemento estrutural pode ser determinada $[49,52]$. Para a definição das cargas críticas dos modos de flambagem é possível realizar análises pelo método dos elementos finitos (MEF), método das faixas finitas (Finite Strip Method - FSM), teoria da viga generalizada (Generalized Beam Theory - GBT) ou soluções teóricas [51]. Portanto, o uso de ferramentas computacionais demonstra ser fundamental para sua avaliação [52]. A figura 2.11 ilustra o esquema conceitual da aplicação da abordagem do MRD, em que a partir da análise de estabilidade e da análise levando em consideração a plastificação do material é possível obter a resistência do membro estrutural.

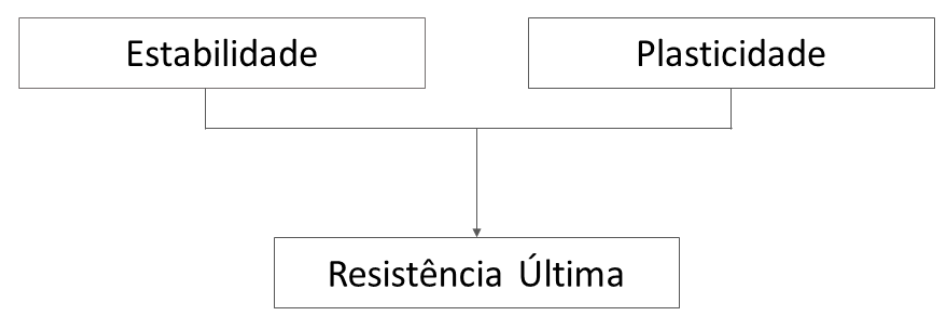

Figura 2.11 - Esquema conceitual da aplicação da abordagem MRD.

O procedimento destinado a membros sob flexão se encontra descrito no capítulo "F" da AISI S100-16 [45]. Primeiramente, são determinados o momento crítico global $\left(M_{c r e}\right)$ e o momento de início de plastificação da seção $\left(M_{y}\right) \cdot M_{p}$ é o momento de plastificação completa da seção. Com esses parâmetros e através das equações calibradas empiricamente para perfis formados a frio, pode-se obter o momento nominal global $\left(M_{n e}\right)$, conforme a Eq. 1.

$$
M_{n e}=M_{p}-\left(M_{p}-M_{y}\right) \frac{\left(\sqrt{M_{y} / M_{\text {cre }}}\right)^{-0.23}}{0.37} \leq M_{p}
$$

Em seguida, são utilizados os valores de $M_{n e}$ do passo anterior e a esbeltez relativa local-global $\left(\lambda_{L G}\right)$, definida como $\lambda_{L G}=\sqrt{M_{n e} / M_{c r l}}$, em uma segunda equação de resistência para se obter o momento nominal 
local $\left(M_{n l}\right)$, Eq. 2 e 3, dessa forma, levando em consideração a interação. $M_{c r l}$ é o momento crítico local.

Se $\lambda_{L G} \leq$

0.766

$$
M_{n l}=M_{n e}
$$

Se $\begin{array}{r}\lambda_{L G}> \\ 0.766\end{array} \quad M_{n l}=\left[1-0.15\left(\frac{M_{c r l}}{M_{n e}}\right)^{0.4}\right]\left(\frac{M_{c r l}}{M_{n e}}\right)^{0.4} M_{n e}$

$\mathrm{Na}$ última década, diversos avanços foram alcançados, estendendo as aplicações do MRD a diferentes seções e condições de contorno para colunas e vigas de perfis formados a frio sob efeito das interações entre os modos [56-61], inclusive expostas à elevadas temperaturas [62]. Moen e Schafer [63-65] estenderam o método para a previsão de perfis formados a frio contendo furos nas almas, constatando que a presença das descontinuidades levava a modos de flambagem naturalmente combinados, podendo aumentar ou reduzir a tensão crítica. A adaptação do método demonstrou bons resultados para previsão da resistência.

Dessa maneira, os trabalhos sugerem diversas novas curvas de resistência e equações, por meio de resultados experimentais e numéricos de amplos estudos paramétricos, pela abordagem da resistência direta. Essa é a metodologia seguida neste trabalho, aplicando o conceito às vigas casteladas biapoiadas em condição de flexão pura. 


\section{3 \\ Modelagem numérica}

Neste capítulo são descritos os processos e as técnicas empregadas na modelagem numérica das vigas casteladas no estudo deste trabalho por meio do método dos elementos finitos, as análises realizadas e as validações.

\section{1.}

\section{Modelo de elementos finitos}

Com o intuito de reproduzir o comportamento de vigas casteladas do tipo Litzka-Schnittführung, são empregadas simulações computacionais através do Método dos Elementos Finitos (MEF). Os modelos gerados e análises são realizados por meio do software comercial ABAQUS [66].

Nesse sentido, utilizando a interface de script, é possível parametrizar o modelo, ou seja, realizar alterações de diversos aspectos, tais como: geometria, propriedades de material, condições de contorno e carregamento, malha, tipos de elementos, entre outros. Essa metodologia possibilita otimizar a geração dos modelos e análises tornando o processo mais rápido e efetivo, e ainda minimizar possíveis erros sistemáticos de modelagem, sendo bastante adequada para a realização de análises paramétricas.

Neste trabalho, o software ABAQUS foi integrado ao script Python que, por sua vez, importou os dados de entrada e características específicas dos modelos a partir de uma planilha Excel contendo tais informações. Assim, ao operar essa metodologia, torna-se viável a manipulação de um grande número de dados.

As técnicas de modelagem descritas neste capítulo foram reproduzidas para todas as vigas presentes no estudo deste trabalho. 
Assim sendo, as vigas geradas para a investigação proposta foram modeladas utilizando elementos de casca na alma e nas mesas. Para acomodar as descontinuidades geométricas da viga castelada, a malha de elementos finitos foi elaborada combinando elementos de casca quadrilaterais e triangulares, ambos possuindo funções de interpolação quadrática para obter melhor aproximação do comportamento à flexão.

Desse modo, nas regiões adjacentes às faces angulares dos orifícios e suas extremidades, nas quais é esperada uma maior concentração de tensões, foram inseridos elementos triangulares com o objetivo de proporcionar melhor adequação e refinamento, assim como, produzir uma zona de transição de malha para os elementos quadrilaterais.

Quanto aos triangulares, foram empregados os elementos STRI65 do software ABAQUS, os quais conferem elementos de casca fina de 6 nós possuindo 5 graus de liberdade (3 deslocamentos e 2 rotações) em cada nó, e utiliza integração reduzida. Em relação aos quadrilaterais, os elementos foram S8R5 do software ABAQUS, correspondentes a cascas finas com 8 nós e 5 graus de liberdade por nó, também utilizando integração reduzida. A utilização de elementos que utilizam integração reduzida é justificada porque esses elementos além de melhorar a eficiência computacional também produzem resultados mais precisos com um menor refinamento.

A malha de elementos finitos, assim definida, foi utilizada com sucesso em trabalhos anteriores [41-43] e, portanto, foi escolhida para esse trabalho. A figura 3.1 ilustra o aspecto da malha de elementos finitos adotada. 


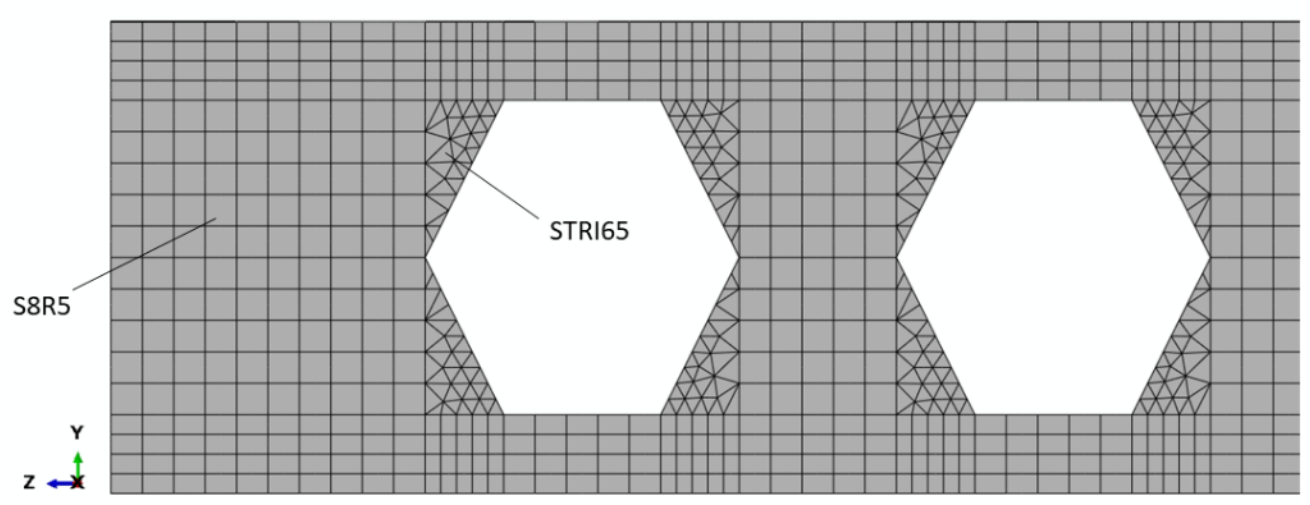

Figura 3.1 - Malha típica adotada e tipos de elementos.

As condições de contorno foram escolhidas com o intuito de garantir liberdade de rotação da viga no plano de maior inércia, bem como de eliminar restrições ao empenamento nos apoios. Através dessa última consideração, deseja-se que as mesas possam rotacionar livremente em seu plano.

Portanto, para designar a viga biapoiada, foram geradas as seguintes restrições no sistema de referência correspondente à figura 3.2: nos nós médios da seção dos extremos das vigas, foram restringidos todos os seus deslocamentos (Ux, Uy e Uz) bem como sua rotação $R z$ e na extremidade oposta permitido seu deslocamento axial (Uz).

Quanto ao carregamento, com o intuito de simular condição de flexão pura, foram aplicados momentos concentrados em ambas extremidades. Para garantir que esse momento fosse distribuído em todos os nós da alma das seções de extremidade, foi necessária a utilização de MPCs (Multi Point Constraints) que relacionam diferentes graus de liberdade dos nós do modelo. Nesse caso, foram designados todos os nós da alma da seção das extremidades como nós escravos do nó intermediário (mestre), possuindo graus de liberdade numericamente equivalentes. Assim, a condição de flexão pura é reproduzida distribuindo o momento concentrado ao longo das almas nas extremidades e preservando a liberdade das mesas. A figura 3.2 ilustra as condições de contorno e o carregamento aplicado nos modelos de elementos finitos. 


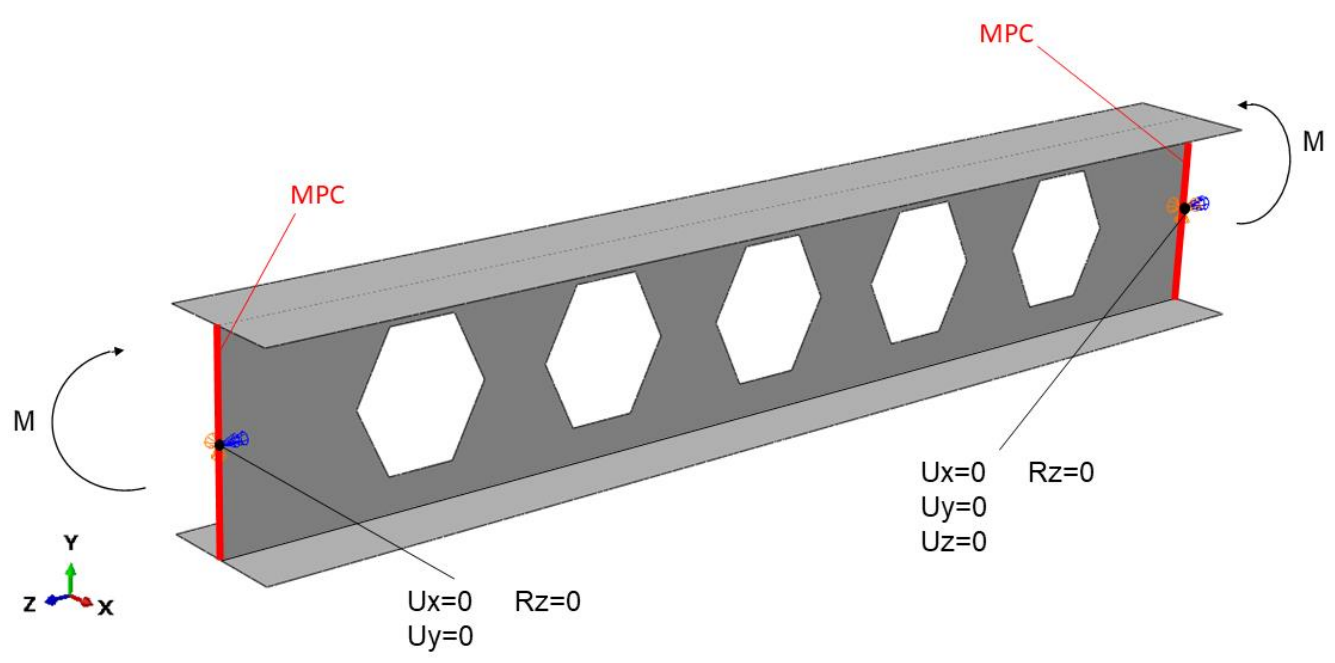

Figura 3.2 - Condições de contorno e carregamento.

Também foi realizado um estudo de convergência de malha para melhor adequação e eficiência dos resultados, além da definição da densidade generalizada dos elementos nos modelos. Assim sendo, foi selecionada a viga de referência, denominada modelo \#1, e obtido o seu valor do momento crítico de flambagem $\left(M_{c r}\right)$ por análise de autovalor. $A$ viga possui altura $(H)$ igual a $222 \mathrm{~mm}$, espessura da alma $\left(t_{w}\right)$ de $4,3 \mathrm{~mm}$, espessura da mesa $\left(t_{f}\right)$ de $4,9 \mathrm{~mm}$ e comprimento total $(L)$ de $2442 \mathrm{~mm}$. Outras informações do modelo \#1 estão disponíveis no Anexo A.

A variação dos resultados em função dos graus de liberdade é exibida na tabela 3.1 e na figura 3.3. A diferença é definida em relação ao resultado anterior como: $\left|M_{c r i+1}-M_{c r i}\right| / M_{c r i}$, sendo “i” o número da malha. Por fim, a densidade de malha correspondente à malha 4 foi escolhida tendo em vista o grande aumento no número dos graus de liberdade e a baixa diferença entre os resultados.

Tabela 3.1 - Análise de convergência.

\begin{tabular}{ccccc} 
Malha & $\begin{array}{c}\text { № } \\
\text { elementos }\end{array}$ & $\begin{array}{c}\text { № graus de } \\
\text { liberdade }\end{array}$ & $M_{c r}[\mathrm{kNm}]$ & dif. \\
\hline 1 & 330 & 8346 & 34,23 & - \\
2 & 1232 & 29490 & 34,16 & $0,19 \%$ \\
3 & 2186 & 50430 & 34,15 & $0,05 \%$ \\
4 & 6350 & 141486 & 34,10 & $0,12 \%$ \\
5 & 22678 & 490530 & 34,09 & $0,03 \%$ \\
\hline
\end{tabular}




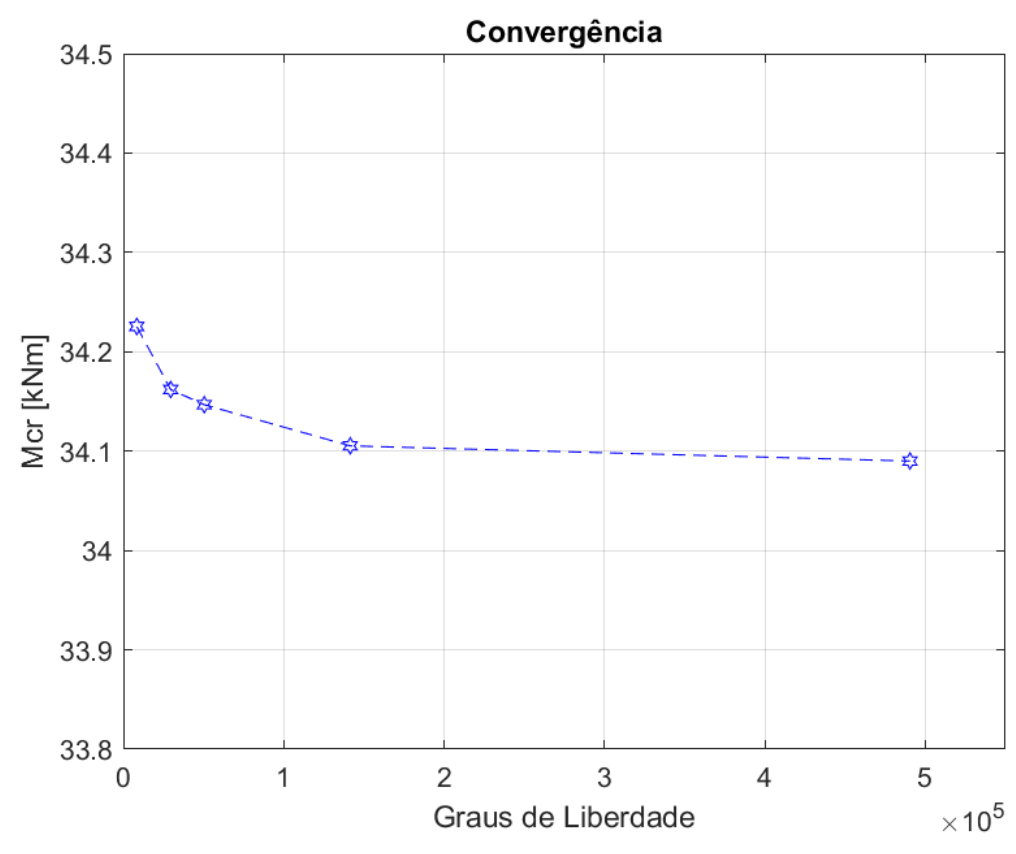

Figura 3.3 - Análise de convergência.

Após as considerações descritas acima, com base no catálogo comercial de vigas casteladas da empresa SOLESA [67], foram geradas as especificações geométricas e de material referentes aos 197 modelos do estudo deste trabalho. Esse foi $O$ banco de dados base para a implementação do estudo através do código Python integrado ao ABAQUS.

A partir do catálogo foram geradas as propriedades das vigas variando em comprimento, altura, resistência do aço e espessuras da alma e mesa para os 197 modelos com o objetivo de cobrir um grande intervalo de esbeltezes relativas global e local $\left(\lambda_{g}\right.$ e $\left.\lambda_{l}\right)$, definidas em Eq.6 e Eq. 7, e captar o comportamento quando sujeitas à flexão pura. As faixas de esbeltezes foram estabelecidas estando nos limites de $0,42<\lambda_{g}<2,85$ e $0,29<\lambda_{l}<2,36$.

As faixas de intervalo dos outros parâmetros do estudo foram de: altura da viga de $222 \mathrm{~mm}<H<925,5 \mathrm{~mm}$, comprimento de $888 \mathrm{~mm}<$ $L<8329,5 \mathrm{~mm}$, espessura da mesa de $4,9 \mathrm{~mm}<t_{f}<22,2 \mathrm{~mm}$, espessura da alma de $4,3 \mathrm{~mm}<t_{w}<17,4 \mathrm{~mm}$ e tensão de escoamento do aço $345 M P a<f_{y}<2300 M P a$.

Alguns valores elevados de tensão de escoamento do aço $\left(f_{y}\right)$, como os superiores a $1210 \mathrm{MPa}$ não são realistas ou práticos para fabricação, porém foram considerados para cobrir um maior intervalo de esbeltez 
relativa local buscando preservar as especificações geométricas dos perfis comerciais. O momento de plastificação $\left(M_{p}\right)$ foi calculado fundamentado nos princípios de resistência dos materiais considerando a seção transversal com o furo totalmente plastificada. O módulo de elasticidade $(E)$ e o coeficiente de Poisson ( $v$ ) adotados foram 200 GPa e 0,3, respectivamente. A descrição dos modelos, bem como seus parâmetros encontram-se disponíveis no Anexo A e no resumo da tabela 3.2.

Tabela 3.2 - Resumo das propriedades dos modelos.

\begin{tabular}{cccccccc} 
Viga & $H[\mathrm{~mm}]$ & $t_{f}$ & $t_{w}[\mathrm{~mm}]$ & $b_{f}[\mathrm{~mm}]$ & $\begin{array}{c}L \\
{[\mathrm{~mm}]}\end{array}$ & $\begin{array}{c}f_{y} \\
{[\mathrm{MPa}]}\end{array}$ & $\begin{array}{c}M_{p} \\
{[\mathrm{Nmm}]}\end{array}$ \\
\hline 1 & 222 & 4,9 & 4,3 & 100 & 2442 & 345 & $4,53 \mathrm{E}+7$ \\
2 & 500 & 9 & 5 & 83,33 & 3000 & 345 & $1,79 \mathrm{E}+8$ \\
3 & 500 & 5 & 5 & 300 & 8000 & 345 & $3,12 \mathrm{E}+8$ \\
4 & 222 & 4,9 & 4,3 & 100 & 1332 & 345 & $4,53 \mathrm{E}+7$ \\
5 & 229,5 & 7,1 & 5,8 & 102 & 2524,5 & 345 & $6,70 \mathrm{E}+7$ \\
$\ldots$ & $\ldots$ & $\ldots$ & $\ldots$ & $\ldots$ & $\ldots$ & $\ldots$ & $\ldots$ \\
\hline
\end{tabular}

\section{2.}

\section{Análise linear de flambagem}

Primeiramente foi conduzida a análise linear de flambagem de todos os modelos, conforme realizada a modelagem das vigas. As análises de autovalor permitem a obtenção dos momentos críticos de flambagem elástica global e local, assim como seus respectivos modos. Seus resultados são essenciais para a compreensão do comportamento dos elementos estruturais em estudo.

Além disso, é necessário o conhecimento de tais valores para posteriormente não apenas definir as esbeltezes relativas global e local, mas também realizar as análises não lineares através da geração de imperfeições iniciais nos modelos. 


\section{3.}

\section{Análise não linear de flambagem}

Após as análises lineares, seus resultados são utilizados como dados de entrada para as análises não lineares de flambagem. O momento crítico é utilizado como a amplitude do carregamento de momento concentrado e os modos de flambagem global e local são aplicados, definindo a forma das imperfeições geométricas. Todas as demais especificações são mantidas.

Assim sendo, as análises são definidas como não lineares de material com imperfeições geométricas. O modelo constitutivo de material utilizado é elástico-perfeitamente plástico e tensões residuais não são consideradas. Ainda, as amplitudes das imperfeições para os modos globais são definidas em milímetros como $L / 1000$ [36, 39] e para os modos locais, $H / 500$ [43], em que " $L$ " é o comprimento destravado da viga e " $H$ " é a altura total da seção.

Foram adotados elementos elásticos lineares em ambas as extremidades para que a plastificação localizada na região de aplicação do carregamento não levasse a uma interrupção prematura das análises. Dessa forma, nas fileiras dos cinco primeiros elementos foram atribuídas propriedades elásticas. Essa região é indicada em laranja na figura 3.4.

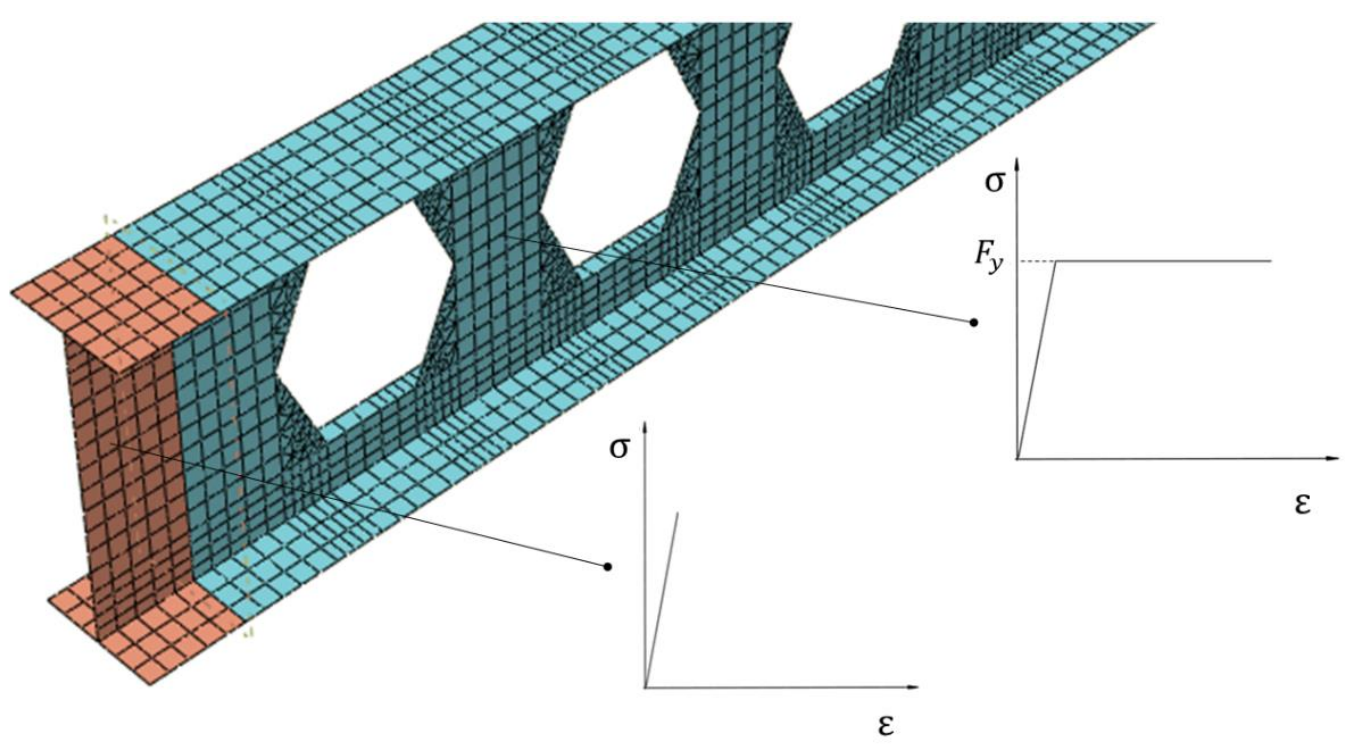

Figura 3.4 - Região de elementos com propriedades elásticas nas análises não lineares.

Através do software ABAQUS, é utilizado o método de Riks modificado para resolução das análises apresentando não linearidades de material e geométricas. Desse modo, são utilizados passos adaptativos e 
definidos o número de incrementos e comprimentos de arco máximo e mínimo. É necessário observar cada modelo para a determinação de tais valores para que o pico de carregamento seja atingido e captado com sucesso.

Logo, com a realização das análises não lineares, é possível obter a aproximação do momento último resistente $\left(M_{u}\right)$ e o modo de falha das vigas do estudo paramétrico, além da relação "carga x deslocamento".

\section{4.}

\section{Validações}

A seguir, são descritas as validações do modelo de elementos finitos quanto às análises lineares de flambagem elástica e análises não lineares de material com imperfeições geométricas iniciais. Também é realizada a validação das condições de contorno utilizadas.

\subsection{1.}

\section{Validação das técnicas de modelagem - análise linear de flambagem}

A validação do modelo computacional de elementos finitos foi realizada em comparação ao trabalho de Souza [43] que validou suas análises com testes experimentais. No trabalho, vigas casteladas biapoiadas se encontram sob ação de momento fletor puro para fins das análises elásticas. Desse modo, é realizada a análise linear de flambagem e os momentos críticos global e local são comparados. O modelo "1" da "Tabela 2" foi escolhido para comparação e possui comprimento destravado $(L)$ igual a $2444 \mathrm{~mm}$, espessura da mesa $\left(t_{f}\right)$ de $4,9 \mathrm{~mm}$, espessura da alma $\left(t_{w}\right)$ de $4,30 \mathrm{~mm}$, altura total $(H)$ de $222 \mathrm{~mm}$, módulo de elasticidade $(E)$ de $200 \mathrm{GPa}$ e coeficiente de Poisson $(v)$ de 0,3.

A figura 3.5 reproduz as condições de contorno e o carregamento aplicado no modelo que foram estabelecidos de forma a simular a configuração do experimento. Foram criadas as mesmas relações de múltiplos pontos do tipo mestre-escravo (Multi Points Constraint - MPC) 
possuindo como nó mestre o ponto médio, entretanto considerando todos os nós das seções transversais de ambas extremidades, incluindo as mesas superior e inferior. Dessa forma, também aplicado o carregamento de momento concentrado no modelo. Nos pontos médios das extremidades foram inseridas as condições de contorno, sendo apoios do segundo gênero com deslocamento axial liberado em uma de suas extremidades. Todas as rotações foram restringidas exceto à flexão $(R x)$.

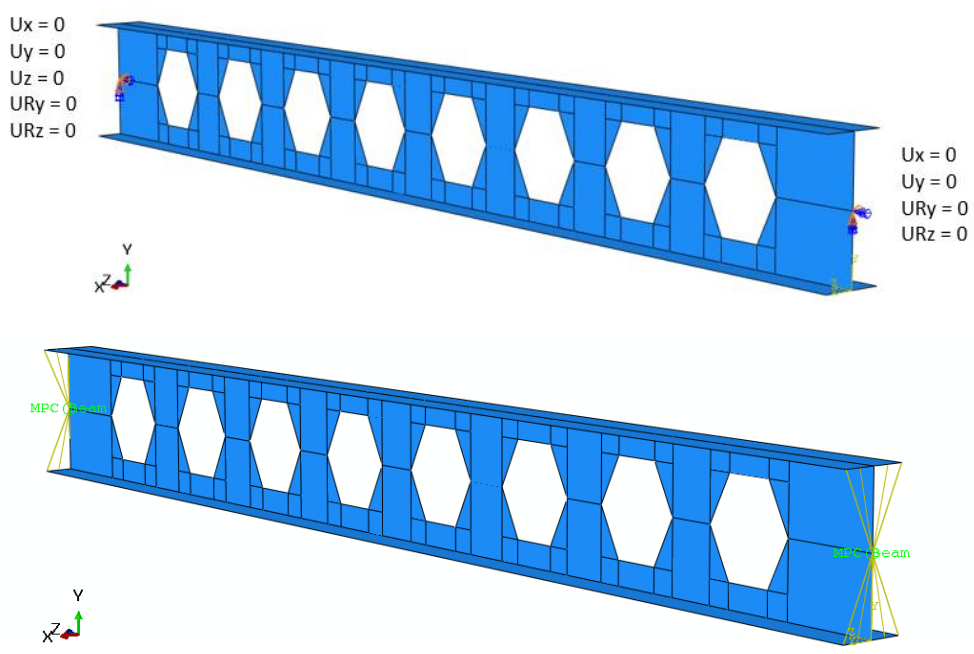

Figura 3.5 - Condições de contorno e MPC, Souza 2019 [43].

Após realizada a análise linear de flambagem, os momentos críticos global e local e os modos foram obtidos. O modelo gerado apresentou uma diferença relativa inferior a 1\%, conforme demonstrado na tabela $3.3 \mathrm{e}$, portanto, as técnicas de modelagem empregadas são consideradas validadas para os fins das análises elásticas de flambagem de autovalor. A diferença relativa é definida, possuindo os valores de referência de Souza [43], como: $\left|M_{c r}-M_{c r, r e f}\right| / M_{c r, r e f}$.

Tabela 3.3 - Validação técnicas de modelagem para as análises lineares.

\begin{tabular}{ccccc} 
& $\begin{array}{c}M_{c r g} \\
{[\mathrm{kNm}]}\end{array}$ & dif.rel. & $\begin{array}{c}M_{c r l} \\
{[\mathrm{kNm}]}\end{array}$ & dif.rel \\
\hline $\begin{array}{c}\text { Souza } \\
\text { [43] }\end{array}$ & 121,0 & - & 132,0 & - \\
& & & & \\
$\begin{array}{c}\text { Trabalho } \\
\text { atual }\end{array}$ & 120,99 & $0,007 \%$ & 133,29 & $0,977 \%$ \\
\hline
\end{tabular}




\subsection{2. \\ Validação das técnicas de modelagem - análise não linear de flambagem}

De maneira similar, foram reproduzidas as mesmas especificações quanto ao tipo dos elementos, malha e demais técnicas empregadas para a modelagem do elemento estrutural, descritas em 3.1. Assim, foi escolhido o trabalho de Sonck \& Belis [39] para fins de comparação das análises não lineares de flambagem e obtenção das cargas últimas resistentes das vigas casteladas.

Os autores realizaram testes experimentais em vigas casteladas sob ação de forças verticais para avaliação do comportamento referente a flambagem lateral com torção (FLT), conforme demonstrado na figura 2.9. O espécime "CS1_L3" do referido trabalho foi selecionado e modelado no software ABAQUS conforme suas especificações geométricas e de material. A tensão de escoamento do aço adotada foi $345 \mathrm{MPa}$ por ser o valor médio informado pelos autores. $O$ perfil que dá origem à seção é o IPE160 e o comprimento total destravado é de $3150 \mathrm{~mm}$, possuindo 15 furos. As demais características encontram-se disponíveis no trabalho original [39]. As condições de contorno e carregamento foram reproduzidas conforme a configuração do ensaio experimental (figura 2.9). A figura 3.6 exibe o resultado da validação realizada nesta subseção em que é possível constatar o modo de falha por FLT e a plastificação nas áreas indicadas em vermelho.

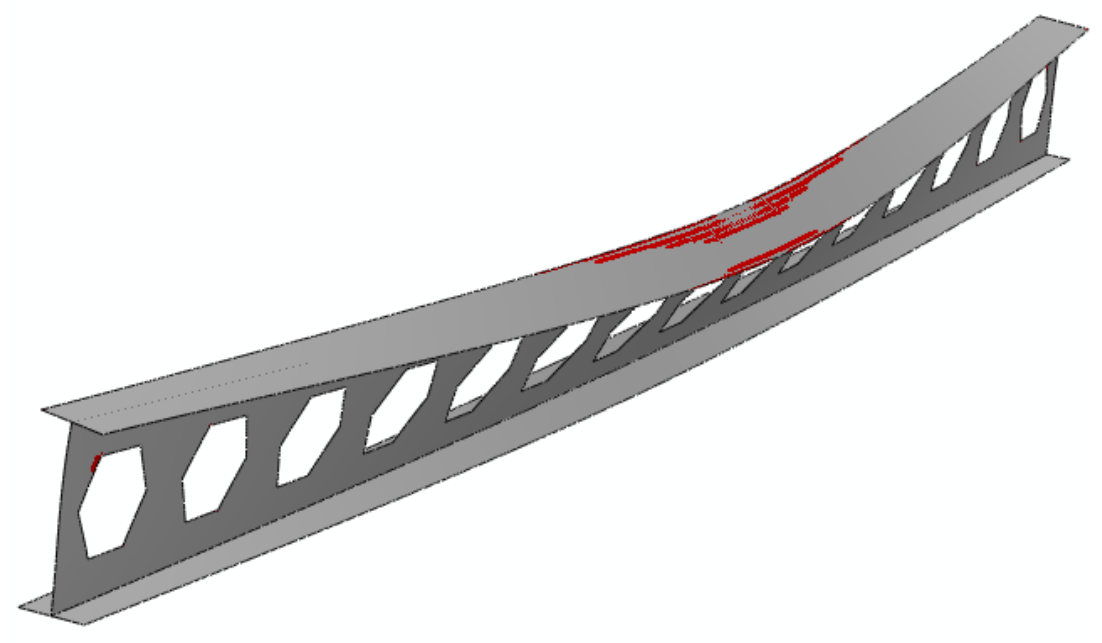

Figura 3.6 - Validação viga CS1_L3. 
Foram realizadas as análises lineares de autovalor para obtenção da carga crítica e modo de flambagem para a aplicação da imperfeição geométrica. A amplitude da imperfeição para o modo global foi estabelecida como $L / 1000$, conforme a indicação dos autores. As análises não lineares foram configuradas com incrementos adaptativos pelo método de Riks modificado. O resultado da resposta é apresentado na figura 3.6, evidenciando a falha por FLT. Na tabela 3.4 são exibidos os valores para a carga última resistente $(F)$ do experimento e modelagem de Sonck \& Belis [39] e do modelo de validação deste trabalho.

Tabela 3.4 - Validação técnicas de modelagem para as análises não lineares.

$$
F[\mathrm{kN}] \quad \text { dif.rel. }
$$

\begin{tabular}{ccc}
\hline $\begin{array}{c}\text { Experimento, } \\
\text { Sonck \& Belis } \\
(2017) \text { [39] }\end{array}$ & 25,92 & - \\
$\begin{array}{c}\text { Modelagem, } \\
\text { Sonck \& Belis } \\
(2017) \text { [39] }\end{array}$ & 24,29 & $6,7 \%$ \\
Trabalho atual & 25,44 & $1,9 \%$ \\
\hline
\end{tabular}

Como a diferença relativa dos valores para a carga resistente $(F)$ entre o ensaio experimental e a atual simulação pelo método dos elementos finitos foi igual a $1,9 \%$, as técnicas de modelagem são consideradas validadas para os fins das análises não lineares de material com imperfeições geométricas.

\subsection{3.}

\section{Validação das condições de contorno}

Com o intuito de verificar a adequação das condições de contorno as quais foram inseridas nos modelos do estudo, foi buscado um valor teórico para momento crítico de uma viga I de seção uniforme. Assim, na norma brasileira ABNT NBR 8800:2008 [68], anexo "G", seção "G.1", foi adotada a equação (Eq. 4) que se baseia nas expressões de Timoshenko e Gere 
[69] para momento crítico de flambagem para vigas de alma não-esbelta de seção I sujeita a flexão pura e com extremidades liberadas quanto ao empenamento.

$$
M_{c r}=\frac{C_{b} \pi^{2} E I_{y}}{L_{b}{ }^{2}} \sqrt{\frac{C_{w}}{I_{y}}\left(1+0,039 \frac{J L_{b}{ }^{2}}{C_{w}}\right)}
$$

Em que,

$C_{b}$ é o fator de modificação de diagrama de momento fletor nãouniforme;

$I_{y}$ é o menor momento de inércia da seção;

$L_{b}$ é o comprimento destravado da viga;

$E$ é o módulo de elasticidade do material;

J é a constante de torção da seção;

$C_{w}$ é a constante de empenamento da seção, dada por: $C_{w}=\frac{I_{y}\left(d-t_{f}\right)^{2}}{4}$;

d é a altura da seção; $e$

$t_{f}$ é a espessura da mesa.

Assim, foi escolhido um perfil comercial (W200 x 19,3) para fins de comparação entre a equação proposta acima e a modelagem numérica pelo método dos elementos finitos. Foi arbitrado um comprimento destravado igual a $3000 \mathrm{~mm}$. Ao reproduzir as condições de contorno e realizar a análise linear de flambagem na simulação numérica foram obtidos os modos de flambagem e o momento crítico.

As condições de contorno foram as mesmas utilizadas na descrição do modelo, em 3.1, e reproduzidas na viga de perfil W200×19,3 descrita nesta subseção. A figura 3.7 demonstra as condições de contorno aplicadas no modelo de validação. Essa condição de contorno leva em consideração o empenamento da seção e permite com que as mesas possam rotacionar em planta, conforme é possível observar na figura 3.8. 


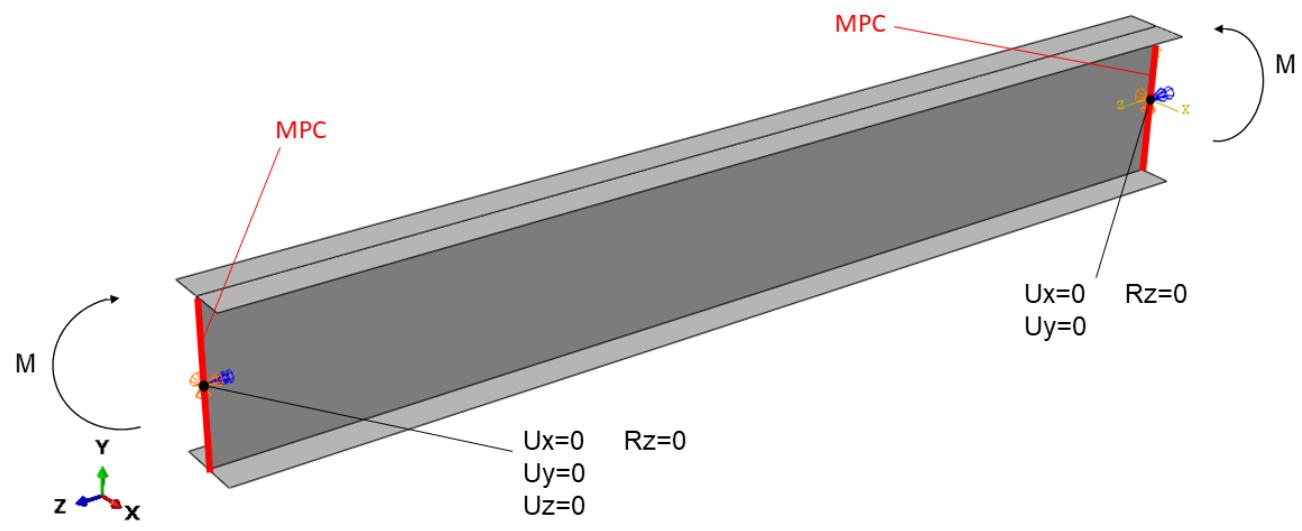

Figura 3.7 - Condições de contorno e carregamento para validação.

Como a diferença relativa entre a previsão teórica (Eq. 4) e a simulação computacional empregada foi de $3,11 \%$, as condições de contorno reproduzidas demonstraram estarem de acordo e foram, portanto, consideradas validadas. A figura 3.8 apresenta o resultado da análise linear de flambagem na qual foi obtido o momento crítico equivalente a $36 \mathrm{kNm}$ e o detalhe demonstrando a rotação em planta das mesas.

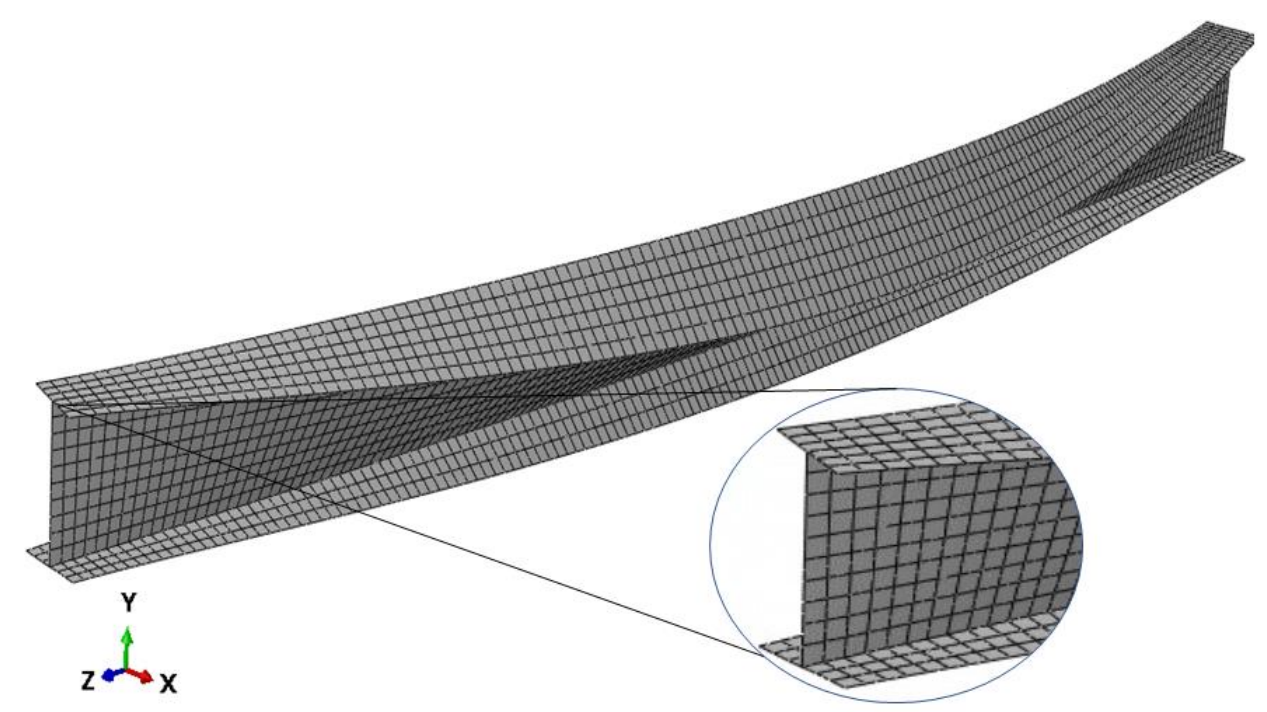

Figura 3.8 - Resultado da análise linear de flambagem para validação das condições de contorno. 


\section{4}

\section{Análises e Resultados}

A seguir, são apresentados e discutidos os resultados referentes às análises descritas nas seções 3.2 e 3.3. Em seguida, é conduzido o trabalho para a abordagem proposta do Método da Resistência Direta e sua aplicação às vigas casteladas. Por fim, é realizada a comparação dos resultados obtidos com os valores de previsão da resistência dos métodos de dimensionamento.

\section{1. Resultados das análises lineares de flambagem}

Para cada um dos 197 modelos correspondentes às vigas casteladas, foram obtidos os autovalores e os modos de flambagem, ou seja, os momentos críticos global e local. Com o conhecimento de tais valores, é possível determinar suas esbeltezes relativas global e local, as quais são definidas por:

$$
\begin{gathered}
\lambda_{g}=\sqrt{\frac{M_{p}}{M_{c r g}}} \\
\lambda_{l}=\sqrt{\frac{M_{p}}{M_{c r l}}}
\end{gathered}
$$

Em que:

$M_{p}$ é o momento de plastificação da seção considerando o furo;

$M_{c r} g$ é o momento crítico de flambagem global.

$M_{c r l}$ é o momento crítico de flambagem local. 
A figura 4.1 demonstra modos de flambagem global e local, característicos das análises lineares, com fatores de escala, equivalentes ao modelo \#1 no qual o modo de flambagem dominante é o global (FLT). As vigas que possuem maiores vãos tendem a apresentar modo de flambagem global dominante. Por outro lado, vigas com maiores valores de razões entre largura e espessura da mesa tendem apresentar modo local dominante.

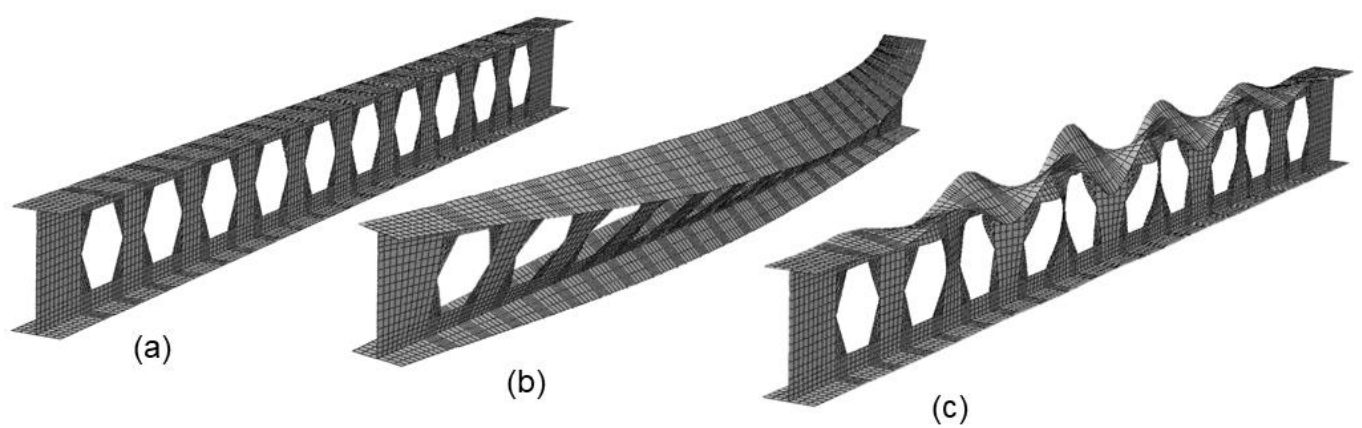

Figura 4.1 - Modos característicos de flambagem: (a) Viga \#1 indeformada; (b) Modo flambagem global - FLT; (c) Modo flambagem local - FT.

Algumas vigas apresentaram acoplamento natural entre os modos de flambagem. O modelo \#111 (ilustrado na figura 4.2) é um exemplo, de forma que seu modo de flambagem global possui características do modo local. Os momentos críticos equivalem a $M_{c r g}=144 \mathrm{kNm}$ e $M_{c r l}=$ $135 \mathrm{kNm}$.

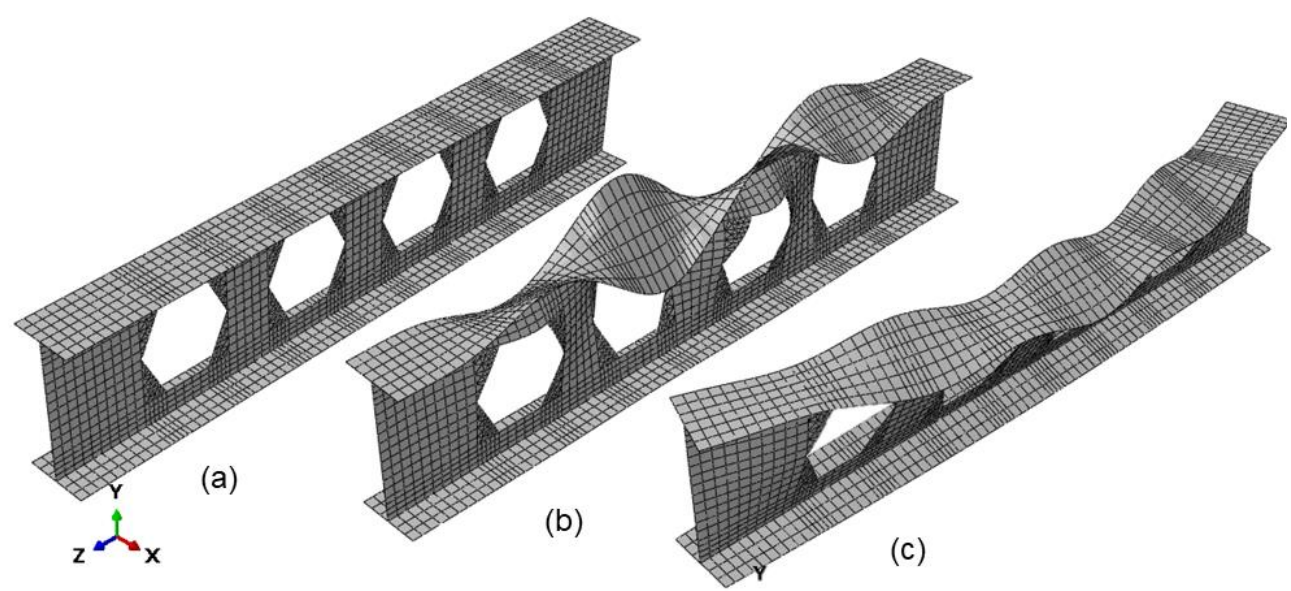

Figura 4.2 - Modos característicos de flambagem: (a) Viga \#111 indeformada; (b) Modo flambagem local do "tê"; (c) Modo flambagem global. 
Os valores computados para os momentos críticos global e local, modos de flambagem e esbeltezes relativas global e local encontram-se no Anexo B. A seguir são exibidos nas figuras 4.3 e 4.4 os momentos críticos global e local em função das esbeltezes relativas de todos os modelos do estudo. Como esperado, devido às definições de esbeltez adotada, é possível observar claramente o comportamento no qual conforme o aumento das esbeltezes relativas, menor é o valor de seus momentos críticos global e local, respectivamente.

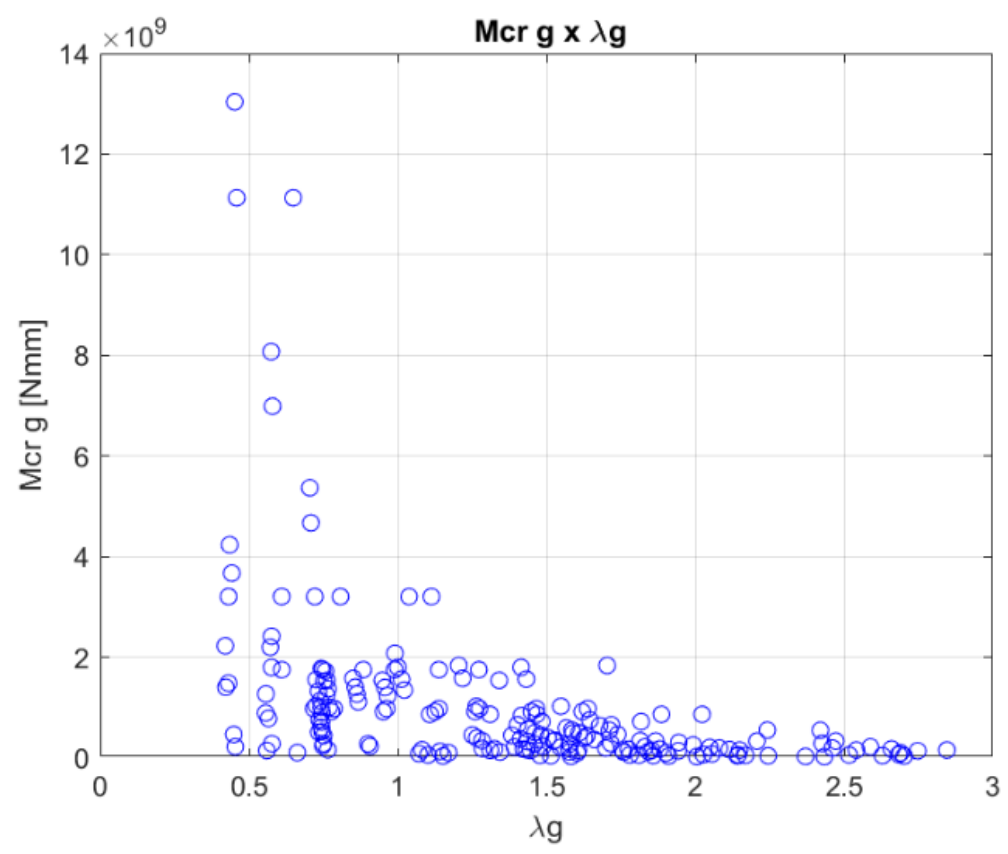

Figura 4.3 - Momento crítico global x esbeltez relativa global. 


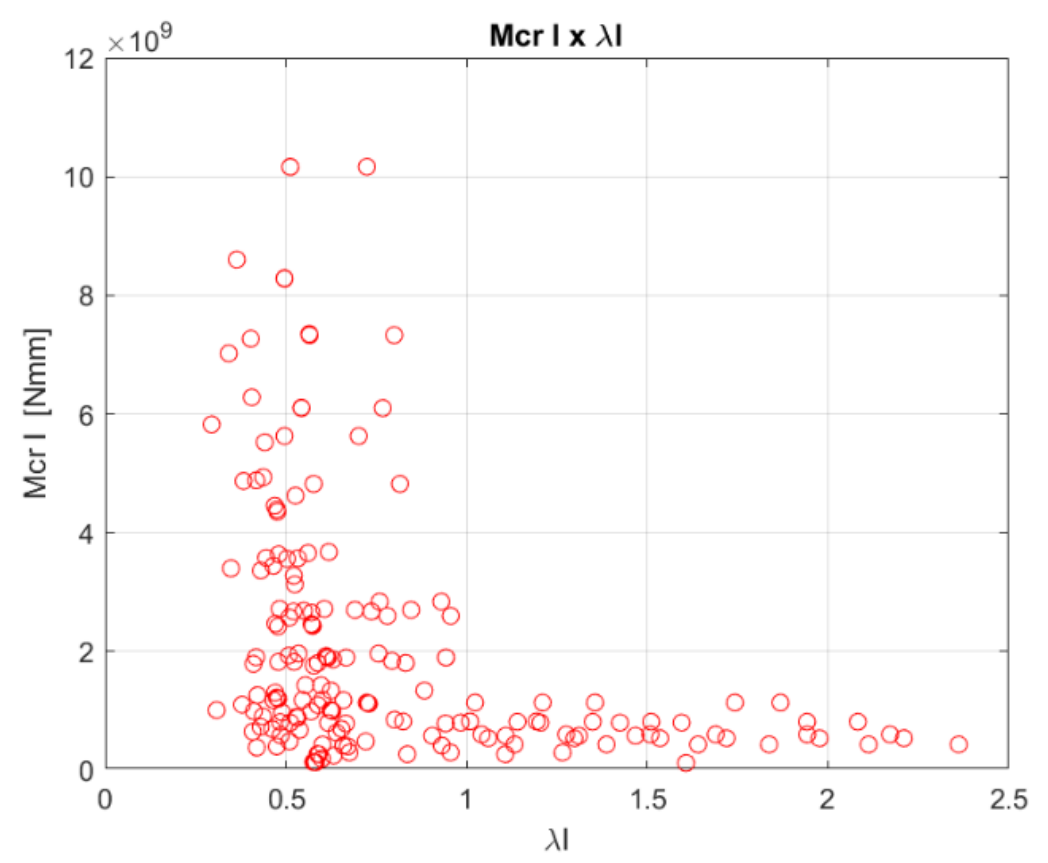

Figura 4.4 - Momento crítico local x esbeltez relativa local.

Também é demonstrado o grande intervalo coberto pelo universo das vigas que constituem esse estudo através da relação de esbeltezes, conforme mostrado na figura 4.5.

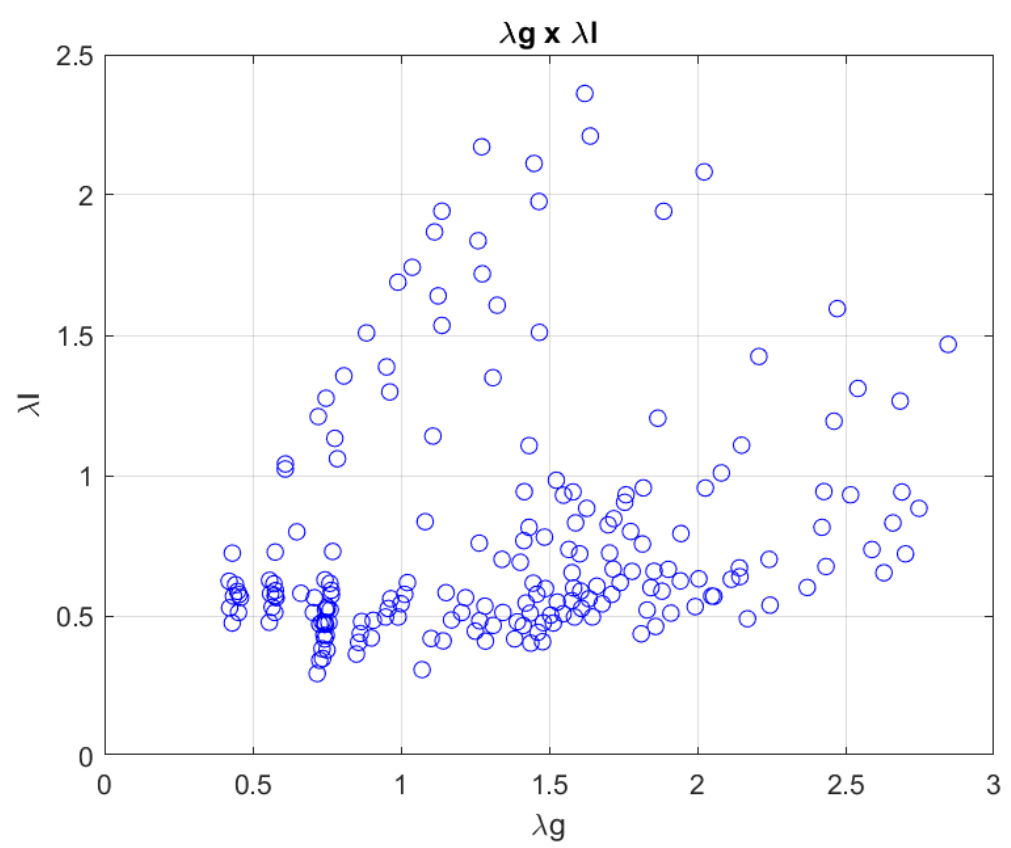

Figura 4.5 - Relação entre esbeltezes global - local.

Finalizadas as análises lineares de flambagem foi possível dar início às análises não lineares e seus resultados são descritos na próxima seção. 


\section{2. \\ Resultados das análises não lineares de flambagem}

Definidas as cargas a fim de serem aplicadas nos modelos a partir das análises lineares, ou seja, seus momentos críticos, assim como a forma das imperfeições geométricas, foi buscado o máximo carregamento resistente de cada uma das vigas do estudo, o momento último $\left(M_{u}\right)$. Os respectivos valores de $M_{u}$ e a escala das imperfeições global e local (Imp.g

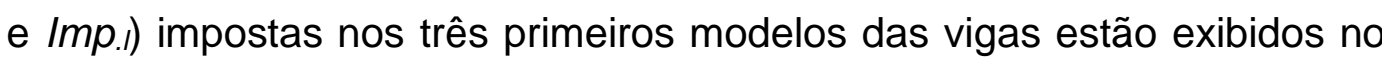
resumo da tabela 4.1 para exemplificação e os demais resultados se encontram no Anexo B.

Tabela 4.1 - Resumo dos resultados das análises de elementos finitos.

\begin{tabular}{cccccccc} 
Viga & $\begin{array}{c}M c r_{g} \\
{[\mathrm{Nmm}]}\end{array}$ & $I m p \cdot g[\mathrm{~mm}]$ & $\begin{array}{c}\mathrm{Mcr}_{l} \\
{[\mathrm{Nmm}]}\end{array}$ & $\operatorname{Imp}_{\cdot l}[\mathrm{~mm}]$ & $\lambda \mathrm{g}$ & $\lambda \mathrm{I}$ & $\begin{array}{c}M_{u} \\
{[\mathrm{Nmm}]}\end{array}$ \\
\hline 1 & $3.41 \mathrm{E}+07$ & 2.44 & $1.33 \mathrm{E}+08$ & 0.44 & 1.15 & 0.58 & $2.80 \mathrm{E}+07$ \\
2 & $5.66 \mathrm{E}+07$ & 3.00 & $4.13 \mathrm{E}+08$ & 1.00 & 1.78 & 0.66 & $5.19 \mathrm{E}+07$ \\
3 & $1.78 \mathrm{E}+08$ & 8.00 & $1.21 \mathrm{E}+08$ & 1.00 & 1.32 & 1.61 & $1.17 \mathrm{E}+08$ \\
$\ldots$ & $\ldots$ & $\ldots$ & $\ldots$ & $\ldots$ & $\ldots$ & $\ldots$ & $\ldots$ \\
\hline
\end{tabular}

As análises não lineares demandam maior custo computacional e os parâmetros para definição variam em cada modelo para captar com sucesso o comportamento e a carga de pico. Por exemplo, as análises não lineares dos modelos das vigas 1, 2 e 3 possuem comprimento de arco máximo iguais a 0,05, 0,07 e 0,03, respectivamente, com 100 incrementos e comprimento de arco mínimo de $10^{-15}$.

As áreas em vermelho nas figuras 4.7, 4.9, 4.11, 4.13 e 4.15 denotam que as tensões de Von Mises são superiores à tensão de escoamento. Ressalta-se que, nas extremidades, foi adotado material de comportamento elástico linear e, portanto, não ocorre plastificação nessa região que possa influenciar na resposta.

A resposta do incremento de carga em função do deslocamento fora do plano (Ux) do modelo \#13 é demonstrada nas figuras 4.6 e 4.7 para fins de exemplificação. $O$ deslocamento $U x$ foi medido no ponto central da mesa superior no meio do vão. Esse modelo é governado pela flambagem global e possui valor de momento último $\left(M_{u}\right)$ próximo do momento crítico global $\left(M_{\text {cr } g}\right)$ e do momento de plastificação $\left(M_{p}\right)$, com esbeltezes relativas global 
e local iguais a $\lambda_{g}=1,17$ e $\lambda_{l}=0,49$, respectivamente. Em função das imperfeições e, possivelmente, da influência da plastificação, a resistência da viga não chega a atingir o momento crítico, apresentando queda de resistência.

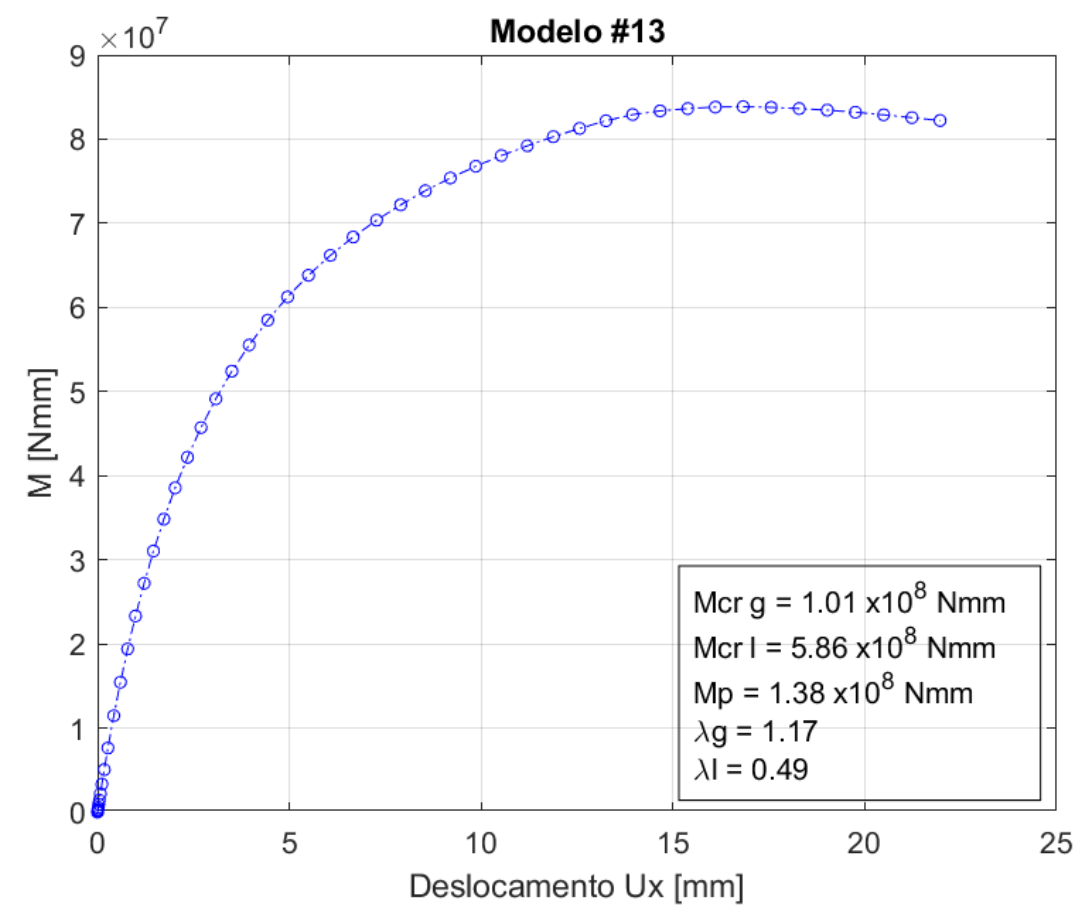

Figura 4.6 - Resposta não linear \#13.

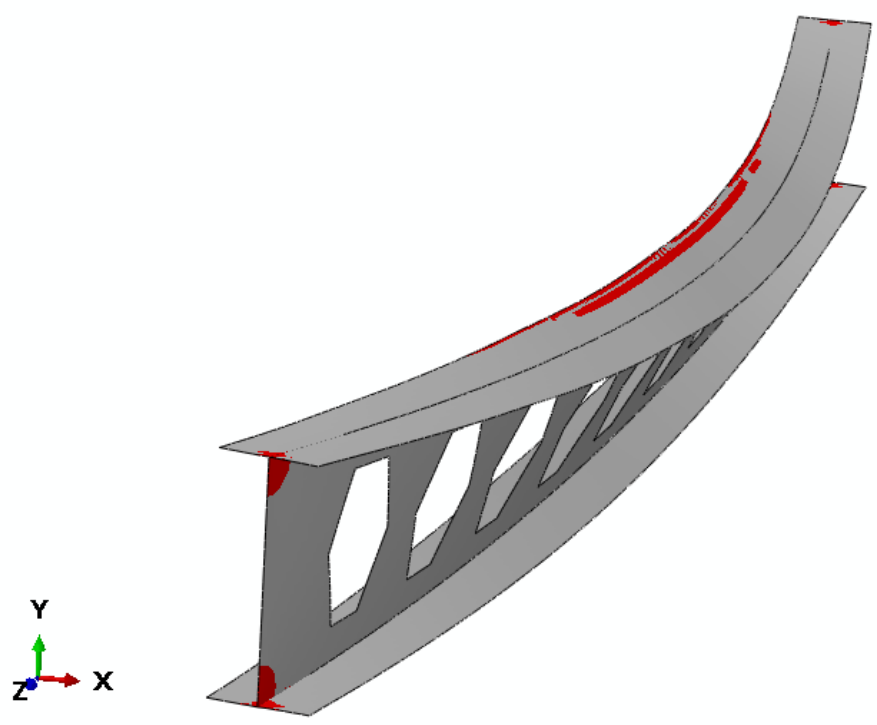

Figura 4.7 - Modo de falha modelo \#13.

A viga do modelo \#80 também é governada pela flambagem global (FLT), possuindo valores de esbeltezes relativas global e local iguais a $\lambda_{g}=$ 
2,05 e $\lambda_{l}=0,57$, respectivamente. A resistência $\left(f_{y}\right)$ do aço é a mesma da viga do modelo \#13, entretanto em decorrência de sua maior esbeltez global, sua resposta exibe um deslocamento fora do plano mais distante da plastificação, conforme verificado na figura 4.8 .

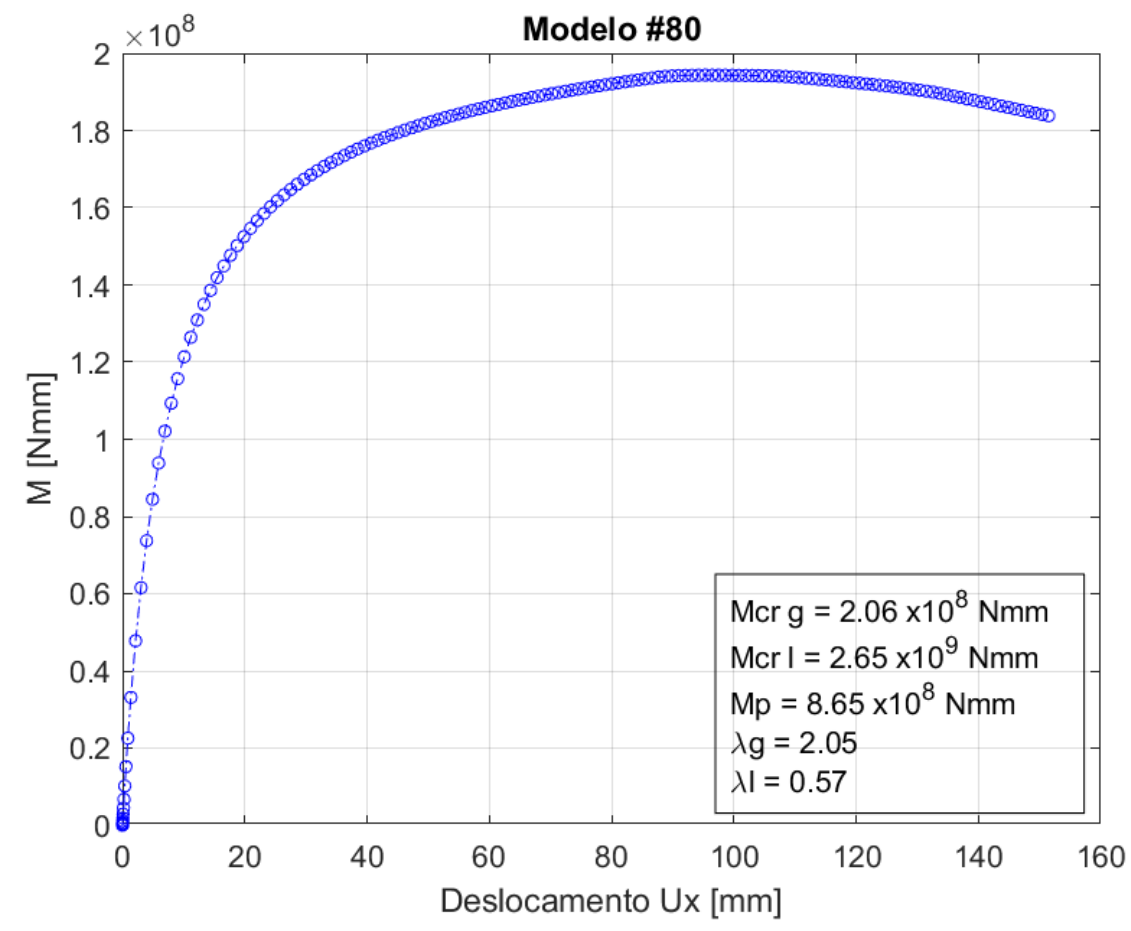

Figura 4.8 - Resposta não linear \#80.

Apesar de ser mais esbelta quando comparada com o modelo \#13, \#80 possui altura total da seção aproximadamente 2,5 vezes maior, o que explica a maior capacidade resistente à flexão: $H_{\# 13}=310,5 \mathrm{~mm}$ e $H_{\# 80}=$ $793,5 \mathrm{~mm}$. Além de maior espessura da alma. A figura 4.9 ilustra o modo de falha da viga \#80.

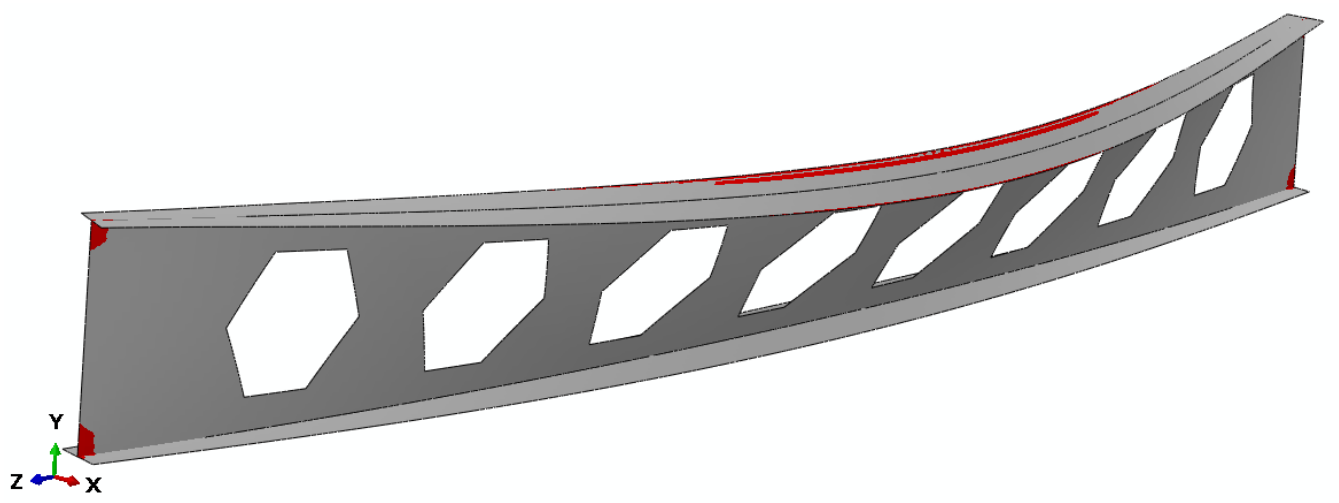

Figura 4.9 - Modo de falha modelo \#80. 
Foram também observados casos em que a flambagem local do "tê" (FT) foi o modo de falha predominante. A viga do modelo \#172, a qual possui valores de esbeltezes $\lambda_{g}=0,72$ e $\lambda_{l}=1,21$, apresentou esse modo de falha, conforme a figura 4.11. O momento último superou o seu momento crítico, possuindo valor de $M_{u}=1,25 \times 10^{9} \mathrm{Nmm}$. Esse comportamento indica resistência pós flambagem, normalmente característico de placas. A resposta não linear em função do deslocamento é apresentada na figura 4.10.

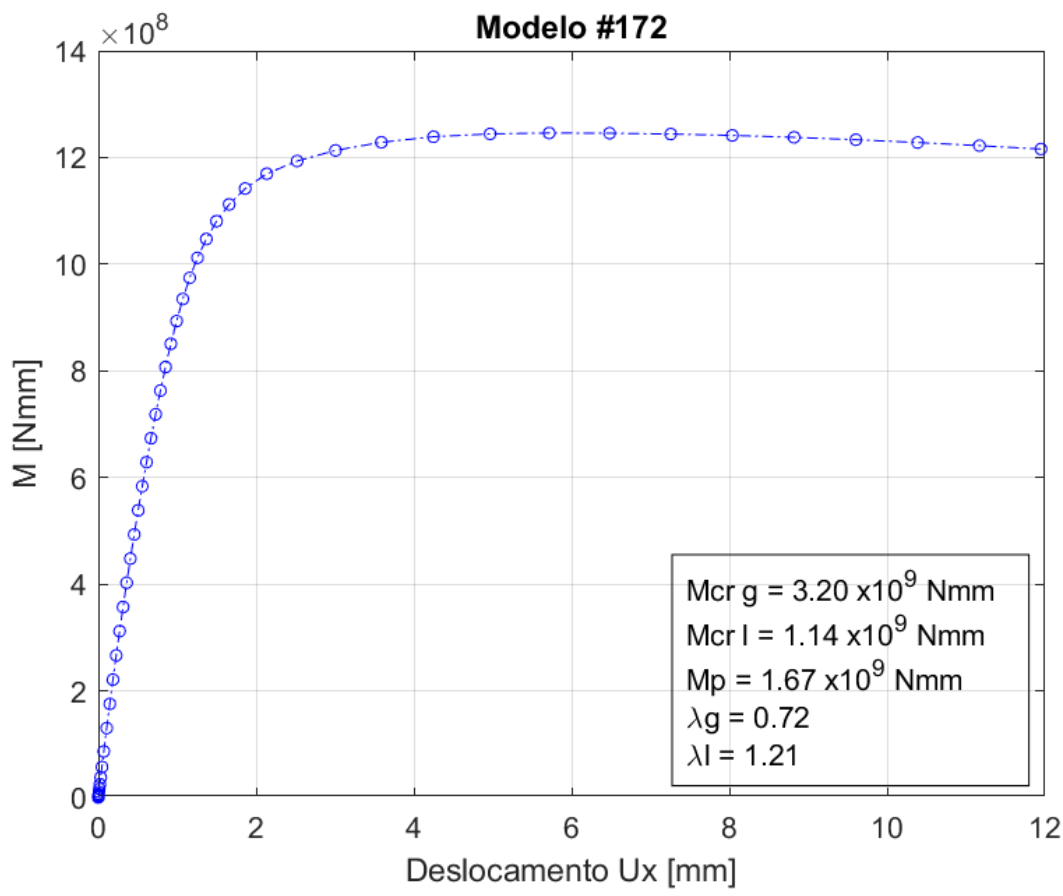

Figura 4.10 - Resposta não linear \#172.

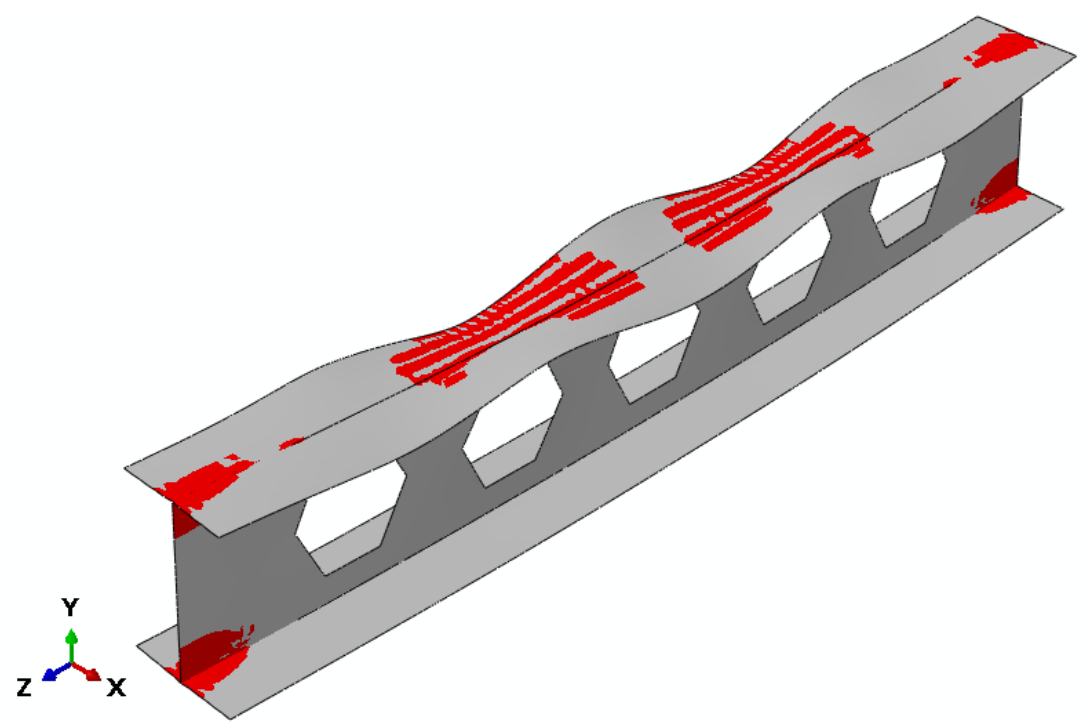

Figura 4.11 - Modo de falha modelo \#172. 
As vigas com esbeltez relativa local $\left(\lambda_{l}\right)$ maior que 1 , tendem a apresentar esse comportamento. Todas as imagens representando os modos de falha aqui exibidas possuem um fator de escala para que a visualização do fenômeno seja mais compreensível.

A viga do modelo \#124 também possui modo de falha referente à flambagem local do "tê" comprimido (FT) porém o valor do momento crítico local $\left(M_{c r l}\right)$ se aproxima do seu momento de plastificação $\left(M_{p}\right)$, conforme ilustra a figura 4.12 e 4.13. Novamente, o $M_{u}$ se aproxima, porém não atinge o momento crítico e a queda da resistência devido à interação entre os dois modos pode ser constatada na sua resposta não linear. Os valores de esbeltezes relativas global e local são $\lambda_{g}=0,61$ e $\lambda_{l}=1,02$, respectivamente.

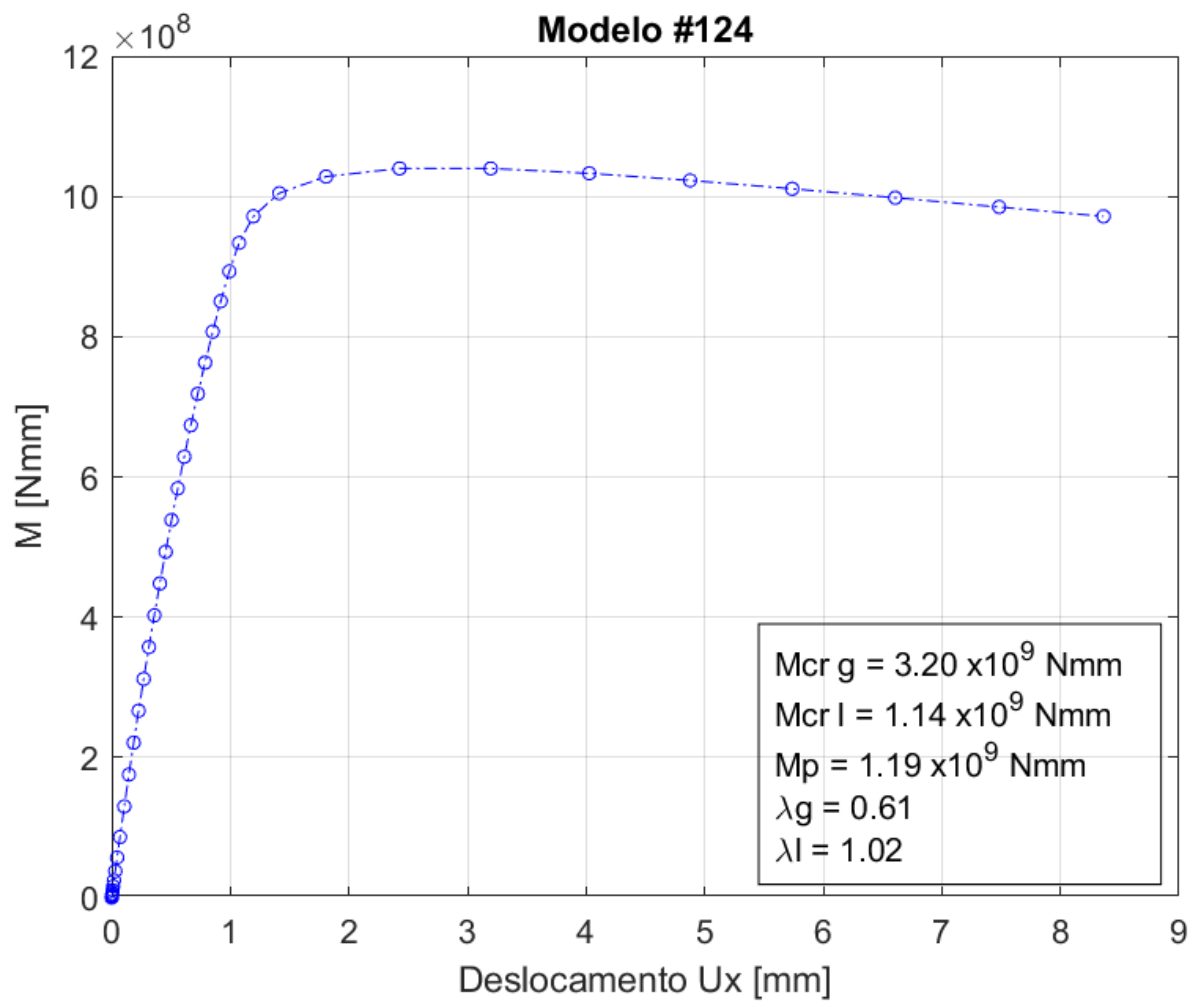

Figura 4.12 - Resposta não linear modelo \#124. 


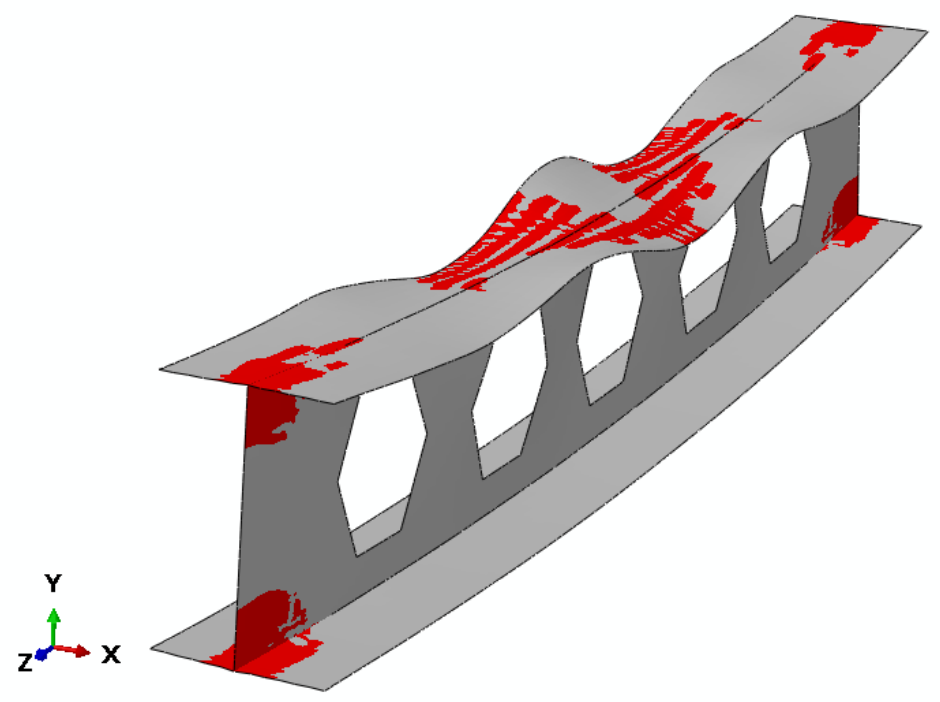

Figura 4.13 - Modo de falha modelo \#124.

Por fim, foram captados modelos que apresentaram modo de falha com acentuada interação entre os modos global e local. A viga \#123, é um exemplo dessa ocorrência como é apresentado nas figuras 4.14 e 4.15. Conforme observado nas análises lineares, seus momentos críticos são próximos, e a combinação dos seus modos de flambagem global e local na presença das imperfeições, caracteriza a interação. Ainda, é observada uma sensibilidade às imperfeições, característica do acoplamento, de forma que a carga de pico é reduzida quando comparada à carga crítica, conforme discutido na literatura [24, 29-32]. 


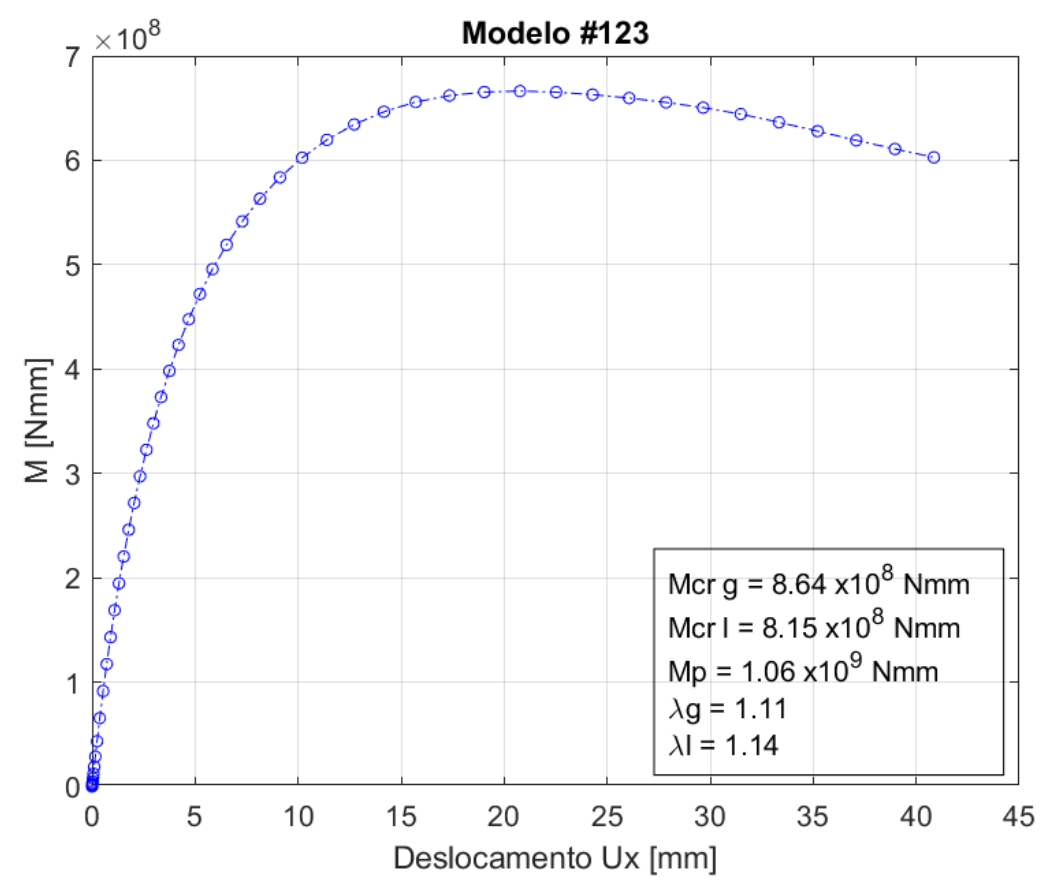

Figura 4.14 - Resposta não linear modelo \#123.

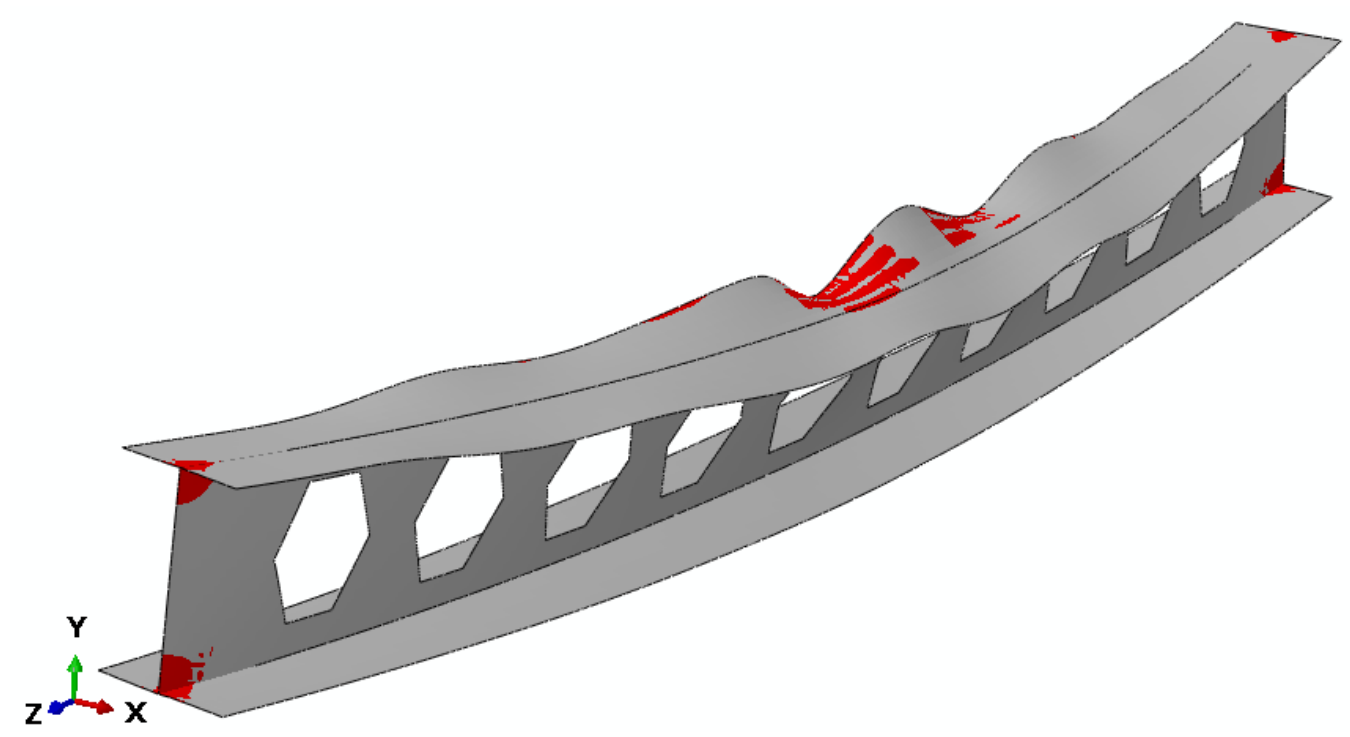

Figura 4.15 - Modo de falha modelo \#123.

A seguir, são exibidos na figura 4.16 os resultados normalizados dos cinco exemplos acima descritos. O parâmetro de resposta "Load Proportionality Factor" (LPF) corresponde ao fator de proporcionalidade de carga que é aplicada no modelo conforme o avanço dos incrementos. A multiplicação de seu valor máximo pelo momento aplicado (crítico) é equivalente ao momento último. O deslocamento foi normalizado em relação ao deslocamento de referência "Ux" fora do plano do pico da curva, medido no nó médio da mesa superior no centro do vão: $U=U_{x} / U_{x, p i c o}$. A 
figura 4.16 apresenta os resultados das vigas citadas anteriormente normalizados em LPF e deslocamento (U).

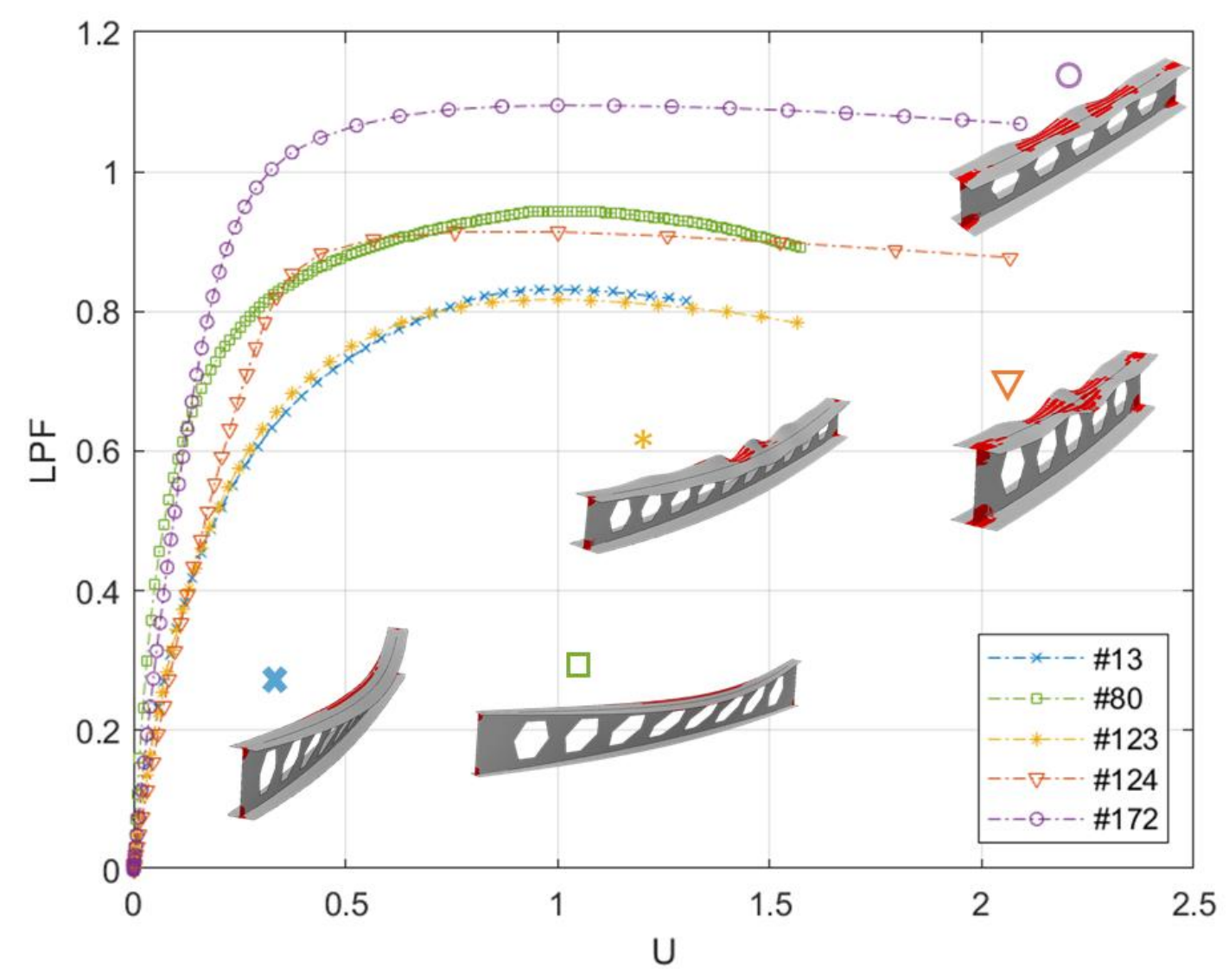

Figura 4.16 - Resultados normalizados das vigas \#13, \#80, \#123, \#124 e \#172.

Analisando a figura 4.16, nota-se que a viga do modelo \#80 se aproxima mais do momento crítico global, quando comparada com à \#13 devido à sua maior esbeltez global. Além disso, a viga do modelo \#13 possui influência das imperfeições e interação entre os modos de falha global e plastificação.

A viga do modelo \#172 possui modo de falha de flambagem local do "tê" dominante e apresenta um comportamento de resistência pós-crítica, indicado pelo $L P F>1$, característico de placas. A viga do modelo \#124 a qual também é governada pelo mesmo modo de falha, porém com influência da plastificação, não atinge o momento crítico local. Já, a viga do modelo \#123 possui uma redução evidente da capacidade de resistência quando comparada com à \#172, em virtude da interação entre os modos de falha global e local na presença das imperfeições. 
Dessa maneira, todos os 197 modelos geraram essas respostas de carga em função do deslocamento de maneira que foi obtido êxito ao constatar o momento último e o modo de falha das vigas em estudo.

\section{3. \\ Proposta baseada no Método da Resistência Direta}

Com o conhecimento dos parâmetros discutidos nos capítulos anteriores, foi dado sequência à metodologia proposta, baseada no Método da Resistência Direta. Para isso, o procedimento seguiu os critérios e procedimentos adotados pelos trabalhos dos autores referenciados [49, 52 , 53, 58, 61], além da normatização AISI S100-16 [45]. Foram buscadas as equações equivalentes às condições deste trabalho, ou seja, vigas casteladas biapoiadas sob efeito de flexão pura.

Primeiramente, procurou-se definir a equação correspondente ao Momento Nominal Global, $M_{n G}$. Então, $M_{u}$ foi normalizado em relação ao momento de plastificação da seção, $M_{p}$, e disposto em função da esbeltez relativa global $\left(\lambda_{g}\right)$, definida na Eq. 6. A normalização pode ser em relação ao momento de plastificação ou à resistência definida para determinado modo, no caso de interação [53].

Para os fins de regressão, foram descartadas as vigas governadas por flambagem local, dado que essa primeira curva representa a flambagem global. Os parâmetros buscados foram os coeficientes $A, B, C$ e D da equação característica dada pela equação 7, cujo formato foi obtido com base nas equações de trabalhos e normatizações que tratam do MRD $[45,49,53,54]$.

$$
F(\lambda)=A \lambda^{C}\left(1-B \lambda^{D}\right)
$$

A regressão foi realizada através do software $M A T L A B$ utilizando o método de regressão não linear dos mínimos quadrados (Nonlinear Least Squares). Foi necessário adicionar uma pequena transição na curva final 
para que o intervalo não apresentasse descontinuidades e fazendo com que fossem considerados os pontos próximos de $M_{u} / M_{p}=1$.

A figura 4.17 demonstra a curva definida para o momento nominal global $\left(M_{n G}\right)$ junto dos primeiros 171 pontos referentes aos respectivos modelos, descartando as vigas governadas pela flambagem local. Alguns modelos com essa característica são captados na amostra definida de 171 vigas e correspondem aos pontos situados abaixo da curva na figura 4.15, porém não foram considerados na regressão.

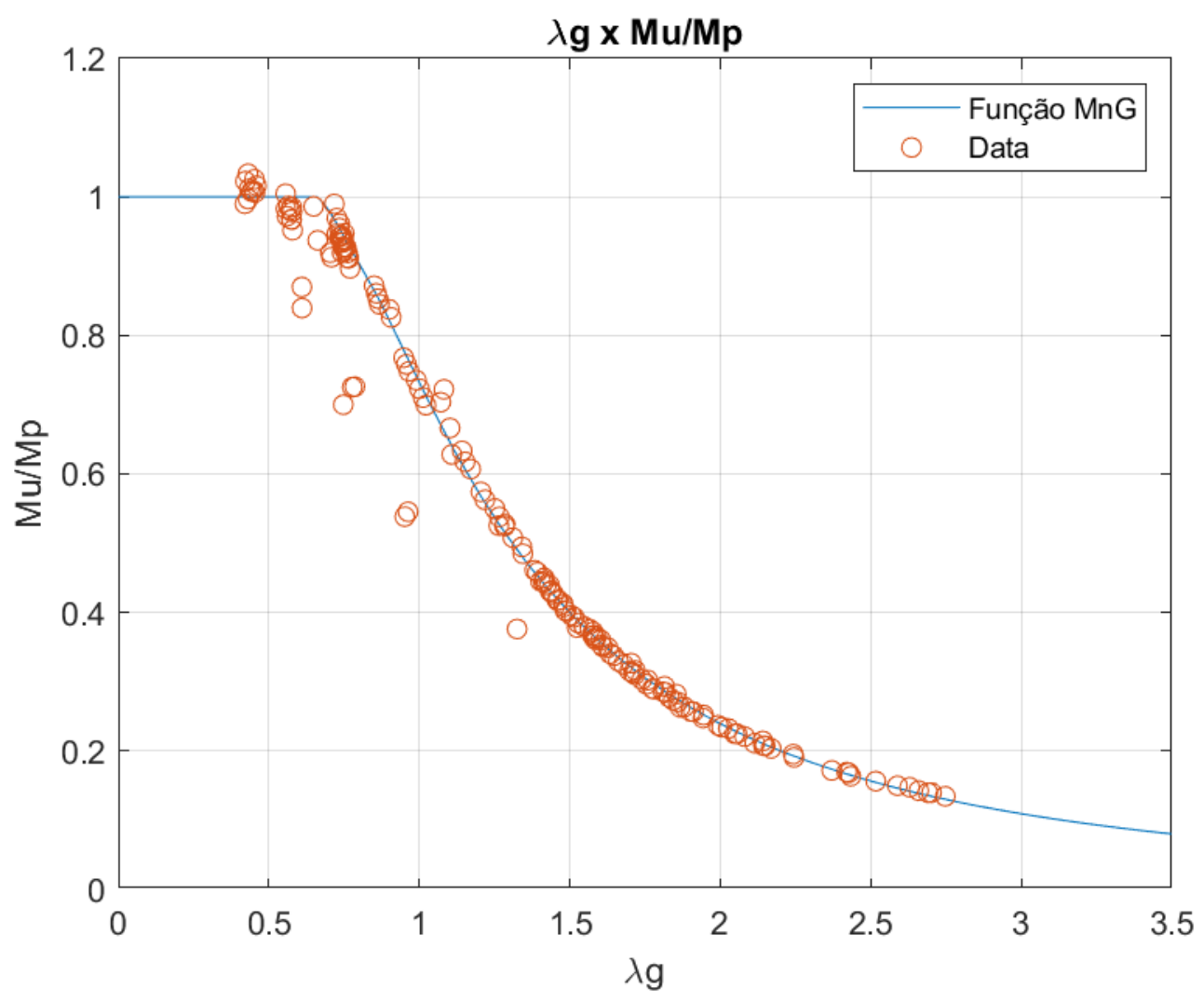

Figura 4.17 - Curva definida para $M_{n G}$.

As equações obtidas pelo processo de regressão para o Momento Nominal Global $\left(M_{n G}\right)$, as quais definem a curva da figura 4.17 , são apresentadas na Eq. 8. 


$$
M_{n G}=\left\{\begin{array}{cc}
M_{p} & \text { se } \lambda_{g} \leq 0,659 \\
1,402 \lambda_{g}{ }^{-2}\left(1-0,494 \lambda_{g}{ }^{-0,801}\right) M_{p} & \text { se } 0,659<\lambda_{g} \leq 0,775 \\
1,556 \lambda_{g}{ }^{-2,213}\left(1-0,5296 \lambda_{g}{ }^{-0,885}\right) M_{p} & \text { se } \lambda_{g}>0,775
\end{array}\right.
$$

Assim sendo, o ajuste da curva principal $\left(\lambda_{g}>0,775\right)$ exibiu bons parâmetros, tais como: $\mathrm{R}^{2}$ e $\mathrm{R}^{2}$ ajustado $=0,9991$; soma dos quadrados dos erros de predição $(\mathrm{SSE})=008593$; raiz quadrada do erro médio $(\mathrm{RMSE})=$ 0,008008 . A figura 4.18 apresenta os limites de previsão da curva principal de $M_{n G}$ com índice confiabilidade de $95 \%$ e a figura 4.19 os seus resíduos.

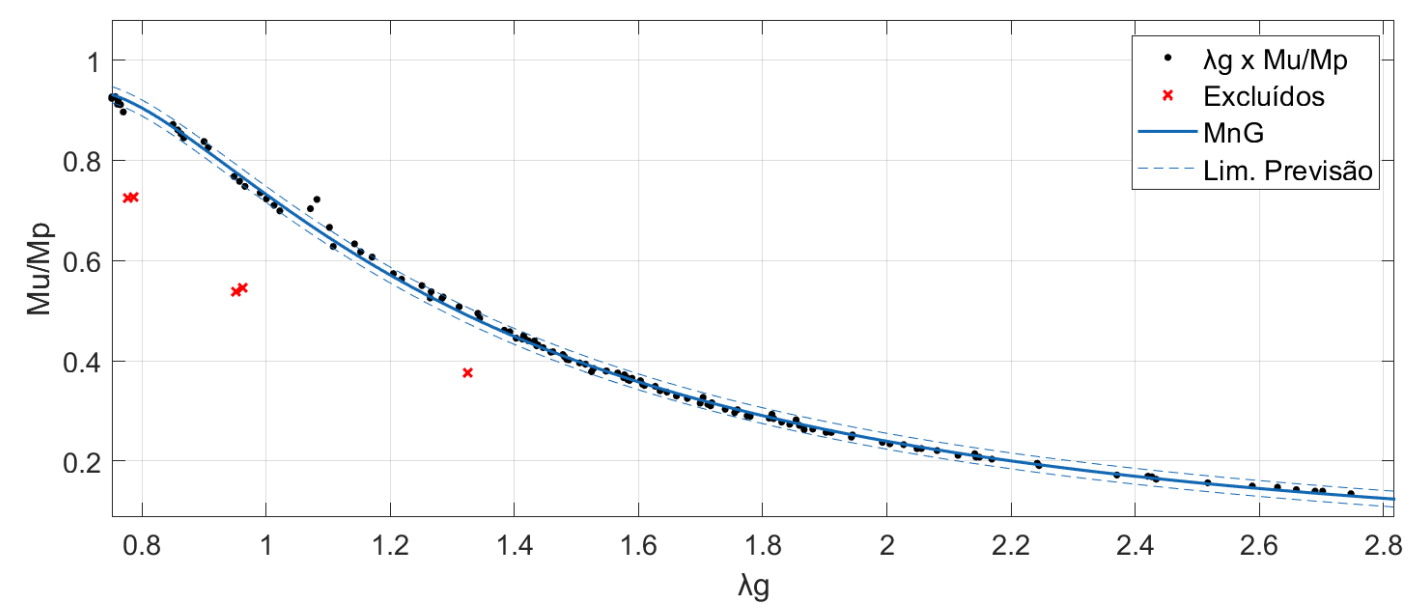

Figura 4.18 - Limites de previsão da principal equação de $M_{n G}$.

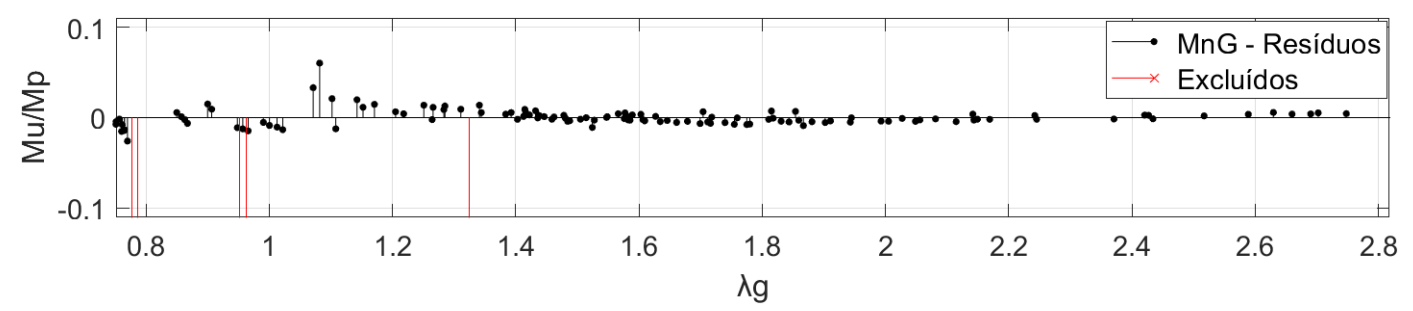

Figura 4.19 - Resíduos da principal equação de $M_{n G}$.

Em seguida, ao definir $M_{n G}$, foi dado início ao mesmo procedimento em relação a $M_{n L G}$. O momento nominal local-global é assim estabelecido por levar em consideração o fenômeno de interação local-global [53]. Assim 
sendo, torna-se necessária a definição da esbeltez relativa local-global $\left(\lambda_{L G}\right)$ :

$$
\lambda_{L G}=\sqrt{\frac{M_{n G}}{M_{c r l}}}
$$

Nota-se que a equação leva em consideração $\circ M_{n G}$, anteriormente determinado, e o momento crítico local $\left(M_{c r l}\right)$. Similarmente, $M_{u}$ passa a ser normalizado em relação a $M_{n G}$. Não foi necessária a inserção de transição de forma que uma única equação foi capaz de descrever bem o comportamento. Todas as 197 vigas foram contempladas, no entanto é possível observar que os pontos os quais possuem flambagem global dominante se localizam no platô, em que $M_{u} / M_{n G}=1$, à esquerda da curva.

A curva obtida através da regressão para $M_{n L G}$, bem como os pontos referentes às 197 vigas dispostos em função da esbeltez relativa localglobal $\left(\lambda_{L G}\right)$, é apresentada na figura 4.20.

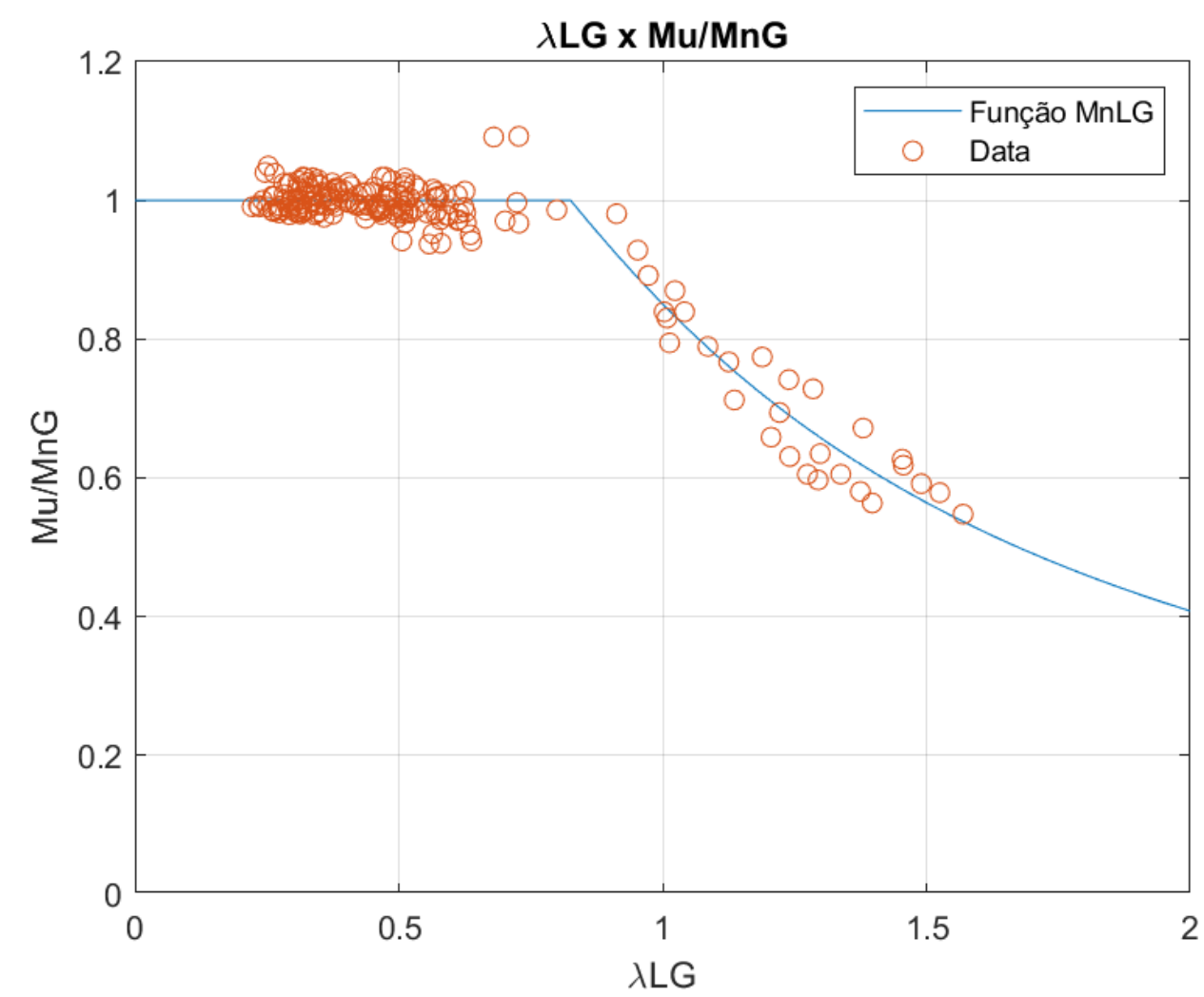

Figura 4.20 - Curva de $M_{n L G}$. 
A seguir, na Eq. 10, são exibidas as equações definidas para a curva do Momento Nominal Local-Global $\left(M_{n L G}\right)$, obtidas pelo processo de regressão.

$M_{n L G}=\left\{\begin{array}{cl}M_{n G} & \text { se } \lambda_{L G} \leq 0,826 \\ 1,1 \lambda_{L G}{ }^{-1,289}\left(1-0,226 \lambda_{L G}{ }^{-1,289}\right) M_{n G} & \text { se } \lambda_{L G}>0,826\end{array}\right.$

É constatada uma maior dispersão dos pontos em comparação a $M_{n G}$, entretanto tal comportamento é esperado tendo em vista que está sendo levada em consideração a interação entre os dois modos. Apesar disso, é possível distinguir claramente o comportamento conforme o aumento da esbeltez relativa local-global $\left(\lambda_{L G}\right)$.

É preciso destacar que a previsão é aplicada com confiabilidade apenas para valores de $\lambda_{L G}<1,6$. No entanto, valores acima desse limite não são propriamente práticos, pois vigas com essa característica demonstram ser fabricadas muito raramente ou fogem da realidade.

A figura 4.21 exibe os limites de previsão com confiabilidade de $95 \%$ correspondentes ao processo de regressão de $M_{n L G}$ e a figura 4.22, os resíduos

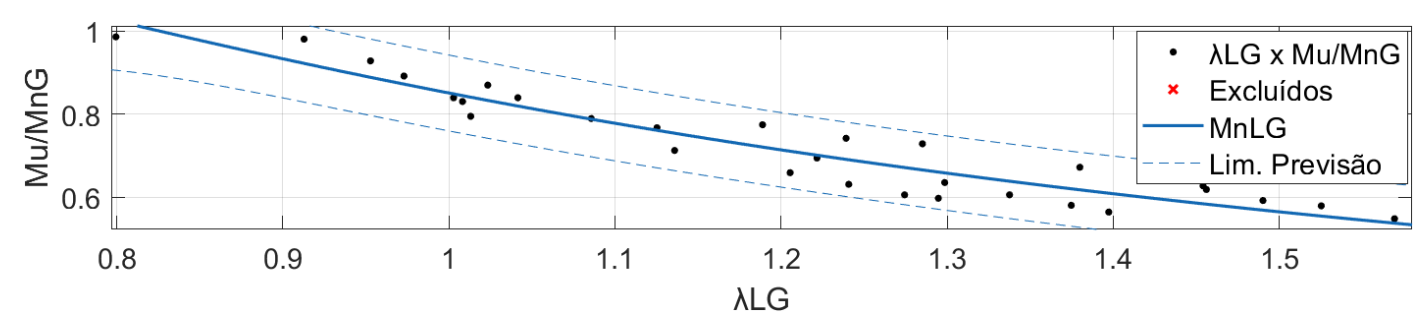

Figura 4.21 - Limites de previsão da equação de $M_{n L G}$.

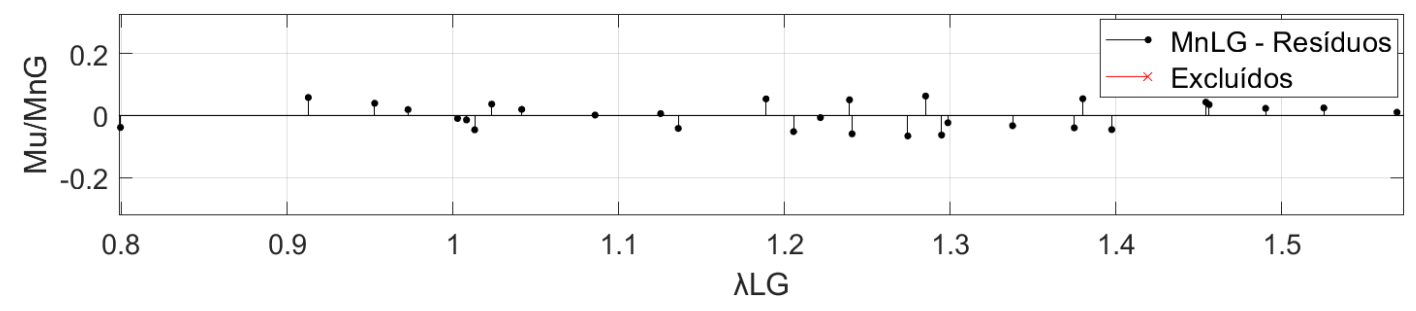

Figura 4.22 - Resíduos da equação de $M_{n L G}$. 
Os parâmetros estatísticos da equação obtida para $M_{n L G}$ foram: $\mathrm{R}^{2}=$ 0,$8977 ; R^{2}$ ajustado $=0,8902$; soma dos quadrados dos erros de predição $(S S E)=0,04942$; raiz quadrada do erro médio $(R M S E)=0,04278$.

Por fim, com ambas as curvas e equações definidas para a aplicação dos conceitos do Método da Resistência Direta às vigas casteladas biapoiadas em flexão pura deste trabalho, pode ser determinado o momento nominal resistente previsto pelo método proposto.

\section{4.}

\section{Comparação dos métodos}

Com o intuito de avaliar a aplicação e eficiência da abordagem proposta baseada no MRD frente aos métodos usuais, uma comparação dos momentos nominais resistentes é realizada. São comparadas as cargas obtidas pelas equações propostas em 4.3, os valores seguindo o procedimento definido pela normatização AISC Steel Design Guide 31/ ANSI-AISC 360-16 [2, 44] e os momentos últimos equivalentes às análises de elementos finitos.

$\mathrm{Na}$ tabela 4.2 são apresentados os valores correspondentes a essa comparação, assim como a diferença relativa dos valores em relação à aproximação de $M_{u}$ das análises de elementos finitos, conforme calculada anteriormente. 
Tabela 4.2 - Comparação da resistência prevista entre o Design Guide 31 e abordagem proposta do MRD em relação ao momento último obtido nas análises de elementos finitos.

\begin{tabular}{|c|c|c|c|c|c|c|c|}
\hline$V i g a_{\#}$ & $M_{u, M E F}$ & $M_{n, D G}$ & dif.rel $_{D G}$ & $M_{n, M R D}$ & dif.rel ${ }_{M R D}$ & $\lambda_{g}$ & $\lambda_{l}$ \\
\hline 1 & 28.0 & 33.3 & $19.1 \%$ & 27.4 & $1.9 \%$ & 1,15 & 0,58 \\
\hline 7 & 67.6 & 77.0 & $13.9 \%$ & 64.4 & $4.7 \%$ & 1,07 & 0,31 \\
\hline 17 & 231.0 & 241.8 & $4.7 \%$ & 235.3 & $1.8 \%$ & 0,75 & 0,53 \\
\hline 23 & 22.9 & 23.9 & $4.17 \%$ & 23.3 & $1.7 \%$ & 2,00 & 0,63 \\
\hline 25 & 40.8 & 42.6 & $6.1 \%$ & 40.6 & $1.0 \%$ & 1,86 & 0,46 \\
\hline 36 & 794.1 & 812.7 & $2.3 \%$ & 787.9 & $0.8 \%$ & 0,73 & 0,34 \\
\hline 46 & 730.6 & 767.3 & $5.0 \%$ & 744.3 & $1.9 \%$ & 0,77 & 0,57 \\
\hline 60 & 804.0 & 861.1 & $7.1 \%$ & 806.2 & $0.3 \%$ & 0,86 & 0,44 \\
\hline 79 & 261.5 & 280.9 & $7.4 \%$ & 266.8 & $2.0 \%$ & 1,72 & 0,67 \\
\hline 88 & 584.6 & 636.6 & $8.9 \%$ & 591.9 & $1.3 \%$ & 1,68 & 0,54 \\
\hline 102 & 94.4 & 90.3 & $4,4 \%$ & 93.6 & $0.9 \%$ & 0,45 & 0,59 \\
\hline 111 & 44.0 & 44.2 & $0,4 \%$ & 45.3 & $2.9 \%$ & 0,56 & 0,58 \\
\hline 123 & 666.3 & 737.9 & $10,7 \%$ & 626.9 & $5.9 \%$ & 1,11 & 1,14 \\
\hline 151 & 448.1 & 266.6 & $40,5 \%$ & 452.7 & $1.0 \%$ & 0,95 & 1,39 \\
\hline 162 & 438.4 & 327.2 & $25,4 \%$ & 464.1 & $5.9 \%$ & 0,79 & 1,06 \\
\hline 175 & 769.2 & 440.4 & $42,7 \%$ & 707.5 & $8.0 \%$ & 0,88 & 1,51 \\
\hline 181 & 797.2 & 440.4 & $44,8 \%$ & 742.7 & $6.8 \%$ & 0,99 & 1,94 \\
\hline
\end{tabular}

${ }^{*}$ Momentos em kNm

É possível perceber que o método proposto de resistência direta consegue realizar uma previsão mais precisa que a normatização (DG), de modo geral. Em todos os casos foi observada uma redução na diferença dos valores previstos pela abordagem de resistência proposta quando comparados ao $M_{u, M E F}$.

Nenhuma viga da amostra demonstrou diferença relativa superior a $10 \%$. Essa melhor eficiência destaca-se principalmente em vigas que possuem modo de flambagem local governante ou esbeltez relativa localglobal $\left(\lambda_{L G}\right)$ maior que 0,8 . Como é o caso da viga \#151, em que a diferença relativa da previsão da normatização, $40,5 \%$, foi reduzida a 1,0\% ao utilizarse do método desenvolvido neste trabalho. Essa redução entre os valores 
e a esbeltez generalizada local-global pode ser constatada na figura 4.23. O único caso da amostra em que a diferença do MRD foi superior a do DG foi a viga \#111, governada pela plastificação, porém, mesmo assim, a diferença do MRD (aproximadamente $3 \%$ ) pode ser desprezada.

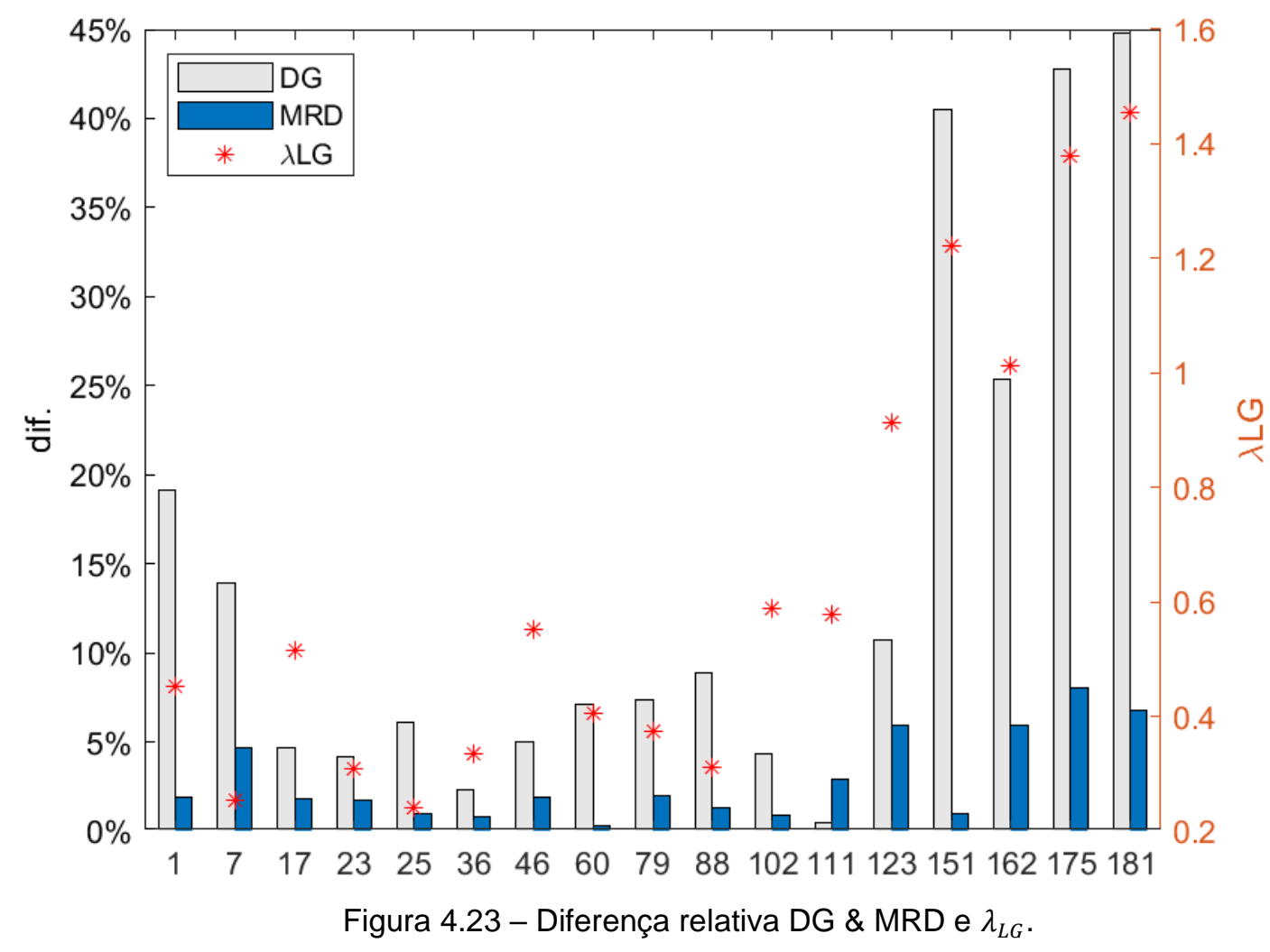

Em algumas vigas governadas pelo modo de flambagem global (FLT), a normatização apresenta aproximações razoáveis, como é o caso dos modelos \#17, \#23, \#36 e \#46. Da mesma forma, no caso em que a plastificação foi o modo de falha dominante, viga \#111, o Design Guide conseguiu prever com sucesso o momento último.

No caso de vigas suscetíveis à interação entre os modos de flambagem na presença das imperfeições, como é o caso da viga \#123, foi constatada uma maior eficiência em prever o momento nominal pela abordagem proposta (MRD). A diferença dos valores quando comparados com o momento último obtido nas análises de elementos finitos caiu de 10,7\% (Design Guide 31) para 5,9\% (MRD). A figura 4.24 traz os resultados das diferenças dos dois métodos em relação ao momento obtido nas análises de elementos finitos em função da esbeltez local-global $\left(\lambda_{L G}\right)$ e da 
razão entre o momento de plastificação e o momento crítico global $\left(M_{p} / M_{\text {cr } g}\right)$.

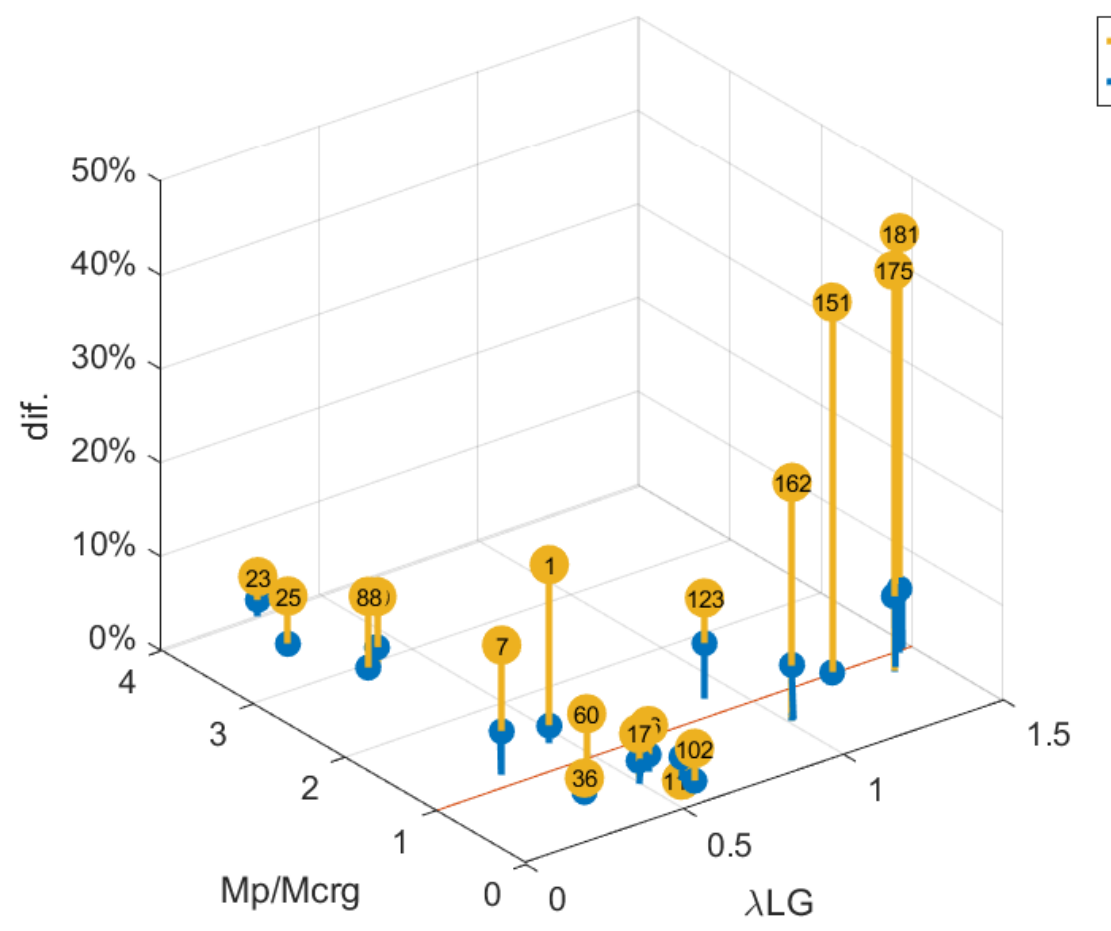

Figura 4.24 - Diferença relativa DG \& MRD, $\lambda_{L G}$ e relação $M_{p} / M_{c r g}$.

As vigas \#1 e \#7, as quais possuem diferença acentuada da previsão do Design Guide, apresentam momento crítico global $\left(M_{\text {cr } g}\right)$ muito próximo ao momento de plastificação $\left(M_{p}\right)$, o que demonstra que a normatização não consegue capturar bem a interação entre esses modos de falha.

Em vista disso, é destacado o papel imprescindível das ferramentas computacionais para a aplicação do Método da Resistência Direta (MRD) a fim de obter os momentos críticos de flambagem. A modelagem pelo método dos elementos finitos (MEF), como utilizada neste trabalho, é recomendada visto que as análises lineares de flambagem não possuem grande complexidade e não demandam grande custo computacional. Entretanto, de modo alternativo, é possível estimar a grandeza dos momentos críticos globais utilizando a equação teórica descrita na subseção 3.4.3 (Eq. 4) ou a sugerida por Sonck [38, 39]. Quanto ao momento crítico local, existe possibilidade em estimá-lo baseado nas equações propostas por Oliveira et al. [42].

Apesar dessas alternativas para estimação dos momentos críticos, não deve ser descartada a análise linear de flambagem. 


\section{5 \\ Conclusões e investigações futuras}

\section{1. Conclusões}

Um amplo estudo abrangendo um universo de 197 modelos de vigas casteladas foi realizado através do Método dos Elementos Finitos. As técnicas de modelagem, bem como as condições de contorno foram adequadas e validadas. Dessa forma, foram obtidos os momentos críticos global e local de flambagem elástica $\left(M_{c r g}\right.$ e $\left.M_{c r l}\right)$, por meio das análises lineares e o momento último de resistência $\left(M_{p}\right)$, pelas análises não lineares de material com imperfeição geométrica. Através da abordagem do Método da Resistência Direta foram desenvolvidas equações referentes às vigas casteladas biapoiadas sob flexão pura.

Após a análise dos resultados, as seguintes conclusões deste trabalho podem ser citadas:

- Foi possível identificar o comportamento de interação entre os modos de flambagem global (FLT), local (FT) e também de plastificação na presença das imperfeições geométricas e sua sensibilidade. Foi possível observar sua influência, proporcionando a queda da capacidade de resistência das vigas casteladas.

- O modo de falha de flambagem local do "tê" (FT) foi observado em valores elevados de $\lambda_{l}$, característica principalmente de aços de alta resistência, entretanto fora da faixa usual.

- A previsão de resistência do Design Guide para o dimensionamento à flexão aparenta ser razoável em alguns casos quando considerando vigas com $\lambda_{g}$ elevada e em que a plastificação foi o modo de falha dominante. Entretanto, especialmente nos casos em que ocorrem interação entre os modos e/ou a flambagem local governa o modo de 
falha, as previsões da normatização demonstraram maiores diferenças subestimando ou superestimando a capacidade de carga em valores com até $40 \%$ de diferença. Porém, novamente, tais vigas fogem da faixa usual de $\lambda_{l}$. Além disso, o Design Guide não conseguiu capturar bem a interação entre os modos de falha de FLT e plastificação, demonstrando também diferença acentuada, sobrestimando esses casos.

- As equações obtidas pelo método proposto, baseado na abordagem da resistência direta, exibem resultados satisfatórios e preveem uma boa aproximação da capacidade de carga para membros em flexão quando comparado com o Design Guide 31, de modo geral. A diferença relativa em relação ao $M_{u, M E F}$ foi reduzida ao ponto de ser inferior a $8 \%$ em todos os casos analisados.

- O MRD proposto para vigas casteladas biapoiadas em flexão pura inclui os efeitos da interação entre os modos global-local e traz melhores resultados de previsão da capacidade resistente, especialmente para as vigas governadas pelo modo local e/ou que apresentem interação entre os modos de falha, quando comparado ao Design Guide 31.

\section{2. \\ Sugestões para investigações futuras}

Entre as sugestões para futuros trabalhos relacionados ao tema, destacam-se:

- Considerar nos modelos efeito de tensões residuais, encruamento do aço e analisar a influência da solda no comportamento das vigas casteladas;

- Estender os estudos da interação perante outras condições de contorno e carregamento, considerando carga distribuída, realização de testes experimentais e investigação do comportamento pós-crítico;

- Ampliar a abordagem do MRD a outras condições de contorno, tipos de aberturas (vigas celulares, octogonais, Angelina), elevadas temperaturas, degradação cíclica e regime inelástico; 
6

\section{Referências bibliográficas}

[1] John A. Martin \& Associates, Inc.: Castellated Beams at Emerson College Los Angeles Barrett - jamauser. Los Angeles, EUA, 18 jul. 2013. Disponível em: http://www.johnmartin.com/castellated-beams-at-emersoncollege-los-angeles.html. Acesso em: 30 jul. 2020.

[2] FARES, S. S.; COULSON, J.; DINEHART, D. W. "Steel Design Guide 31 - Castellated and Cellular Beam Design", Am. Inst. Steel Constr., 2016 [3] KNOWLES, P. R. Castellated beams. Proceedings of the Institution of Civil Engineers (London). Part 1 - Design \& Construction, v. 90, n. pt 1, p. 521-536, 1991.

[4] BOYD, G.M. Patente: Improvements in Built-up Structural Members. Depositante: Geoffrey Murray Boyd. GB498281. Depósito: 4 maio 1937. Concessão: 4 jan. 1939, Reino Unido.

[5] AGLAN, A.A.; REDWOOD, R.G. Web buckling in castellated beams. Proc. Instn. Civil Eng., 57, part 2 (June 1974) 307-20.

[6] Arcelor Mittal Europe - Long products, Sections and Merchant Bars. $A C B \AA$ and Angelina $\AA$ : A new generation of castellated beams.

[7] GRÜNBAUER BV, Diemen - Nederland. Disponível em: http://www.grunbauer.nl/eng/raatvorm.htm. Acesso em: 27 jul. 2020.

[8] SRIMANI, S. S. L.; DAS, P. K. Finite element analysis of castellated beams. Computers and Structures, v. 9, n. 2, p. 169-174, 1978.

[9] BOYER, J. P. Castellated beams - new developments. AISC Engineering Journal, v. 1, n. 3, p. 104, 1964.

[10] GalamBOS, A. R.; HOSAIN, M. U.; SPEIRS, W. G. Optimum expansion ratio of castellated steel beams. Engineering Optimization, v. 1, n. 4, p. 213-225, 1975.

[11] KERDAL, D.; NETHERCOT, D. A. Failure modes for castellated beams. Journal of Constructional Steel Research, v. 4, n. 4, p. 295-315, 1984. 
[12] CHUNG, K. F.; LIU, T. C. H.; KO, A. C. H. Investigation on vierendeel mechanism in steel beams with circular web openings. Journal of Constructional Steel Research, v. 57, n. 5, p. 467-490, 2001

[13] AMAYREH, L.; SAKA, M. P. Failure load prediction of castellated beams using artificial neural networks. Asian Journal of Civil Engineering (Building and Housing), v. 6, n. 1-2, p. 35-54, 2005.

[14] HOSAIN, M. U.; SPEIRS, W. G. Experiments on Castellated Steel Beams. Welding Journal (Miami, Fla), v. 52, n. 8, p. 329-342, 1973.

[15] REDWOOD, R.; DEMIRDJIAN, S. Castellated beam web buckling in shear. Journal of Structural Engineering, v. 124, n. 10, p. 1202-1207, 1998.

[16] LIU, T. C. H.; CHUNG, K. F. Steel beams with large web openings of various shapes and sizes: Finite element investigation. Journal of Constructional Steel Research, v. 59, n. 9, p. 1159-1176, 2003.

[17] MENKULASI, F.; MOEN, C.D.; EATHERTON, M.R.; KURUPPUARACHCHI, D. Investigation of Stiffener Requirements in Castellated Beams. Proceedings of the Annual Stability Conference Structural Stability Research Council, Nashville, Tennessee, March 2427, 2015.

[18] CHUNG, K. F.; LIU, C. H.; KO, A. C. H. Steel beams with large web openings of various shapes and sizes: An empirical design method using a generalised moment-shear interaction curve. Journal of Constructional Steel Research, v. 59, n. 9, p. 1177-1200, 2003.

[19] ZAAROUR, W.; REDWOOD, R. Web buckling in thin webbed castellated beams. Journal of Structural Engineering, v. 122, n. 8, p. 860-866, 1996.

[20] DEMIRDJIAN, S. Stability of Castellated Beam Webs. 1999. Thesis, degree of Master of Engineering - Department of Civil Engineering and Applied Mechanics, McGill University, Montreal, Canada, 1999.

[21] ERDAL, F.; SAKA, M. P. Ultimate load carrying capacity of optimally designed steel cellular beams. Journal of Constructional Steel Research, v. 80, p. 355-368, 2013.

[22] KOITER, W. T., Over de stabiliteit van her elastisch evenwicht. PhD Thesis, H.J. Paris, Amsterdam, The Netherlands, 1945. English translation 
as NASDA TTF-10,833, 1957 and AFFDL Report TR 70-25, 1970 (in Dutch).

[23] CHILVER, A. H. Coupled modes of elastic buckling. Journal of the Mechanics and Physics of Solids, v. 15, n. 1, p. 15-28, 1967.

[24] BUDIANSKY, B. Theory of buckling and post-buckling behavior of elastic structures. In: Advances in applied mechanics. Elsevier, 1974. p. $1-65$.

[25] VAN DER NEUT, A. The interaction of local buckling and column failure of thin-walled compression members. Applied Mechanics, p. 389-399, 1969.

[26] HO, D. The influence of imperfections on systems with coincident buckling loads. International Journal of Non-Linear Mechanics, v. 7, n. 3, p. 311-321, 1972.

[27] TVERGAARD, V. Influence of post-buckling behaviour on optimum design of stiffened panels. International Journal of Solids and Structures, v. 9, n. 12, p. 1519-1533, 1973.

[28] JOHNS, K. C. Some statistical aspects of coupled buckling structures. In: Buckling of Structures. Springer, Berlin, Heidelberg, 1976. p. 199-207. [29] BAŽANT, Z. P.; CEDOLIN, L. Stability of Structures: Elastic, Inelastic, Fracture and Damage Theories. Singapore: World Scientific Publishing Company, 2010. 1011 p. ISBN 978-9814317030.

[30] ESDEP course, Može, P., acessado em: 29/07/2020, http://fggweb.fgg.unilj.si/ /pmoze/esdep/master/toc.htm.

[31] GOLTERMANN, P.; MØLLMANN, H. Interactive buckling in thin-walled beams-II. Applications. International Journal of Solids and Structures, v. 25, n. 7, p. 729-749, 1989.

[32] WADEE, M. A.; GARDNER, L. Cellular buckling from mode interaction in I-beams under uniform bending. Proceedings of the Royal Society A: Mathematical, Physical and Engineering Sciences, v. 468, n. 2137, p. 245-268, 2012.

[33] SHOKOUHIAN, M.; SHI, Y.; HEAD, M. Interactive buckling failure modes of hybrid steel flexural members. Engineering Structures, v. 125, p. 153-166, 2016. 
[34] SHERBOURNE, A. N.; VAN OOSTROM, J. Plastic analysis of castellated beams-I interaction of moment, shear and axial force. Computers and Structures, v. 2, n. 1-2, p. 79-109, 1972.

[35] ZIRAKIAN, T.; SHOWKATI, H. Distortional buckling of castellated beams. Journal of Constructional Steel Research, v. 62, n. 9, p. 863$871,2006$.

[36] ELLOBODY, E. Interaction of buckling modes in castellated steel beams. Journal of Constructional Steel Research, v. 67, n. 5, p. 814825, 2011.

[37] BOISSONNADE, N.; NSEIR, J.; LO, M.; SOMJA, H. Design of cellular beams against lateral torsional buckling. Proceedings of the Institution of Civil Engineers-Structures and Buildings, v. 167, n. 7, p. 436-444, 2014. [38] SONCK, D.; BELIS, J. Lateral-torsional buckling resistance of cellular beams. Journal of Constructional Steel Research, v. 105, p. 119-128, 2015.

[39] SONCK, D.; BELIS, J. Lateral-torsional buckling resistance of castellated beams. Journal of Structural Engineering (United States), v. 143, n. 3, p. 1-9, 2017.

[40] SOLTANI, M. R.; BOUCHAÏR, A.; MIMOUNE, M. Nonlinear FE analysis of the ultimate behavior of steel castellated beams. Journal of Constructional Steel Research, v. 70, p. 101-114, 2012.

[41] DE OLIVEIRA, J. P.; CARDOSO, D. C. T.; SOTELINO, E. D. Elastic flexural local buckling of Litzka castellated beams: Explicit equations and FE parametric study. Engineering Structures, v. 186, n. November 2018, p. 436-445, 2019.

[42] LINHARES, D. A. Mapping of Failure Modes and Resistance of Castellated Beams under Flexure. 2018. Dissertação (Mestrado pelo Programa de Pós-Graduação em Engenharia Civil da PUC-Rio) Departamento de Engenharia Civil e Ambiental, Pontifícia Universidade Católica do Rio de Janeiro, Rio de Janeiro, 2018.

[43] SOUZA, F. C. T. T.; CARDOSO, D. C. T.; SOTELINO, E. D. A Numerical Investigation on the Interaction Between Global and Local Buckling Modes in Castellated Beams. CILAMCE 2019 Proceedings of the 
XL Ibero-Latin-American Congress on Computational Methods in Engineering, ABMEC, Natal/RN, Brazil, November 11-14, 2019.

[44] AISC, "ANSI I AISC 360-16, Specification for Structural Steel Buildings", Am. Inst. Steel Constr., p. 676, 2016.

[45] AISI, "AISI S100-16, North American Specification for the Design of Cold-Formed Steel Structural Members", Am. Inst. Steel Constr., p. 509, 2016.

[46] HANCOCK, G. J.; KWON, Y. B.; STEFAN BERNARD, E. Strength design curves for thin-walled sections undergoing distortional buckling. Journal of Constructional Steel Research, v. 31, n. 2-3, p. 169-186, 1994.

[47] PEKÖZ, T. Development of a Unified Approach To the Design of ColdFormed Steel Members. AISI-Specifications for the Design of ColdFormed Steel Structural Members. v. 1986, n. May, p. 77-84, 1986.

[48] SCHAFER, B. W.; PEKÖZ, T. Direct strength prediction of cold-formed steel members using numerical elastic buckling solutions. International Specialty Conference on Cold-Formed Steel Structures: Recent Research and Developments in Cold-Formed Steel Design and Construction, p. 69-76, 1998.

[49] SCHAFER, B. W. Review: The Direct Strength Method of cold-formed steel member design. Journal of Constructional Steel Research, v. 64, n. 7-8, p. 766-778, 2008.

[50] SCHAFER, B. W. Distortional Buckling of Cold-formed Steel Columns: Final Report. The American Iron and Steel Institute, n. August, p. 102, 2000.

[51] B. Schafer, "Direct Strength Method (DSM) Design Guide", Des. Guid. CF06-1, Am. Iron Steel Inst., 2006.

[52] CAMOTIM, D.; DINIS, P. B.; MARTINS, A. D. Direct strength methoda general approach for the design of cold-formed steel structures. Recent trends in cold-formed steel construction. Elsevier Ltd, 2016. v. 3.

[53] SCHAFER, B. W. Advances in the Direct Strength Method of coldformed steel design. Thin-Walled Structures, v. 140, n. December 2018, p. 533-541, 2019. 
[54] AISI, "AISI S100-07, North American Specification for the Design of Cold-Formed Steel Structural Members", Am. Inst. Steel Constr., 2007.

[55] ASSOCIAÇÃO BRASILEIRA DE NORMAS TÉCNICAS. NBR 14762:2010 Dimensionamento de estruturas de aço constituídas por perfis formados a frio. Rio de Janeiro, p. 87. 2010.

[56] YOUNG, B.; SILVESTRE, N.; CAMOTIM, D. Cold-formed steel lipped channel columns influenced by local-distortional interaction: Strength and DSM design. Journal of Structural Engineering (United States), v. 139, n. 6, p. 1059-1074, 2013.

[57] LANDESMANN, A.; CAMOTIM, D. On the Direct Strength Method (DSM) design of cold-formed steel columns against distortional failure. Thin-Walled Structures, v. 67, p. 168-187, 2013.

[58] DINIS, P. B.; CAMOTIM, D. A novel DSM-based approach for the rational design of fixed-ended and pin-ended short-to-intermediate thinwalled angle columns. Thin-Walled Structures, v. 87, p. 158-182, 2015. [59] LANDESMANN, A.; CAMOTIM, D.; DINIS, P.B.; CRUZ, R. Short-tointermediate slender pin-ended cold-formed steel equal-leg angle columns: Experimental investigation, numerical simulations and DSM design. Engineering Structures, v. 132, p. 471-493, 2017.

[60] DINIS, P. B.; CAMOTIM, D.; YOUNG, B.; BATISTA, E.M. CFS lipped channel columns affected by L-D-G interaction. Part II: Numerical simulations and design considerations. Computers and Structures, v. 207, p. 200-218, 2018.

[61] YOUNG, B.; DINIS, P. B.; CAMOTIM, D. CFS lipped channel columns affected by L-D-G interaction. Part I: Experimental investigation. Computers and Structures, v. 207, p. 219-232, 2018.

[62] LANDESMANN, A.; CAMOTIM, D. Distortional failure and DSM design of cold-formed steel lipped channel beams under elevated temperatures. Thin-Walled Structures, v. 98, p. 75-93, 2016.

[63] MOEN, C. D.; SCHAFER, B. W. Elastic buckling of thin plates with holes in compression or bending. Thin-Walled Structures, v. 47, n. 12, p. 15971607, 2009. 
[64] MOEN, C. D.; SCHAFER, B. W. Impact of holes on the elastic buckling of cold- formed steel columns. International Specialty Conference on Cold-Formed Steel Structures., p. 269-283, 2006.

[65] MOEN, C. D.; SCHAFER, B. W. Direct strength method for design of cold-formed steel columns with holes. Journal of Structural Engineering, v. 137, n. 5, p. 559-570, 2011.

[66] ABAQUS, FEA computer software, Version 6.12, Product of Dassault Systèmes Simulia Corp., Providence, RI, USA.

[67] SOLESA, Centro de Soluções, Tabela de Bitolas Perfis WCS Catálogo Vigas Casteladas. Cariacica, ES, Brasil.

[68] ASSOCIAÇÃO BRASILEIRA DE NORMAS TÉCNICAS. NBR 8800:2008 Projeto de estruturas de aço e de estruturas mistas de aço e concreto de edifícios. Rio de Janeiro, p. 237. 2008.

[69] TIMOSHENKO, S. P.; GERE, J. M. Theory of Elastic Stability. 2. ed. McGraw- Hill, 541 p., 1963. 


\section{Anexos}

\section{Anexo A - Tabela das especificações do estudo}

\begin{tabular}{|c|c|c|c|c|c|c|c|c|c|}
\hline Viga & $\underset{[\mathrm{mm}]}{\mathbf{H}}$ & $\begin{array}{c}\mathbf{t}_{\mathrm{f}} \\
{[\mathrm{mm}]}\end{array}$ & $\begin{array}{c}t_{w} \\
{[\mathrm{~mm}]}\end{array}$ & $\begin{array}{c}\mathbf{b}_{\mathrm{f}} \\
{[\mathrm{mm}]}\end{array}$ & $\begin{array}{c}\mathbf{b}_{\mathrm{w}} \\
{[\mathrm{mm}]}\end{array}$ & $\mathbf{N}$ & $\underset{[\mathrm{mm}]}{\mathbf{L}}$ & $\begin{array}{c}\mathbf{f}_{\mathrm{y}} \\
{[\mathrm{MPa}]}\end{array}$ & $M_{p}[\mathrm{Nmm}]$ \\
\hline 1 & 222 & 4.9 & 4.3 & 100 & 37.00 & 10 & 2442 & 345 & $4.53 E+07$ \\
\hline 2 & 500 & 9 & 5 & 83.33 & 83.33 & 5 & 3000 & 345 & $1.79 \mathrm{E}+08$ \\
\hline 3 & 500 & 5 & 5 & 300 & 83.33 & 15 & 8000 & 345 & $3.12 \mathrm{E}+08$ \\
\hline 4 & 222 & 4.9 & 4.3 & 100 & 37.00 & 5 & 1332 & 345 & $4.53 \mathrm{E}+07$ \\
\hline 5 & 229.5 & 7.1 & 5.8 & 102 & 38.25 & 10 & 2524.5 & 345 & $6.70 \mathrm{E}+07$ \\
\hline 6 & 228 & 7.1 & 5.8 & 152 & 38.00 & 10 & 2508 & 345 & $9.36 \mathrm{E}+07$ \\
\hline 7 & 240 & 10.3 & 6.6 & 102 & 40.00 & 10 & 2640 & 345 & $9.61 \mathrm{E}+07$ \\
\hline 8 & 235.5 & 10.3 & 6.6 & 153 & 39.25 & 10 & 2590.5 & 345 & $1.35 \mathrm{E}+08$ \\
\hline 9 & 243 & 11.6 & 8.1 & 154 & 40.50 & 10 & 2673 & 345 & $1.58 \mathrm{E}+08$ \\
\hline 10 & 300 & 5.2 & 4.3 & 100 & 50.00 & 10 & 3300 & 345 & $6.92 \mathrm{E}+07$ \\
\hline 11 & 304.5 & 6.5 & 5.8 & 102 & 50.75 & 10 & 3349.5 & 345 & $9.01 \mathrm{E}+07$ \\
\hline 12 & 309 & 8 & 6.2 & 102 & 51.50 & 10 & 3399 & 345 & $1.08 \mathrm{E}+08$ \\
\hline 13 & 310.5 & 8.4 & 5.8 & 133 & 51.75 & 10 & 3415.5 & 345 & $1.38 \mathrm{E}+08$ \\
\hline 14 & 315 & 10.2 & 6.4 & 134 & 52.50 & 10 & 3465 & 345 & $1.67 \mathrm{E}+08$ \\
\hline 15 & 301.5 & 10.2 & 6.2 & 165 & 50.25 & 10 & 3316.5 & 345 & $1.90 \mathrm{E}+08$ \\
\hline 16 & 307.5 & 11.8 & 7.2 & 166 & 51.25 & 10 & 3382.5 & 345 & $2.24 \mathrm{E}+08$ \\
\hline 17 & 304.5 & 11 & 7.2 & 203 & 50.75 & 10 & 3349.5 & 345 & $2.50 \mathrm{E}+08$ \\
\hline 18 & 309 & 12.6 & 7.9 & 204 & 51.50 & 10 & 3399 & 345 & $2.89 E+08$ \\
\hline 19 & 306 & 11.3 & 11.3 & 207 & 51.00 & 10 & 3366 & 345 & $2.76 \mathrm{E}+08$ \\
\hline 20 & 315 & 14.2 & 9.1 & 205 & 52.50 & 10 & 3465 & 345 & $3.32 \mathrm{E}+08$ \\
\hline 21 & 324 & 17.4 & 10.2 & 206 & 54.00 & 10 & 3564 & 345 & $4.12 \mathrm{E}+08$ \\
\hline 22 & 333 & 20.6 & 13 & 209 & 55.50 & 10 & 3663 & 345 & $5.04 \mathrm{E}+08$ \\
\hline 23 & 376.5 & 5.3 & 4.8 & 101 & 62.75 & 10 & \begin{tabular}{|l|}
4141.5 \\
\end{tabular} & 345 & $9.79 E+07$ \\
\hline 24 & 381 & 6.9 & 5.8 & 102 & 63.50 & 10 & 4191 & 345 & $1.26 \mathrm{E}+08$ \\
\hline 25 & 385.5 & 8.4 & 6.1 & 102 & 64.25 & 10 & \begin{tabular}{|l|}
4240.5 \\
\end{tabular} & 345 & $1.48 \mathrm{E}+08$ \\
\hline 26 & 390 & 10 & 6.4 & 102 & 65.00 & 10 & 4290 & 345 & $1.72 \mathrm{E}+08$ \\
\hline 27 & 387 & 9.1 & 6.1 & 146 & 64.50 & 10 & 4257 & 345 & $2.10 \mathrm{E}+08$ \\
\hline 28 & 393 & 11.2 & 6.6 & 147 & 65.50 & 10 & 4323 & 345 & $2.56 \mathrm{E}+08$ \\
\hline 29 & 399 & 13 & 7.6 & 148 & 66.50 & 10 & 4389 & 345 & $3.01 E+08$ \\
\hline 30 & 369 & 10.7 & 10.5 & 256 & 61.50 & 10 & 4059 & 345 & $3.93 E+08$ \\
\hline 31 & 379.5 & 14.2 & 8.6 & 254 & 63.25 & 10 & \begin{tabular}{|l|}
4174.5 \\
\end{tabular} & 345 & $4.99 E+08$ \\
\hline 32 & 384 & 15.6 & 9.4 & 255 & 64.00 & 10 & 4224 & 345 & $5.53 \mathrm{E}+08$ \\
\hline 33 & 381 & 14.4 & 14.4 & 260 & 63.50 & 10 & 4191 & 345 & $5.47 \mathrm{E}+08$ \\
\hline 34 & 390 & 17.3 & 10.7 & 256 & 65.00 & 10 & 4290 & 345 & $6.24 \mathrm{E}+08$ \\
\hline
\end{tabular}




\begin{tabular}{|c|c|c|c|c|c|c|c|c|c|}
\hline 35 & 396 & 19.6 & 11.9 & 257 & 66.00 & 10 & 4356 & 345 & $7.13 E+08$ \\
\hline 36 & 403.5 & 22.1 & 13.5 & 259 & 67.25 & 10 & 4438.5 & 345 & $8.19 E+08$ \\
\hline 37 & 454.5 & 5.7 & 5.1 & 101 & 75.75 & 10 & 4999.5 & 345 & $1.35 E+08$ \\
\hline 38 & 457.5 & 6.7 & 5.6 & 101 & 76.25 & 10 & 5032.5 & 345 & $1.56 \mathrm{E}+08$ \\
\hline 39 & 463.5 & 8.9 & 6 & 102 & 77.25 & 10 & 5098.5 & 345 & $1.96 \mathrm{E}+08$ \\
\hline 40 & 469.5 & 10.8 & 6.6 & 102 & 78.25 & 10 & 5164.5 & 345 & $2.33 E+08$ \\
\hline 41 & 465 & 9.7 & 5.8 & 165 & 77.50 & 10 & 5115 & 345 & $3.03 E+08$ \\
\hline 42 & 469.5 & 11.2 & 6.6 & 166 & 78.25 & 10 & 5164.5 & 345 & $3.52 E+08$ \\
\hline 43 & 475.5 & 13.2 & 7.6 & 167 & 79.25 & 10 & 5230.5 & 345 & $4.18 E+08$ \\
\hline 44 & 448.5 & 11 & 11 & 306 & 74.75 & 10 & 4933.5 & 345 & $5.96 \mathrm{E}+08$ \\
\hline 45 & 454.5 & 13.1 & 13.1 & 308 & 75.75 & 10 & 4999.5 & 345 & $7.18 \mathrm{E}+08$ \\
\hline 46 & 462 & 15.4 & 9.9 & 305 & 77.00 & 10 & 5082 & 345 & $8.01 E+08$ \\
\hline 47 & 466.5 & 17 & 10.9 & 306 & 77.75 & 10 & 5131.5 & 345 & $8.92 E+08$ \\
\hline 48 & 462 & 15.5 & 15.4 & 310 & 77.00 & 10 & 5082 & 345 & $8.61 E+08$ \\
\hline 49 & 471 & 18.7 & 11.9 & 307 & 78.50 & 10 & 5181 & 345 & $9.88 E+08$ \\
\hline 50 & 468 & 17.4 & 17.4 & 312 & 78.00 & 10 & 5148 & 345 & $9.79 \mathrm{E}+08$ \\
\hline 51 & 523.5 & 8.5 & 5.8 & 127 & 87.25 & 10 & 5758.5 & 345 & $2.59 E+08$ \\
\hline 52 & 529.5 & 10.7 & 6.5 & 128 & 88.25 & 10 & 5824.5 & 345 & $3.20 E+08$ \\
\hline 53 & 528 & 9.8 & 6.9 & 171 & 88.00 & 10 & 5808 & 345 & $3.80 E+08$ \\
\hline 54 & 532.5 & 11.6 & 7.2 & 171 & 88.75 & 10 & 5857.5 & 345 & $4.39 E+08$ \\
\hline 55 & 537 & 13.1 & 7.9 & 172 & 89.50 & 10 & 5907 & 345 & $4.98 E+08$ \\
\hline 56 & 520.5 & 13.5 & 7.7 & 203 & 86.75 & 10 & 5725.5 & 345 & $5.61 \mathrm{E}+08$ \\
\hline 57 & 525 & 15.1 & 8.6 & 204 & 87.50 & 10 & 5775 & 345 & $6.33 E+08$ \\
\hline 58 & 531 & 16.8 & 9.4 & 205 & 88.50 & 10 & 5841 & 345 & $7.10 \mathrm{E}+08$ \\
\hline 59 & 529.5 & 16.4 & 9.5 & 254 & 88.25 & 8 & 4765.5 & 345 & 8.37E+08 \\
\hline 60 & 535.5 & 18.3 & 10.5 & 255 & 89.25 & 8 & 4819.5 & 345 & $9.43 E+08$ \\
\hline 61 & 540 & 19.9 & 11.4 & 256 & 90.00 & 8 & 4860 & 345 & $1.03 E+09$ \\
\hline 62 & 544.5 & 21.7 & 13 & 257 & 90.75 & 8 & 4900.5 & 345 & $1.14 \mathrm{E}+09$ \\
\hline 63 & 598.5 & 8.8 & 6.4 & 140 & 99.75 & 8 & 5386.5 & 345 & $3.49 E+08$ \\
\hline 64 & 604.5 & 11.2 & 7 & 140 & 100.75 & 8 & 5440.5 & 345 & $4.27 \mathrm{E}+08$ \\
\hline 65 & 604.5 & 10.9 & 7.5 & 177 & 100.75 & 8 & 5440.5 & 345 & $5.10 \mathrm{E}+08$ \\
\hline 66 & 610.5 & 12.8 & 7.7 & 178 & 101.75 & 8 & 5494.5 & 345 & $5.87 \mathrm{E}+08$ \\
\hline 67 & 615 & 14.4 & 8.8 & 179 & 102.50 & 8 & 5535 & 345 & $6.67 \mathrm{E}+08$ \\
\hline 68 & 619.5 & 16 & 9.7 & 180 & 103.25 & 8 & 5575.5 & 345 & $7.46 \mathrm{E}+08$ \\
\hline 69 & 625.5 & 18.2 & 10.9 & 181 & 104.25 & 8 & 5629.5 & 345 & $8.53 E+08$ \\
\hline 70 & 675 & 10.8 & 7.6 & 152 & 112.50 & 8 & 6075 & 345 & $5.23 E+08$ \\
\hline 71 & 682.5 & 13.3 & 8 & 153 & 113.75 & 8 & 6142.5 & 345 & $6.24 E+08$ \\
\hline 72 & 688.5 & 15.4 & 9.1 & 154 & 114.75 & 8 & 6196.5 & 345 & $7.25 \mathrm{E}+08$ \\
\hline 73 & 685.5 & 14.5 & 9 & 190 & 114.25 & 8 & 6169.5 & 345 & $8.10 \mathrm{E}+08$ \\
\hline 74 & 690 & 16 & 9.9 & 191 & 115.00 & 8 & 6210 & 345 & $9.00 \mathrm{E}+08$ \\
\hline 75 & 694.5 & 17.7 & 10.5 & 192 & 115.75 & 8 & 6250.5 & 345 & $9.93 E+08$ \\
\hline 76 & 699 & 19 & 11.4 & 193 & 116.50 & 8 & 6291 & 345 & $1.08 E+09$ \\
\hline 77 & 703.5 & 20.6 & 12.6 & 194 & 117.25 & 8 & 6331.5 & 345 & $1.18 \mathrm{E}+09$ \\
\hline 78 & 787.5 & 11.4 & 8.9 & 165 & 131.25 & 8 & 7087.5 & 345 & $7.41 \mathrm{E}+08$ \\
\hline 79 & 786 & 10.9 & 9 & 207 & 131.00 & 8 & 7074 & 345 & $8.44 E+08$ \\
\hline 80 & 793.5 & 13.6 & 9.7 & 166 & 132.25 & 8 & 7141.5 & 345 & $8.65 E+08$ \\
\hline
\end{tabular}




\begin{tabular}{|c|c|c|c|c|c|c|c|c|c|}
\hline 81 & 792 & 13.3 & 9.5 & 209 & 132.00 & 8 & 7128 & 345 & $9.98 \mathrm{E}+08$ \\
\hline 82 & 802.5 & 16.5 & 10.3 & 166 & 133.75 & 8 & 7222.5 & 345 & $1.01 E+09$ \\
\hline 83 & 799.5 & 15.6 & 10.2 & 209 & 133.25 & 8 & 7195.5 & 345 & $1.15 E+09$ \\
\hline 84 & 805.5 & 17.4 & 10.9 & 210 & 134.25 & 8 & 7249.5 & 345 & $1.28 E+09$ \\
\hline 85 & 808.5 & 18.8 & 11.6 & 211 & 134.75 & 8 & 7276.5 & 345 & $1.38 \mathrm{E}+09$ \\
\hline 86 & 904.5 & 14.9 & 10.5 & 228 & 150.75 & 8 & 8140.5 & 345 & $1.41 \mathrm{E}+09$ \\
\hline 87 & 912 & 17.3 & 11.2 & 228 & 152.00 & 8 & 8208 & 345 & $1.60 \mathrm{E}+09$ \\
\hline 88 & 918 & 19.6 & 11.9 & 229 & 153.00 & 8 & 8262 & 345 & $1.80 \mathrm{E}+09$ \\
\hline 89 & 925.5 & 22.2 & 13.1 & 230 & 154.25 & 8 & 8329.5 & 345 & $2.04 \mathrm{E}+09$ \\
\hline 90 & 916.5 & 19 & 12.7 & 324 & 152.75 & 8 & 8248.5 & 345 & $2.34 E+09$ \\
\hline 91 & 924 & 21.6 & 14 & 325 & 154.00 & 8 & 8316 & 345 & $2.66 E+09$ \\
\hline 92 & 799.5 & 15.6 & 10.2 & 209 & 133.25 & 4 & 3997.5 & 345 & $1.15 E+09$ \\
\hline 93 & 805.5 & 17.4 & 10.9 & 210 & 134.25 & 4 & 4027.5 & 345 & $1.28 \mathrm{E}+09$ \\
\hline 94 & 808.5 & 18.8 & 11.6 & 211 & 134.75 & 4 & 4042.5 & 345 & $1.38 E+09$ \\
\hline 95 & 904.5 & 14.9 & 10.5 & 228 & 150.75 & 4 & 4522.5 & 345 & $1.41 E+09$ \\
\hline 96 & 912 & 17.3 & 11.2 & 228 & 152.00 & 4 & 4560 & 345 & $1.60 \mathrm{E}+09$ \\
\hline 97 & 918 & 19.6 & 11.9 & 229 & 153.00 & 4 & 4590 & 345 & $1.80 E+09$ \\
\hline 98 & 925.5 & 22.2 & 13.1 & 230 & 154.25 & 4 & 4627.5 & 345 & $2.04 \mathrm{E}+09$ \\
\hline 99 & 916.5 & 19 & 12.7 & 324 & 152.75 & 4 & 4582.5 & 345 & $2.34 \mathrm{E}+09$ \\
\hline 100 & 924 & 21.6 & 14 & 325 & 154.00 & 4 & 4620 & 345 & $2.66 E+09$ \\
\hline 101 & 222 & 4.9 & 4.3 & 100 & 37.00 & 3 & 888 & 345 & $4.53 \mathrm{E}+07$ \\
\hline 102 & 228 & 7.1 & 5.8 & 152 & 38.00 & 5 & 1368 & 345 & $9.36 \mathrm{E}+07$ \\
\hline 103 & 304.5 & 11 & 7.2 & 203 & 50.75 & 5 & 1827 & 345 & $2.50 \mathrm{E}+08$ \\
\hline 104 & 306 & 11.3 & 11.3 & 207 & 51.00 & 5 & 1836 & 345 & $2.76 \mathrm{E}+08$ \\
\hline 105 & 369 & 10.7 & 10.5 & 256 & 61.50 & 5 & 2214 & 345 & $3.93 E+08$ \\
\hline 106 & 448.5 & 11 & 11 & 306 & 74.75 & 5 & 2691 & 345 & $5.96 \mathrm{E}+08$ \\
\hline 107 & 454.5 & 13.1 & 13.1 & 308 & 75.75 & 5 & 2727 & 345 & $7.18 E+08$ \\
\hline 108 & 462 & 15.4 & 9.9 & 305 & 77.00 & 5 & 2772 & 345 & $8.01 E+08$ \\
\hline 109 & 916.5 & 19 & 12.7 & 324 & 152.75 & 2 & 2749.5 & 345 & $2.34 \mathrm{E}+09$ \\
\hline 110 & 924 & 21.6 & 14 & 325 & 154.00 & 2 & 2772 & 345 & $2.66 E+09$ \\
\hline 111 & 222 & 4.9 & 4.3 & 100 & 37.00 & 4 & 1110 & 345 & $4.53 \mathrm{E}+07$ \\
\hline 112 & 228 & 7.1 & 5.8 & 152 & 38.00 & 7 & 1824 & 345 & $9.36 \mathrm{E}+07$ \\
\hline 113 & 304.5 & 11 & 7.2 & 203 & 50.75 & 7 & 2436 & 345 & $2.50 \mathrm{E}+08$ \\
\hline 114 & 306 & 11.3 & 11.3 & 207 & 51.00 & 7 & 2448 & 345 & $2.76 \mathrm{E}+08$ \\
\hline 115 & 369 & 10.7 & 10.5 & 256 & 61.50 & 7 & 2952 & 345 & $3.93 E+08$ \\
\hline 116 & 448.5 & 11 & 11 & 306 & 74.75 & 7 & 3588 & 345 & $5.96 \mathrm{E}+08$ \\
\hline 117 & 454.5 & 13.1 & 13.1 & 308 & 75.75 & 7 & 3636 & 345 & $7.18 E+08$ \\
\hline 118 & 462 & 15.4 & 9.9 & 305 & 77.00 & 7 & 3696 & 345 & $8.01 E+08$ \\
\hline 119 & 916.5 & 19 & 12.7 & 324 & 152.75 & 3 & 3666 & 345 & $2.34 E+09$ \\
\hline 120 & 924 & 21.6 & 14 & 325 & 154.00 & 3 & 3696 & 345 & $2.66 \mathrm{E}+09$ \\
\hline 121 & 228 & 7.1 & 5.8 & 152 & 38.00 & 10 & 2508 & 690 & $1.87 E+08$ \\
\hline 122 & 304.5 & 6.5 & 5.8 & 102 & 50.75 & 10 & 3349.5 & 690 & $1.80 \mathrm{E}+08$ \\
\hline 123 & 448.5 & 9.5 & 11 & 306 & 74.75 & 10 & 4933.5 & 690 & $1.06 \mathrm{E}+09$ \\
\hline 124 & 448.5 & 11 & 11 & 306 & 74.75 & 5 & 2691 & 690 & $1.19 \mathrm{E}+09$ \\
\hline 125 & 381 & 6.9 & 5.8 & 102 & 63.50 & 10 & 4191 & 690 & $2.52 \mathrm{E}+08$ \\
\hline 126 & 385.5 & 8.4 & 6.1 & 102 & 64.25 & 10 & 4240.5 & 690 & $2.96 \mathrm{E}+08$ \\
\hline
\end{tabular}




\begin{tabular}{|c|c|c|c|c|c|c|c|c|c|}
\hline 127 & 500 & 9 & 5 & 83.33 & 83.33 & 5 & 3000 & 690 & $3.59 E+08$ \\
\hline 128 & 393 & 11.2 & 6.6 & 147 & 65.50 & 10 & 4323 & 690 & $5.12 E+08$ \\
\hline 129 & 520.5 & 13.5 & 7.7 & 203 & 86.75 & 10 & 5725.5 & 690 & $1.12 E+09$ \\
\hline 130 & 598.5 & 8.8 & 6.4 & 140 & 99.75 & 8 & 5386.5 & 690 & $6.98 \mathrm{E}+08$ \\
\hline 131 & 454.5 & 5.7 & 5.1 & 101 & 75.75 & 5 & 2727 & 690 & $2.70 \mathrm{E}+08$ \\
\hline 132 & 675 & 10.8 & 7.6 & 152 & 112.50 & 8 & 6075 & 690 & $1.05 E+09$ \\
\hline 133 & 682.5 & 13.3 & 8 & 153 & 113.75 & 8 & 6142.5 & 690 & $1.25 E+09$ \\
\hline 134 & 688.5 & 15.4 & 9.1 & 154 & 114.75 & 8 & 6196.5 & 690 & $1.45 E+09$ \\
\hline 135 & 786 & 10.9 & 9 & 207 & 131.00 & 8 & 7074 & 690 & 1.69E+09 \\
\hline 136 & 808.5 & 18.8 & 11.6 & 211 & 134.75 & 8 & 7276.5 & 690 & $2.77 E+09$ \\
\hline 137 & 912 & 17.3 & 11.2 & 228 & 152.00 & 8 & 8208 & 690 & $3.21 E+09$ \\
\hline 138 & 924 & 21.6 & 14 & 325 & 154.00 & 8 & 8316 & 690 & $5.33 E+09$ \\
\hline 139 & 918 & 19.6 & 11.9 & 229 & 153.00 & 4 & 4590 & 690 & $3.60 E+09$ \\
\hline 140 & 916.5 & 19 & 12.7 & 324 & 152.75 & 2 & 2749.5 & 690 & $4.69 E+09$ \\
\hline 141 & 381 & 6.9 & 5.8 & 102 & 63.50 & 5 & 2286 & 690 & $2.52 E+08$ \\
\hline 142 & 385.5 & 8.4 & 6.1 & 102 & 64.25 & 5 & 2313 & 690 & $2.96 \mathrm{E}+08$ \\
\hline 143 & 500 & 9 & 5 & 83.33 & 83.33 & 3 & 2000 & 690 & $3.59 E+08$ \\
\hline 144 & 598.5 & 8.8 & 6.4 & 140 & 99.75 & 4 & 2992.5 & 690 & $6.98 \mathrm{E}+08$ \\
\hline 145 & 675 & 10.8 & 7.6 & 152 & 112.50 & 4 & 3375 & 690 & $1.05 E+09$ \\
\hline 146 & 682.5 & 13.3 & 8 & 153 & 113.75 & 4 & 3412.5 & 690 & $1.25 E+09$ \\
\hline 147 & 688.5 & 15.4 & 9.1 & 154 & 114.75 & 4 & 3442.5 & 690 & $1.45 E+09$ \\
\hline 148 & 786 & 10.9 & 9 & 207 & 131.00 & 4 & 3930 & 690 & 1.69E+09 \\
\hline 149 & 808.5 & 18.8 & 11.6 & 211 & 134.75 & 4 & 4042.5 & 690 & $2.77 E+09$ \\
\hline 150 & 912 & 17.3 & 11.2 & 228 & 152.00 & 4 & 4560 & 690 & $3.21 E+09$ \\
\hline 151 & 448.5 & 6.9 & 11 & 306 & 74.75 & 8 & 4036.5 & 690 & $8.32 E+08$ \\
\hline 152 & 454.5 & 7.1 & 13.1 & 308 & 75.75 & 8 & 4090.5 & 690 & $9.06 \mathrm{E}+08$ \\
\hline 153 & 462 & 8.4 & 9.9 & 305 & 77.00 & 6 & 3234 & 690 & $9.78 E+08$ \\
\hline 154 & 912 & 11 & 11.2 & 228 & 152.00 & 5 & 5472 & 690 & $2.38 E+09$ \\
\hline 155 & 675 & 5.7 & 7.6 & 152 & 112.50 & 5 & 4050 & 690 & $7.12 E+08$ \\
\hline 156 & 682.5 & 7.1 & 8 & 153 & 113.75 & 5 & 4095 & 690 & $8.37 E+08$ \\
\hline 157 & 688.5 & 11 & 9.1 & 154 & 114.75 & 5 & 4131 & 690 & $1.16 \mathrm{E}+09$ \\
\hline 158 & 786 & 5.9 & 9 & 207 & 131.00 & 5 & 4716 & 690 & $1.16 \mathrm{E}+09$ \\
\hline 159 & 808.5 & 11 & 11.6 & 211 & 134.75 & 5 & 4851 & 690 & $1.93 E+09$ \\
\hline 160 & 918 & 11 & 11.9 & 229 & 153.00 & 4 & 4590 & 690 & $2.46 \mathrm{E}+09$ \\
\hline 161 & 448.5 & 6.9 & 11 & 306 & 74.75 & 8 & 4036.5 & 460 & $5.55 \mathrm{E}+08$ \\
\hline 162 & 454.5 & 7.1 & 13.1 & 308 & 75.75 & 8 & 4090.5 & 460 & $6.04 \mathrm{E}+08$ \\
\hline 163 & 462 & 8.4 & 9.9 & 305 & 77.00 & 6 & 3234 & 460 & $6.52 E+08$ \\
\hline 164 & 912 & 11 & 11.2 & 228 & 152.00 & 5 & 5472 & 460 & $1.58 \mathrm{E}+09$ \\
\hline 165 & 675 & 5.7 & 7.6 & 152 & 112.50 & 5 & 4050 & 460 & $4.75 \mathrm{E}+08$ \\
\hline 166 & 682.5 & 7.1 & 8 & 153 & 113.75 & 5 & 4095 & 460 & $5.58 E+08$ \\
\hline 167 & 688.5 & 5.9 & 9.1 & 154 & 114.75 & 5 & 4131 & 460 & $5.44 \mathrm{E}+08$ \\
\hline 168 & 786 & 5.9 & 9 & 207 & 131.00 & 5 & 4716 & 460 & $7.74 \mathrm{E}+08$ \\
\hline 169 & 808.5 & 11 & 11.6 & 211 & 134.75 & 5 & 4851 & 460 & $1.29 E+09$ \\
\hline 170 & 918 & 11 & 11.9 & 229 & 153.00 & 4 & 4590 & 460 & $1.64 \mathrm{E}+09$ \\
\hline 171 & 448.5 & 9.5 & 11 & 306 & 74.75 & 10 & 4933.5 & 965 & $1.48 E+09$ \\
\hline 172 & 448.5 & 11 & 11 & 306 & 74.75 & 5 & 2691 & 965 & $1.67 \mathrm{E}+09$ \\
\hline
\end{tabular}




\begin{tabular}{|c|c|c|c|c|c|c|c|c|c|}
\hline 173 & 448.5 & 6.9 & 11 & 306 & 74.75 & 8 & 4036.5 & 965 & $1.16 \mathrm{E}+09$ \\
\hline 174 & 454.5 & 7.1 & 13.1 & 308 & 75.75 & 8 & 4090.5 & 965 & $1.27 \mathrm{E}+09$ \\
\hline 175 & 462 & 8.4 & 9.9 & 305 & 77.00 & 6 & 3234 & 965 & $1.37 \mathrm{E}+09$ \\
\hline 176 & 675 & 5.7 & 7.6 & 152 & 112.50 & 5 & 4050 & 965 & $9.96 \mathrm{E}+08$ \\
\hline 177 & 682.5 & 7.1 & 8 & 153 & 113.75 & 5 & 4095 & 965 & $1.17 \mathrm{E}+09$ \\
\hline 178 & 786 & 5.9 & 9 & 207 & 131.00 & 5 & 4716 & 965 & $1.62 \mathrm{E}+09$ \\
\hline 179 & 448.5 & 6.9 & 11 & 306 & 74.75 & 8 & 4036.5 & 1210 & $1.46 \mathrm{E}+09$ \\
\hline 180 & 454.5 & 7.1 & 13.1 & 308 & 75.75 & 8 & 4090.5 & 1210 & $1.59 \mathrm{E}+09$ \\
\hline 181 & 462 & 8.4 & 9.9 & 305 & 77.00 & 6 & 3234 & 1210 & $1.72 \mathrm{E}+09$ \\
\hline 182 & 786 & 5.9 & 9 & 207 & 131.00 & 5 & 4716 & 1210 & $2.04 \mathrm{E}+09$ \\
\hline 183 & 448.5 & 9.5 & 11 & 306 & 74.75 & 10 & 4933.5 & 1210 & $1.86 \mathrm{E}+09$ \\
\hline 184 & 448.5 & 11 & 11 & 306 & 74.75 & 5 & 2691 & 1210 & $2.09 \mathrm{E}+09$ \\
\hline 185 & 675 & 5.7 & 7.6 & 152 & 112.50 & 5 & 4050 & 1210 & $1.25 \mathrm{E}+09$ \\
\hline 186 & 454.5 & 5.7 & 5.1 & 101 & 75.75 & 5 & 2727 & 1210 & $4.74 \mathrm{E}+08$ \\
\hline 187 & 228 & 7.1 & 5.8 & 152 & 38.00 & 10 & 2508 & 1210 & $3.28 \mathrm{E}+08$ \\
\hline 188 & 448.5 & 9.5 & 11 & 306 & 74.75 & 10 & 4933.5 & 2000 & $3.08 \mathrm{E}+09$ \\
\hline 189 & 448.5 & 11 & 11 & 306 & 74.75 & 5 & 2691 & 2000 & $3.45 \mathrm{E}+09$ \\
\hline 190 & 448.5 & 6.9 & 11 & 306 & 74.75 & 8 & 4036.5 & 2000 & $2.41 \mathrm{E}+09$ \\
\hline 191 & 454.5 & 7.1 & 13.1 & 308 & 75.75 & 8 & 4090.5 & 2000 & $2.63 \mathrm{E}+09$ \\
\hline 192 & 462 & 8.4 & 9.9 & 305 & 77.00 & 6 & 3234 & 2000 & $2.84 \mathrm{E}+09$ \\
\hline 193 & 448.5 & 6.9 & 11 & 306 & 74.75 & 8 & 4036.5 & 1600 & $1.93 \mathrm{E}+09$ \\
\hline 194 & 454.5 & 7.1 & 13.1 & 308 & 75.75 & 8 & 4090.5 & 1600 & $2.10 \mathrm{E}+09$ \\
\hline 195 & 462 & 8.4 & 9.9 & 305 & 77.00 & 6 & 3234 & 1600 & $2.27 \mathrm{E}+09$ \\
\hline 196 & 448.5 & 9.5 & 11 & 306 & 74.75 & 10 & 4933.5 & 2300 & $3.54 \mathrm{E}+09$ \\
\hline 197 & 448.5 & 11 & 11 & 306 & 74.75 & 5 & 2691 & 2300 & $3.97 \mathrm{E}+09$ \\
\hline & & & & & & & & & \\
\hline
\end{tabular}

\section{Anexo B - Tabela dos resultados do estudo}

\begin{tabular}{|c|c|c|c|c|c|c|c|}
\hline Viga & $\begin{array}{c}\boldsymbol{M}_{\boldsymbol{c r} \boldsymbol{g}} \\
{[\mathbf{N m m}]}\end{array}$ & $\begin{array}{c}\boldsymbol{I m p} \cdot \boldsymbol{g} \\
{[\mathbf{m m}]}\end{array}$ & $\begin{array}{c}\boldsymbol{M}_{\boldsymbol{c r} \boldsymbol{l}} \\
{[\mathbf{N m m}]}\end{array}$ & $\begin{array}{c}\boldsymbol{I m p} \cdot \boldsymbol{l} \\
{[\mathbf{m m}]}\end{array}$ & $\boldsymbol{\lambda}_{\mathbf{g}}$ & $\boldsymbol{\lambda}_{\mathbf{I}}$ & $\begin{array}{c}\boldsymbol{M}_{\boldsymbol{u}} \\
{[\mathbf{N m m}]}\end{array}$ \\
\hline 1 & $3.41 \mathrm{E}+07$ & 2.44 & $1.33 \mathrm{E}+08$ & 0.44 & 1.15 & 0.58 & $2.80 \mathrm{E}+07$ \\
\hline 2 & $5.66 \mathrm{E}+07$ & 3.00 & $4.13 \mathrm{E}+08$ & 1.00 & 1.78 & 0.66 & $5.19 \mathrm{E}+07$ \\
\hline 3 & $1.78 \mathrm{E}+08$ & 8.00 & $1.21 \mathrm{E}+08$ & 1.00 & 1.32 & 1.61 & $1.17 \mathrm{E}+08$ \\
\hline 4 & $1.03 \mathrm{E}+08$ & 1.33 & $1.34 \mathrm{E}+08$ & 0.44 & 0.66 & 0.58 & $4.24 \mathrm{E}+07$ \\
\hline 5 & $5.52 \mathrm{E}+07$ & 2.52 & $3.81 \mathrm{E}+08$ & 0.46 & 1.10 & 0.42 & $4.47 \mathrm{E}+07$ \\
\hline 6 & $1.60 \mathrm{E}+08$ & 2.51 & $2.68 \mathrm{E}+08$ & 0.46 & 0.76 & 0.59 & $8.52 \mathrm{E}+07$ \\
\hline 7 & $8.37 \mathrm{E}+07$ & 2.64 & $1.01 \mathrm{E}+09$ & 0.48 & 1.07 & 0.31 & $6.76 \mathrm{E}+07$ \\
\hline 8 & $2.41 \mathrm{E}+08$ & 2.59 & $7.29 \mathrm{E}+08$ & 0.47 & 0.75 & 0.43 & $1.27 \mathrm{E}+08$ \\
\hline 9 & $2.81 \mathrm{E}+08$ & 2.67 & $1.10 \mathrm{E}+09$ & 0.49 & 0.75 & 0.38 & $1.50 \mathrm{E}+08$ \\
\hline 10 & $2.76 \mathrm{E}+07$ & 3.30 & $1.92 \mathrm{E}+08$ & 0.60 & 1.58 & 0.60 & $2.50 \mathrm{E}+07$ \\
\hline 11 & $3.93 \mathrm{E}+07$ & 3.35 & $4.00 \mathrm{E}+08$ & 0.61 & 1.51 & 0.47 & $3.54 \mathrm{E}+07$ \\
\hline 12 & $4.94 \mathrm{E}+07$ & 3.40 & $6.49 \mathrm{E}+08$ & 0.62 & 1.48 & 0.41 & $4.45 \mathrm{E}+07$ \\
\hline 13 & $1.01 \mathrm{E}+08$ & 3.42 & $5.86 \mathrm{E}+08$ & 0.62 & 1.17 & 0.49 & $8.39 \mathrm{E}+07$ \\
\hline 14 & $1.28 \mathrm{E}+08$ & 3.47 & $9.91 \mathrm{E}+08$ & 0.63 & 1.14 & 0.41 & $1.06 \mathrm{E}+08$ \\
\hline
\end{tabular}




\begin{tabular}{|c|c|c|c|c|c|c|c|}
\hline 15 & $2.31 E+08$ & 3.32 & $8.10 \mathrm{E}+08$ & 0.60 & 0.91 & 0.48 & $1.57 E+08$ \\
\hline 16 & $2.76 \mathrm{E}+08$ & 3.38 & $1.26 \mathrm{E}+09$ & 0.62 & 0.90 & 0.42 & $1.87 \mathrm{E}+08$ \\
\hline 17 & $4.43 E+08$ & 3.35 & $8.83 E+08$ & 0.61 & 0.75 & 0.53 & $2.31 E+08$ \\
\hline 18 & $5.19 \mathrm{E}+08$ & 3.40 & $1.31 \mathrm{E}+09$ & 0.62 & 0.75 & 0.47 & $2.70 \mathrm{E}+08$ \\
\hline 19 & $5.11 \mathrm{E}+08$ & 3.37 & $1.20 \mathrm{E}+09$ & 0.61 & 0.73 & 0.48 & $2.60 E+08$ \\
\hline 20 & $6.01 E+08$ & 3.47 & $1.90 \mathrm{E}+09$ & 0.63 & 0.74 & 0.42 & $3.13 E+08$ \\
\hline 21 & $7.60 \mathrm{E}+08$ & 3.56 & $3.40 \mathrm{E}+09$ & 0.65 & 0.74 & 0.35 & $3.96 \mathrm{E}+08$ \\
\hline 22 & $9.79 E+08$ & 3.66 & $5.83 \mathrm{E}+09$ & 0.67 & 0.72 & 0.29 & $4.99 E+08$ \\
\hline 23 & $2.44 \mathrm{E}+07$ & 4.14 & $2.45 \mathrm{E}+08$ & 0.75 & 2.00 & 0.63 & $2.29 E+07$ \\
\hline 24 & $3.45 E+07$ & 4.19 & $4.85 \mathrm{E}+08$ & 0.76 & 1.91 & 0.51 & $3.24 \mathrm{E}+07$ \\
\hline 25 & $4.29 E+07$ & 4.24 & $6.94 \mathrm{E}+08$ & 0.77 & 1.86 & 0.46 & $4.02 E+07$ \\
\hline 26 & $5.25 E+07$ & 4.29 & $9.05 E+08$ & 0.78 & 1.81 & 0.44 & $4.91 E+07$ \\
\hline 27 & $1.16 \mathrm{E}+08$ & 4.26 & $8.01 \mathrm{E}+08$ & 0.77 & 1.34 & 0.51 & $1.02 E+08$ \\
\hline 28 & $1.49 E+08$ & 4.32 & $1.18 \mathrm{E}+09$ & 0.79 & 1.31 & 0.47 & $1.30 E+08$ \\
\hline 29 & $1.82 \mathrm{E}+08$ & 4.39 & $1.79 \mathrm{E}+09$ & 0.80 & 1.28 & 0.41 & $1.59 \mathrm{E}+08$ \\
\hline 30 & $7.11 \mathrm{E}+08$ & 4.06 & $9.95 \mathrm{E}+08$ & 0.74 & 0.74 & 0.63 & $3.62 E+08$ \\
\hline 31 & $8.97 E+08$ & 4.17 & $1.82 \mathrm{E}+09$ & 0.76 & 0.75 & 0.52 & $4.62 E+08$ \\
\hline 32 & $1.00 \mathrm{E}+09$ & 4.22 & $2.42 \mathrm{E}+09$ & 0.77 & 0.74 & 0.48 & $5.17 \mathrm{E}+08$ \\
\hline 33 & $E+09$ & 4.19 & $2.47 \mathrm{E}+09$ & 0.76 & 0.73 & 0.47 & $5.18 \mathrm{E}+08$ \\
\hline 34 & $1.14 \mathrm{E}+09$ & 4.29 & $3.36 \mathrm{E}+09$ & 0.78 & 0.74 & 0.43 & $5.88 \mathrm{E}+08$ \\
\hline 35 & $1.32 \mathrm{E}+09$ & 4.36 & $4.87 \mathrm{E}+09$ & 0.79 & 0.73 & 0.38 & $6.81 E+08$ \\
\hline 36 & $1.55 \mathrm{E}+09$ & 4.44 & $7.02 \mathrm{E}+09$ & 0.81 & 0.73 & 0.34 & $7.94 \mathrm{E}+08$ \\
\hline 37 & $2.28 E+07$ & 5.00 & $2.96 \mathrm{E}+08$ & 0.91 & 2.43 & 0.68 & $2.21 E+07$ \\
\hline 38 & $2.77 E+07$ & 5.03 & $4.30 \mathrm{E}+08$ & 0.92 & 2.37 & 0.60 & $2.68 \mathrm{E}+07$ \\
\hline 39 & $3.88 E+07$ & 5.10 & $6.76 \mathrm{E}+08$ & 0.93 & 2.25 & 0.54 & $3.73 E+07$ \\
\hline 40 & $4.95 E+07$ & 5.16 & $9.71 \mathrm{E}+08$ & 0.94 & 2.17 & 0.49 & $4.74 \mathrm{E}+07$ \\
\hline 41 & $1.45 E+08$ & 5.12 & $7.96 \mathrm{E}+08$ & 0.93 & 1.45 & 0.62 & $1.29 E+08$ \\
\hline 42 & $1.74 \mathrm{E}+08$ & 5.16 & $1.18 \mathrm{E}+09$ & 0.94 & 1.42 & 0.55 & $1.55 \mathrm{E}+08$ \\
\hline 43 & $2.16 E+08$ & 5.23 & $1.82 \mathrm{E}+09$ & 0.95 & 1.39 & 0.48 & $1.91 E+08$ \\
\hline 44 & $1.01 \mathrm{E}+09$ & 4.93 & $1.12 \mathrm{E}+09$ & 0.90 & 0.77 & 0.73 & $5.34 \mathrm{E}+08$ \\
\hline 45 & $1.24 \mathrm{E}+09$ & 5.00 & $1.89 \mathrm{E}+09$ & 0.91 & 0.76 & 0.62 & $6.55 E+08$ \\
\hline 46 & $1.37 E+09$ & 5.08 & $2.43 \mathrm{E}+09$ & 0.92 & 0.77 & 0.57 & $7.31 \mathrm{E}+08$ \\
\hline 47 & $1.54 \mathrm{E}+09$ & 5.13 & $3.28 \mathrm{E}+09$ & 0.93 & 0.76 & 0.52 & $8.20 E+08$ \\
\hline 48 & $1.52 \mathrm{E}+09$ & 5.08 & $3.13 \mathrm{E}+09$ & 0.92 & 0.75 & 0.52 & $7.98 \mathrm{E}+08$ \\
\hline 49 & $1.72 \mathrm{E}+09$ & 5.18 & $4.35 \mathrm{E}+09$ & 0.94 & 0.76 & 0.48 & $9.16 \mathrm{E}+08$ \\
\hline 50 & $1.77 E+09$ & 5.15 & $4.45 \mathrm{E}+09$ & 0.94 & 0.74 & 0.47 & $9.20 \mathrm{E}+08$ \\
\hline 51 & $5.64 \mathrm{E}+07$ & 5.76 & $6.33 \mathrm{E}+08$ & 1.05 & 2.14 & 0.64 & $5.38 \mathrm{E}+07$ \\
\hline 52 & $7.57 \mathrm{E}+07$ & 5.82 & $9.87 \mathrm{E}+08$ & 1.06 & 2.06 & 0.57 & $7.20 \mathrm{E}+07$ \\
\hline 53 & $1.47 E+08$ & 5.81 & 1.10E+09 & 1.06 & 1.61 & 0.59 & $1.34 \mathrm{E}+08$ \\
\hline 54 & $1.77 E+08$ & 5.86 & $1.43 \mathrm{E}+09$ & 1.07 & 1.58 & 0.55 & $1.61 \mathrm{E}+08$ \\
\hline 55 & $2.08 E+08$ & 5.91 & $1.93 \mathrm{E}+09$ & 1.07 & 1.55 & 0.51 & $1.89 E+08$ \\
\hline 56 & $3.41 \mathrm{E}+08$ & 5.73 & $1.96 \mathrm{E}+09$ & 1.04 & 1.28 & 0.53 & $2.94 \mathrm{E}+08$ \\
\hline 57 & $3.95 E+08$ & 5.78 & $2.72 \mathrm{E}+09$ & 1.05 & 1.27 & 0.48 & $3.40 \mathrm{E}+08$ \\
\hline 58 & $4.54 \mathrm{E}+08$ & 5.84 & $3.58 \mathrm{E}+09$ & 1.06 & 1.25 & 0.45 & $3.91 \mathrm{E}+08$ \\
\hline 59 & $1.11 \mathrm{E}+09$ & 4.77 & $3.64 \mathrm{E}+09$ & 1.06 & 0.87 & 0.48 & $7.08 \mathrm{E}+08$ \\
\hline 60 & $1.27 E+09$ & 4.82 & $4.93 \mathrm{E}+09$ & 1.07 & 0.86 & 0.44 & $8.04 \mathrm{E}+08$ \\
\hline
\end{tabular}




\begin{tabular}{|c|c|c|c|c|c|c|c|}
\hline 61 & $1.40 \mathrm{E}+09$ & 4.86 & $6.28 \mathrm{E}+09$ & 1.08 & 0.86 & 0.41 & $8.89 E+08$ \\
\hline 62 & $1.58 \mathrm{E}+09$ & 4.90 & $8.60 \mathrm{E}+09$ & 1.09 & 0.85 & 0.36 & $9.94 \mathrm{E}+08$ \\
\hline 63 & $9.65 E+07$ & 5.39 & $7.87 \mathrm{E}+08$ & 1.20 & 1.90 & 0.67 & $8.98 E+07$ \\
\hline 64 & $1.26 \mathrm{E}+08$ & 5.44 & 1.19E+09 & 1.21 & 1.84 & 0.60 & $1.17 \mathrm{E}+08$ \\
\hline 65 & $2.30 \mathrm{E}+08$ & 5.44 & $1.43 \mathrm{E}+09$ & 1.21 & 1.49 & 0.60 & $2.05 E+08$ \\
\hline 66 & $2.76 \mathrm{E}+08$ & 5.49 & $1.76 \mathrm{E}+09$ & 1.22 & 1.46 & 0.58 & $2.45 E+08$ \\
\hline 67 & $3.24 \mathrm{E}+08$ & 5.54 & $2.57 \mathrm{E}+09$ & 1.23 & 1.44 & 0.51 & $2.87 E+08$ \\
\hline 68 & $3.74 \mathrm{E}+08$ & 5.58 & $3.44 \mathrm{E}+09$ & 1.24 & 1.41 & 0.47 & $3.31 E+08$ \\
\hline 69 & $4.46 \mathrm{E}+08$ & 5.63 & $4.88 \mathrm{E}+09$ & 1.25 & 1.38 & 0.42 & $3.93 E+08$ \\
\hline 70 & $1.39 E+08$ & 6.08 & $1.34 \mathrm{E}+09$ & 1.35 & 1.94 & 0.62 & $1.30 \mathrm{E}+08$ \\
\hline 71 & $1.76 \mathrm{E}+08$ & 6.14 & $1.80 \mathrm{E}+09$ & 1.37 & 1.88 & 0.59 & $1.64 \mathrm{E}+08$ \\
\hline 72 & $2.16 \mathrm{E}+08$ & 6.20 & $2.67 \mathrm{E}+09$ & 1.38 & 1.83 & 0.52 & $2.01 E+08$ \\
\hline 73 & $3.47 E+08$ & 6.17 & $2.69 \mathrm{E}+09$ & 1.37 & 1.53 & 0.55 & $3.12 E+08$ \\
\hline 74 & $3.97 E+08$ & 6.21 & $3.56 \mathrm{E}+09$ & 1.38 & 1.50 & 0.50 & $3.56 E+08$ \\
\hline 75 & $4.53 E+08$ & 6.25 & $4.39 \mathrm{E}+09$ & 1.39 & 1.48 & 0.48 & $4.05 E+08$ \\
\hline 76 & $5.04 E+08$ & 6.29 & $5.52 \mathrm{E}+09$ & 1.40 & 1.46 & 0.44 & $4.50 \mathrm{E}+08$ \\
\hline 77 & $5.70 \mathrm{E}+08$ & 6.33 & $7.27 \mathrm{E}+09$ & 1.41 & 1.44 & 0.40 & $5.09 E+08$ \\
\hline 78 & $1.66 \mathrm{E}+08$ & 7.09 & $1.86 \mathrm{E}+09$ & 1.58 & 2.11 & 0.63 & $1.57 \mathrm{E}+08$ \\
\hline 79 & $2.86 \mathrm{E}+08$ & 7.07 & $1.90 \mathrm{E}+09$ & 1.57 & 1.72 & 0.67 & $2.62 E+08$ \\
\hline 80 & $2.06 \mathrm{E}+08$ & 7.14 & $2.65 \mathrm{E}+09$ & 1.59 & 2.05 & 0.57 & $1.94 \mathrm{E}+08$ \\
\hline 81 & $3.62 E+08$ & 7.13 & $2.72 \mathrm{E}+09$ & 1.58 & 1.66 & 0.61 & $3.29 E+08$ \\
\hline 82 & $2.55 E+08$ & 7.22 & $3.57 \mathrm{E}+09$ & 1.61 & 1.99 & 0.53 & $2.41 E+08$ \\
\hline 83 & $4.31 E+08$ & 7.20 & $3.66 \mathrm{E}+09$ & 1.60 & 1.63 & 0.56 & $3.92 E+08$ \\
\hline 84 & $4.95 E+08$ & 7.25 & $4.62 \mathrm{E}+09$ & 1.61 & 1.61 & 0.53 & $4.49 \mathrm{E}+08$ \\
\hline 85 & $5.51 E+08$ & 7.28 & $5.63 \mathrm{E}+09$ & 1.62 & 1.59 & 0.50 & $4.99 E+08$ \\
\hline 86 & $4.65 E+08$ & 8.14 & $3.68 \mathrm{E}+09$ & 1.81 & 1.74 & 0.62 & $4.26 \mathrm{E}+08$ \\
\hline 87 & $5.48 \mathrm{E}+08$ & 8.21 & $4.82 \mathrm{E}+09$ & 1.82 & 1.71 & 0.58 & $5.02 E+08$ \\
\hline 88 & $6.39 \mathrm{E}+08$ & 8.26 & $6.11 \mathrm{E}+09$ & 1.84 & 1.68 & 0.54 & $5.85 \mathrm{E}+08$ \\
\hline 89 & $7.53 E+08$ & 8.33 & $8.28 \mathrm{E}+09$ & 1.85 & 1.65 & 0.50 & $6.88 E+08$ \\
\hline 90 & $1.58 \mathrm{E}+09$ & 8.25 & $7.35 \mathrm{E}+09$ & 1.83 & 1.22 & 0.56 & $1.32 E+09$ \\
\hline 91 & $1.84 \mathrm{E}+09$ & 8.32 & $1.02 \mathrm{E}+10$ & 1.85 & 1.20 & 0.51 & $1.53 E+09$ \\
\hline 92 & $1.23 E+09$ & 4.00 & $3.66 \mathrm{E}+09$ & 1.60 & 0.97 & 0.56 & $8.61 E+08$ \\
\hline 93 & $1.40 \mathrm{E}+09$ & 4.03 & $4.62 \mathrm{E}+09$ & 1.61 & 0.96 & 0.53 & $9.71 E+08$ \\
\hline 94 & $1.54 \mathrm{E}+09$ & 4.04 & $5.63 \mathrm{E}+09$ & 1.62 & 0.95 & 0.50 & $1.06 \mathrm{E}+09$ \\
\hline 95 & $1.35 E+09$ & 4.52 & $3.67 \mathrm{E}+09$ & 1.81 & 1.02 & 0.62 & $9.83 E+08$ \\
\hline 96 & $1.56 \mathrm{E}+09$ & 4.56 & $4.82 \mathrm{E}+09$ & 1.82 & 1.01 & 0.58 & $1.14 \mathrm{E}+09$ \\
\hline 97 & $1.80 E+09$ & 4.59 & $6.10 \mathrm{E}+09$ & 1.84 & 1.00 & 0.54 & 1.30E+09 \\
\hline 98 & $2.08 \mathrm{E}+09$ & 4.63 & $8.29 E+09$ & 1.85 & 0.99 & 0.50 & $1.50 \mathrm{E}+09$ \\
\hline 99 & $4.67 E+09$ & 4.58 & $7.35 \mathrm{E}+09$ & 1.83 & 0.71 & 0.56 & $2.14 \mathrm{E}+09$ \\
\hline 100 & $5.37 E+09$ & 4.62 & $1.02 \mathrm{E}+10$ & 1.85 & 0.70 & 0.51 & $2.45 E+09$ \\
\hline 101 & $2.20 \mathrm{E}+08$ & 0.89 & 1.37E+08 & 0.44 & 0.45 & 0.58 & $4.56 \mathrm{E}+07$ \\
\hline 102 & $4.65 E+08$ & 1.37 & $2.71 \mathrm{E}+08$ & 0.46 & 0.45 & 0.59 & $9.44 \mathrm{E}+07$ \\
\hline 103 & $1.40 \mathrm{E}+09$ & 1.83 & $8.95 \mathrm{E}+08$ & 0.61 & 0.42 & 0.53 & $2.56 \mathrm{E}+08$ \\
\hline 104 & $1.48 \mathrm{E}+09$ & 1.84 & $1.22 \mathrm{E}+09$ & 0.61 & 0.43 & 0.47 & $2.85 \mathrm{E}+08$ \\
\hline 105 & $2.23 E+09$ & 2.21 & $1.01 \mathrm{E}+09$ & 0.74 & 0.42 & 0.62 & $3.89 \mathrm{E}+08$ \\
\hline 106 & $3.20 E+09$ & 2.69 & $1.14 \mathrm{E}+09$ & 0.90 & 0.43 & 0.72 & $5.94 \mathrm{E}+08$ \\
\hline
\end{tabular}




\begin{tabular}{|c|c|c|c|c|c|c|c|}
\hline 107 & $3.67 E+09$ & 2.73 & $1.92 \mathrm{E}+09$ & 0.91 & 0.44 & 0.61 & $7.23 E+08$ \\
\hline 108 & $4.23 E+09$ & 2.77 & $2.46 \mathrm{E}+09$ & 0.92 & 0.44 & 0.57 & $8.11 \mathrm{E}+08$ \\
\hline 109 & $1.11 \mathrm{E}+10$ & 2.75 & $7.33 \mathrm{E}+09$ & 1.83 & 0.46 & 0.57 & $2.38 \mathrm{E}+09$ \\
\hline 110 & $1.30 \mathrm{E}+10$ & 2.77 & $1.02 \mathrm{E}+10$ & 1.85 & 0.45 & 0.51 & $2.73 \mathrm{E}+09$ \\
\hline 111 & $1.44 \mathrm{E}+08$ & 1.11 & $1.35 \mathrm{E}+08$ & 0.44 & 0.56 & 0.58 & $4.40 \mathrm{E}+07$ \\
\hline 112 & $2.81 E+08$ & 1.82 & $2.69 \mathrm{E}+08$ & 0.46 & 0.58 & 0.59 & $9.15 E+07$ \\
\hline 113 & $7.82 E+08$ & 2.44 & $8.89 \mathrm{E}+08$ & 0.61 & 0.57 & 0.53 & $2.47 E+08$ \\
\hline 114 & $8.91 E+08$ & 2.45 & $1.21 \mathrm{E}+09$ & 0.61 & 0.56 & 0.48 & $2.77 E+08$ \\
\hline 115 & $1.27 E+09$ & 2.95 & $1.00 \mathrm{E}+09$ & 0.74 & 0.56 & 0.63 & $3.87 E+08$ \\
\hline 116 & $1.80 \mathrm{E}+09$ & 3.59 & $1.13 \mathrm{E}+09$ & 0.90 & 0.58 & 0.73 & $5.76 \mathrm{E}+08$ \\
\hline 117 & $2.20 \mathrm{E}+09$ & 3.64 & $1.90 \mathrm{E}+09$ & 0.91 & 0.57 & 0.61 & $7.05 E+08$ \\
\hline 118 & $2.42 \mathrm{E}+09$ & 3.70 & $2.45 \mathrm{E}+09$ & 0.92 & 0.58 & 0.57 & $7.90 \mathrm{E}+08$ \\
\hline 119 & $6.99 \mathrm{E}+09$ & 3.67 & $7.35 \mathrm{E}+09$ & 1.83 & 0.58 & 0.56 & $2.23 E+09$ \\
\hline 120 & $8.07 E+09$ & 3.70 & $1.02 \mathrm{E}+10$ & 1.85 & 0.57 & 0.51 & $2.58 \mathrm{E}+09$ \\
\hline 121 & $1.60 \mathrm{E}+08$ & 2.51 & $2.68 \mathrm{E}+08$ & 0.46 & 1.08 & 0.84 & $1.35 \mathrm{E}+08$ \\
\hline 122 & $3.93 E+07$ & 3.35 & $4.00 \mathrm{E}+08$ & 0.61 & 2.14 & 0.67 & $3.86 \mathrm{E}+07$ \\
\hline 123 & $8.64 \mathrm{E}+08$ & 4.93 & $8.15 \mathrm{E}+08$ & 0.90 & 1.11 & 1.14 & $6.66 \mathrm{E}+08$ \\
\hline 124 & $3.20 \mathrm{E}+09$ & 2.69 & $1.14 \mathrm{E}+09$ & 0.90 & 0.61 & 1.02 & $1.04 \mathrm{E}+09$ \\
\hline 125 & +07 & 4.19 & $4.85 \mathrm{E}+08$ & 0.76 & 2.70 & 0.72 & $3.52 E+07$ \\
\hline 126 & $4.29 \mathrm{E}+07$ & 4.24 & $6.94 \mathrm{E}+08$ & 0.77 & 2.63 & 0.65 & $4.38 \mathrm{E}+07$ \\
\hline 127 & $5.66 \mathrm{E}+07$ & 3.00 & $4.13 \mathrm{E}+08$ & 1.00 & 2.52 & 0.93 & $5.61 \mathrm{E}+07$ \\
\hline 128 & $1.49 \mathrm{E}+08$ & 4.32 & $1.18 \mathrm{E}+09$ & 0.79 & 1.85 & 0.66 & $1.44 \mathrm{E}+08$ \\
\hline 129 & $3.41 \mathrm{E}+08$ & 5.73 & $1.96 \mathrm{E}+09$ & 1.04 & 1.81 & 0.76 & $3.29 E+08$ \\
\hline 130 & $9.65 E+07$ & 5.39 & $7.87 \mathrm{E}+08$ & 1.20 & 2.69 & 0.94 & $9.76 \mathrm{E}+07$ \\
\hline 131 & $6.58 \mathrm{E}+07$ & 2.73 & $2.96 \mathrm{E}+08$ & 0.91 & 2.03 & 0.96 & $6.29 E+07$ \\
\hline 132 & $1.39 \mathrm{E}+08$ & 6.08 & $1.34 \mathrm{E}+09$ & 1.35 & 2.75 & 0.88 & $1.41 \mathrm{E}+08$ \\
\hline 133 & $1.76 \mathrm{E}+08$ & 6.14 & $1.81 \mathrm{E}+09$ & 1.37 & 2.66 & 0.83 & $1.78 \mathrm{E}+08$ \\
\hline 134 & $2.16 \mathrm{E}+08$ & 6.20 & $2.67 \mathrm{E}+09$ & 1.38 & 2.59 & 0.74 & $2.17 \mathrm{E}+08$ \\
\hline 135 & $2.86 E+08$ & 7.07 & $1.90 \mathrm{E}+09$ & 1.57 & 2.43 & 0.94 & $2.84 E+08$ \\
\hline 136 & $5.51 \mathrm{E}+08$ & 7.28 & $5.63 \mathrm{E}+09$ & 1.62 & 2.24 & 0.70 & $5.41 \mathrm{E}+08$ \\
\hline 137 & $5.48 E+08$ & 8.21 & $4.82 \mathrm{E}+09$ & 1.82 & 2.42 & 0.82 & $5.44 \mathrm{E}+08$ \\
\hline 138 & $1.84 \mathrm{E}+09$ & 8.32 & $1.02 \mathrm{E}+10$ & 1.85 & 1.70 & 0.72 & $1.74 \mathrm{E}+09$ \\
\hline 139 & $1.80 E+09$ & 4.59 & $6.10 \mathrm{E}+09$ & 1.84 & 1.41 & 0.77 & $1.62 E+09$ \\
\hline 140 & $1.11 \mathrm{E}+10$ & 2.75 & 7.33E+09 & 1.83 & 0.65 & 0.80 & $4.62 E+09$ \\
\hline 141 & $9.81 \mathrm{E}+07$ & 2.29 & $4.85 \mathrm{E}+08$ & 0.76 & 1.60 & 0.72 & $9.08 \mathrm{E}+07$ \\
\hline 142 & $1.19 \mathrm{E}+08$ & 2.31 & $6.93 \mathrm{E}+08$ & 0.77 & 1.58 & 0.65 & $1.10 \mathrm{E}+08$ \\
\hline 143 & $1.16 \mathrm{E}+08$ & 2.00 & $4.13 \mathrm{E}+08$ & 1.00 & 1.76 & 0.93 & $1.08 E+08$ \\
\hline 144 & $2.80 \mathrm{E}+08$ & 2.99 & $7.87 \mathrm{E}+08$ & 1.20 & 1.58 & 0.94 & $2.56 \mathrm{E}+08$ \\
\hline 145 & $3.95 E+08$ & 3.38 & $1.34 \mathrm{E}+09$ & 1.35 & 1.63 & 0.88 & $3.65 E+08$ \\
\hline 146 & $4.94 \mathrm{E}+08$ & 3.41 & $1.80 \mathrm{E}+09$ & 1.37 & 1.59 & 0.83 & $4.55 E+08$ \\
\hline 147 & $5.91 E+08$ & 3.44 & $2.67 \mathrm{E}+09$ & 1.38 & 1.57 & 0.74 & $5.45 E+08$ \\
\hline 148 & $8.41 \mathrm{E}+08$ & 3.93 & $1.90 \mathrm{E}+09$ & 1.57 & 1.42 & 0.94 & $7.52 \mathrm{E}+08$ \\
\hline 149 & $1.54 \mathrm{E}+09$ & 4.04 & $5.63 \mathrm{E}+09$ & 1.62 & 1.34 & 0.70 & 1.37E+09 \\
\hline 150 & $1.56 \mathrm{E}+09$ & 4.56 & $4.82 \mathrm{E}+09$ & 1.82 & 1.43 & 0.82 & $1.41 \mathrm{E}+09$ \\
\hline 151 & $9.19 \mathrm{E}+08$ & 4.04 & $4.32 \mathrm{E}+08$ & 0.90 & 0.95 & 1.39 & $4.48 \mathrm{E}+08$ \\
\hline 152 & $9.78 \mathrm{E}+08$ & 4.09 & $5.37 \mathrm{E}+08$ & 0.91 & 0.96 & 1.30 & $4.94 \mathrm{E}+08$ \\
\hline
\end{tabular}




\begin{tabular}{|c|c|c|c|c|c|c|c|}
\hline 153 & $1.75 E+09$ & 3.23 & $6.01 \mathrm{E}+08$ & 0.92 & 0.75 & 1.28 & $6.85 \mathrm{E}+08$ \\
\hline 154 & $7.19 \mathrm{E}+08$ & 5.47 & $2.60 \mathrm{E}+09$ & 1.82 & 1.82 & 0.96 & $6.76 \mathrm{E}+08$ \\
\hline 155 & $1.54 \mathrm{E}+08$ & 4.05 & $5.80 \mathrm{E}+08$ & 1.35 & 2.15 & 1.11 & $1.48 \mathrm{E}+08$ \\
\hline 156 & $1.93 E+08$ & 4.10 & $8.21 \mathrm{E}+08$ & 1.37 & 2.08 & 1.01 & $1.85 \mathrm{E}+08$ \\
\hline 157 & $3.06 E+08$ & 4.13 & $1.84 \mathrm{E}+09$ & 1.38 & 1.94 & 0.79 & $2.92 E+08$ \\
\hline 158 & $3.33 E+08$ & 4.72 & $8.01 \mathrm{E}+08$ & 1.57 & 1.87 & 1.20 & $3.05 E+08$ \\
\hline 159 & $6.55 E+08$ & 4.85 & $2.70 \mathrm{E}+09$ & 1.62 & 1.72 & 0.85 & $6.11 \mathrm{E}+08$ \\
\hline 160 & $1.02 \mathrm{E}+09$ & 4.59 & $2.84 \mathrm{E}+09$ & 1.84 & 1.55 & 0.93 & $9.33 E+08$ \\
\hline 161 & $9.19 E+08$ & 4.04 & $4.32 \mathrm{E}+08$ & 0.90 & 0.78 & 1.13 & $4.02 E+08$ \\
\hline 162 & $9.78 \mathrm{E}+08$ & 4.09 & $5.37 E+08$ & 0.91 & 0.79 & 1.06 & $4.38 E+08$ \\
\hline 163 & $1.75 E+09$ & 3.23 & $6.01 \mathrm{E}+08$ & 0.92 & 0.61 & 1.04 & $5.48 \mathrm{E}+08$ \\
\hline 164 & $7.19 E+08$ & 5.47 & $2.60 \mathrm{E}+09$ & 1.82 & 1.48 & 0.78 & $6.38 E+08$ \\
\hline 165 & $1.54 \mathrm{E}+08$ & 4.05 & $5.80 \mathrm{E}+08$ & 1.35 & 1.75 & 0.90 & $1.41 E+08$ \\
\hline 166 & $1.93 E+08$ & 4.10 & $8.21 \mathrm{E}+08$ & 1.37 & 1.70 & 0.82 & $1.76 \mathrm{E}+08$ \\
\hline 167 & $1.73 E+08$ & 4.13 & $8.49 \mathrm{E}+08$ & 1.38 & 1.77 & 0.80 & $1.58 \mathrm{E}+08$ \\
\hline 168 & $3.33 E+08$ & 4.72 & $8.01 \mathrm{E}+08$ & 1.57 & 1.52 & 0.98 & $2.93 E+08$ \\
\hline 169 & $6.55 E+08$ & 4.85 & $2.70 \mathrm{E}+09$ & 1.62 & 1.40 & 0.69 & $5.74 \mathrm{E}+08$ \\
\hline 170 & $1.02 \mathrm{E}+09$ & 4.59 & $2.84 \mathrm{E}+09$ & 1.84 & 1.26 & 0.76 & $8.60 \mathrm{E}+08$ \\
\hline 171 & $8.64 \mathrm{E}+08$ & 4.93 & $8.15 E+08$ & 0.90 & 1.31 & 1.35 & $6.87 E+08$ \\
\hline 172 & $3.20 \mathrm{E}+09$ & 2.69 & $1.14 \mathrm{E}+09$ & 0.90 & 0.72 & 1.21 & $1.25 E+09$ \\
\hline 173 & $9.19 E+08$ & 4.04 & $4.32 \mathrm{E}+08$ & 0.90 & 1.13 & 1.64 & $4.63 E+08$ \\
\hline 174 & $9.78 \mathrm{E}+08$ & 4.09 & $5.37 \mathrm{E}+08$ & 0.91 & 1.14 & 1.54 & $5.14 \mathrm{E}+08$ \\
\hline 175 & $1.75 E+09$ & 3.23 & $6.01 \mathrm{E}+08$ & 0.92 & 0.88 & 1.51 & $7.69 E+08$ \\
\hline 176 & $1.54 \mathrm{E}+08$ & 4.05 & $5.80 \mathrm{E}+08$ & 1.35 & 2.54 & 1.31 & $1.53 \mathrm{E}+08$ \\
\hline 177 & $1.93 E+08$ & 4.10 & $8.21 \mathrm{E}+08$ & 1.37 & 2.46 & 1.19 & $1.91 E+08$ \\
\hline 178 & $3.33 E+08$ & 4.72 & $8.01 \mathrm{E}+08$ & 1.57 & 2.21 & 1.42 & $3.07 E+08$ \\
\hline 179 & $9.19 E+08$ & 4.04 & $4.32 \mathrm{E}+08$ & 0.90 & 1.26 & 1.84 & $4.68 \mathrm{E}+08$ \\
\hline 180 & $9.78 \mathrm{E}+08$ & 4.09 & $5.37 \mathrm{E}+08$ & 0.91 & 1.27 & 1.72 & $5.22 \mathrm{E}+08$ \\
\hline 181 & $1.75 E+09$ & 3.23 & $6.01 \mathrm{E}+08$ & 0.92 & 0.99 & 1.69 & $7.97 E+08$ \\
\hline 182 & $3.33 E+08$ & 4.72 & $8.01 \mathrm{E}+08$ & 1.57 & 2.47 & 1.60 & $3.07 E+08$ \\
\hline 183 & $8.64 E+08$ & 4.93 & $8.15 E+08$ & 0.90 & 1.47 & 1.51 & $6.88 E+08$ \\
\hline 184 & $3.20 E+09$ & 2.69 & $1.14 \mathrm{E}+09$ & 0.90 & 0.81 & 1.36 & $1.37 \mathrm{E}+09$ \\
\hline 185 & $1.54 \mathrm{E}+08$ & 4.05 & $5.80 \mathrm{E}+08$ & 1.35 & 2.85 & 1.47 & $1.57 E+08$ \\
\hline 186 & $6.58 \mathrm{E}+07$ & 2.73 & $2.96 \mathrm{E}+08$ & 0.91 & 2.68 & 1.27 & $6.68 \mathrm{E}+07$ \\
\hline 187 & $1.60 \mathrm{E}+08$ & 2.51 & $2.68 \mathrm{E}+08$ & 0.46 & 1.43 & 1.11 & $1.55 \mathrm{E}+08$ \\
\hline 188 & $8.64 \mathrm{E}+08$ & 4.93 & $8.15 E+08$ & 0.90 & 1.89 & 1.94 & $6.88 \mathrm{E}+08$ \\
\hline 189 & $3.20 E+09$ & 2.69 & $1.14 \mathrm{E}+09$ & 0.90 & 1.04 & 1.74 & $1.49 E+09$ \\
\hline 190 & $9.19 E+08$ & 4.04 & $4.32 \mathrm{E}+08$ & 0.90 & 1.62 & 2.36 & $4.76 \mathrm{E}+08$ \\
\hline 191 & $9.78 \mathrm{E}+08$ & 4.09 & $5.37 \mathrm{E}+08$ & 0.91 & 1.64 & 2.21 & $5.38 \mathrm{E}+08$ \\
\hline 192 & $1.75 E+09$ & 3.23 & $6.01 \mathrm{E}+08$ & 0.92 & \begin{tabular}{|l|}
1.27 \\
\end{tabular} & 2.17 & $8.11 \mathrm{E}+08$ \\
\hline 193 & $9.19 \mathrm{E}+08$ & 4.04 & $4.32 \mathrm{E}+08$ & 0.90 & 1.45 & 2.11 & $4.74 \mathrm{E}+08$ \\
\hline 194 & $9.78 \mathrm{E}+08$ & 4.09 & $5.37 \mathrm{E}+08$ & 0.91 & 1.47 & 1.98 & $5.28 E+08$ \\
\hline 195 & $1.75 E+09$ & 3.23 & $6.01 \mathrm{E}+08$ & 0.92 & 1.14 & 1.94 & $8.10 \mathrm{E}+08$ \\
\hline 196 & $8.64 \mathrm{E}+08$ & 4.93 & $8.15 E+08$ & 0.90 & 2.02 & 2.08 & $6.88 \mathrm{E}+08$ \\
\hline 197 & $3.20 E+09$ & 2.69 & $1.14 \mathrm{E}+09$ & 0.90 & 1.11 & 1.87 & $1.50 \mathrm{E}+09$ \\
\hline
\end{tabular}

